PREPROCESSOR AND POSTPROCESSOR COMPUTER PROGRAMS FOR A RADIAL-FLOW, FINITE-ELEMENT MODEL

By Amleto A. Pucci, Jr. and Daryll A. Pope

U.S. GEOLOGICAL SURVEY

Open-File Report 87-680

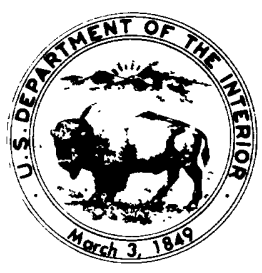

West Trenton, New Jersey 
DEPARTMENT OF THE INTERIOR

DONALD PAUL HODEL, Secretary

U.S. GEOLOGICAL SURVEY

Dallas L. Peck, Director

For additional information write to:

U.S. Geological Survey Mountain View Office Park 810 Bear Tavern Rd Suite 206

West Trenton, New Jersey 08628
Copies of this report

can be purchased from:

U.S. Geological Survey Books and Open-file Reports

Box 25425, Federal Center, Bldg. 810 Denver, Colorado 80225 


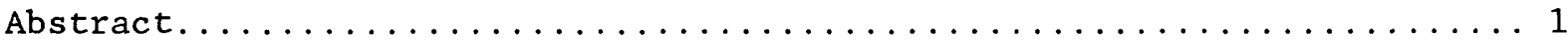

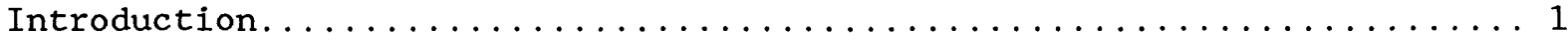

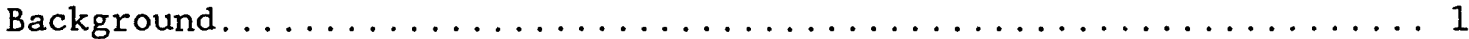

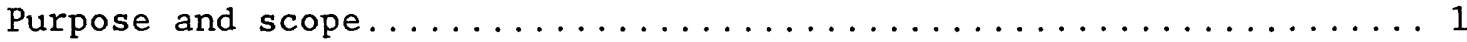

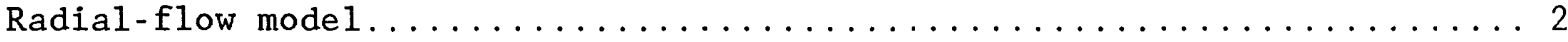

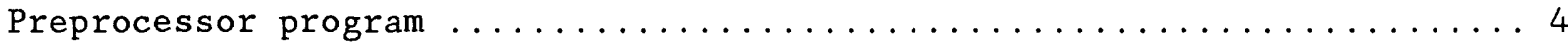

Preprocessor concepts........................... 7

Preprocessor algorithms........................ 8

Division of subregions....................... 8

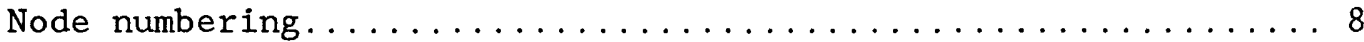

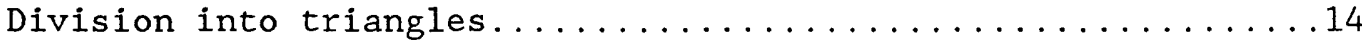

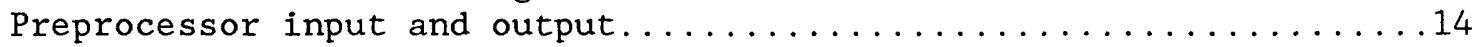

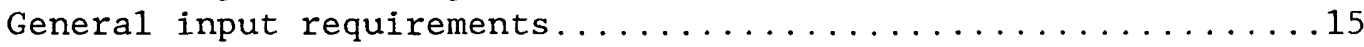

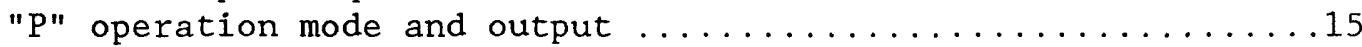

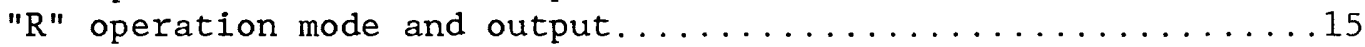

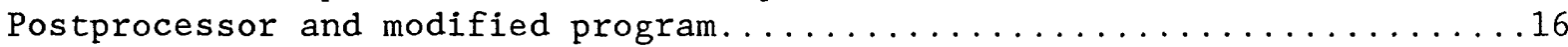

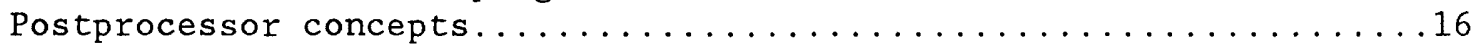

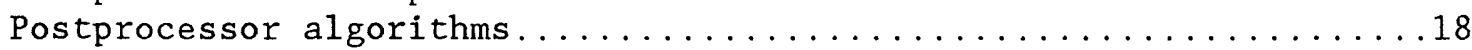

Calculation of observation-well drawdowns.............

Calculation of the Gaussian norm..................

General postprocessor input and output description...........18

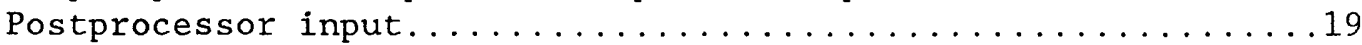

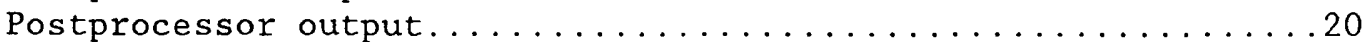

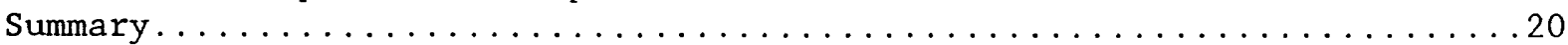

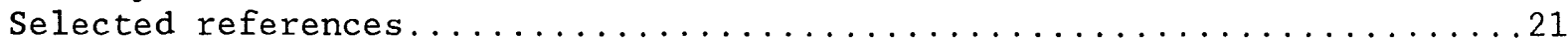

\section{APPENDIXES}

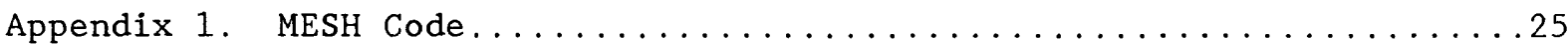

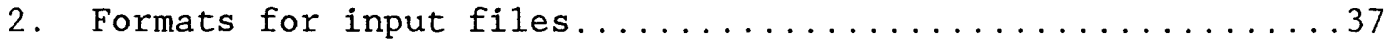

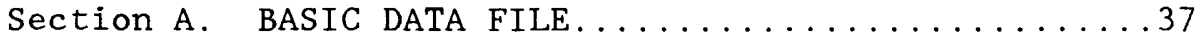

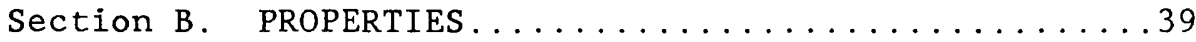

Section C. OB.WELL.................... $\ldots 1$

Section $D$ Observation well data file..........42

3. Example of BASIC DATA FILE for the six subregion example

mesh shown in figure $3 \ldots \ldots \ldots \ldots \ldots \ldots \ldots \ldots \ldots$

4. Data files used for example simulation shown in figure $4 \ldots 44$

Section A. BASIC DATA FILE for generating figure $4 \ldots \ldots 44$

Section B. PROPERTIES data file for region shown in

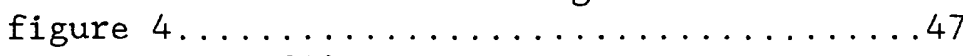

Section C. OB.WELL data file used to generate

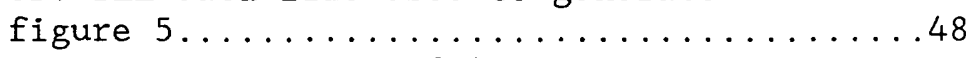

Section D. Observed field-data file used to generate

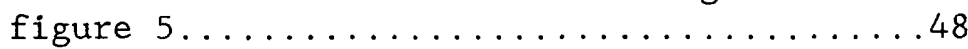

5. Example of OUTPUT file from MESH P mode for example

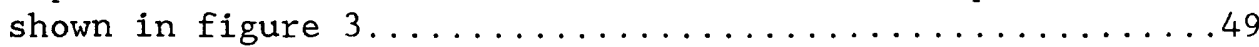

6. RADFLOW $-\mathrm{s}$ Code.............................. 53 
Figure 1. Conceptual model for a radially-symmetric ground-water

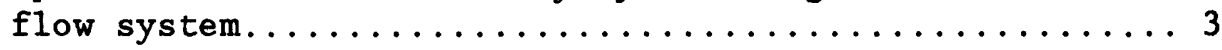

2. An example of a finite-element mesh for a radial groundwater flow region. .................... 5

3. Schematic diagrams of transformation between global and local reference frames, and the division of a subregion into

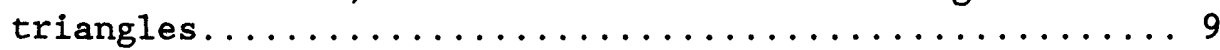

4. Sample problem region with subregions, lithology, and final calibrated hydrogeologic properties..............11

5. Plot of simulated and observed drawdowns for sample problem

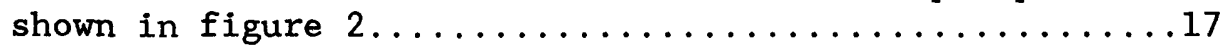

\section{TABLES}

Table 1. Global node numbers, and number of column and row increments for each subregion in figure $3(a) \ldots \ldots \ldots \ldots \ldots$

2. Connectivity matrix for the subregion mesh shown

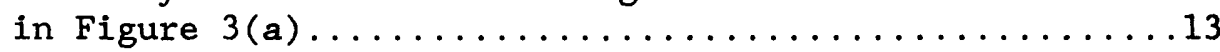


For use of readers who prefer to use metric (International System) units, conversion factors for the inch-pound terms used in this report are listed below:

Multiply Inch-Pound Unit

To Obtain Metric Unit

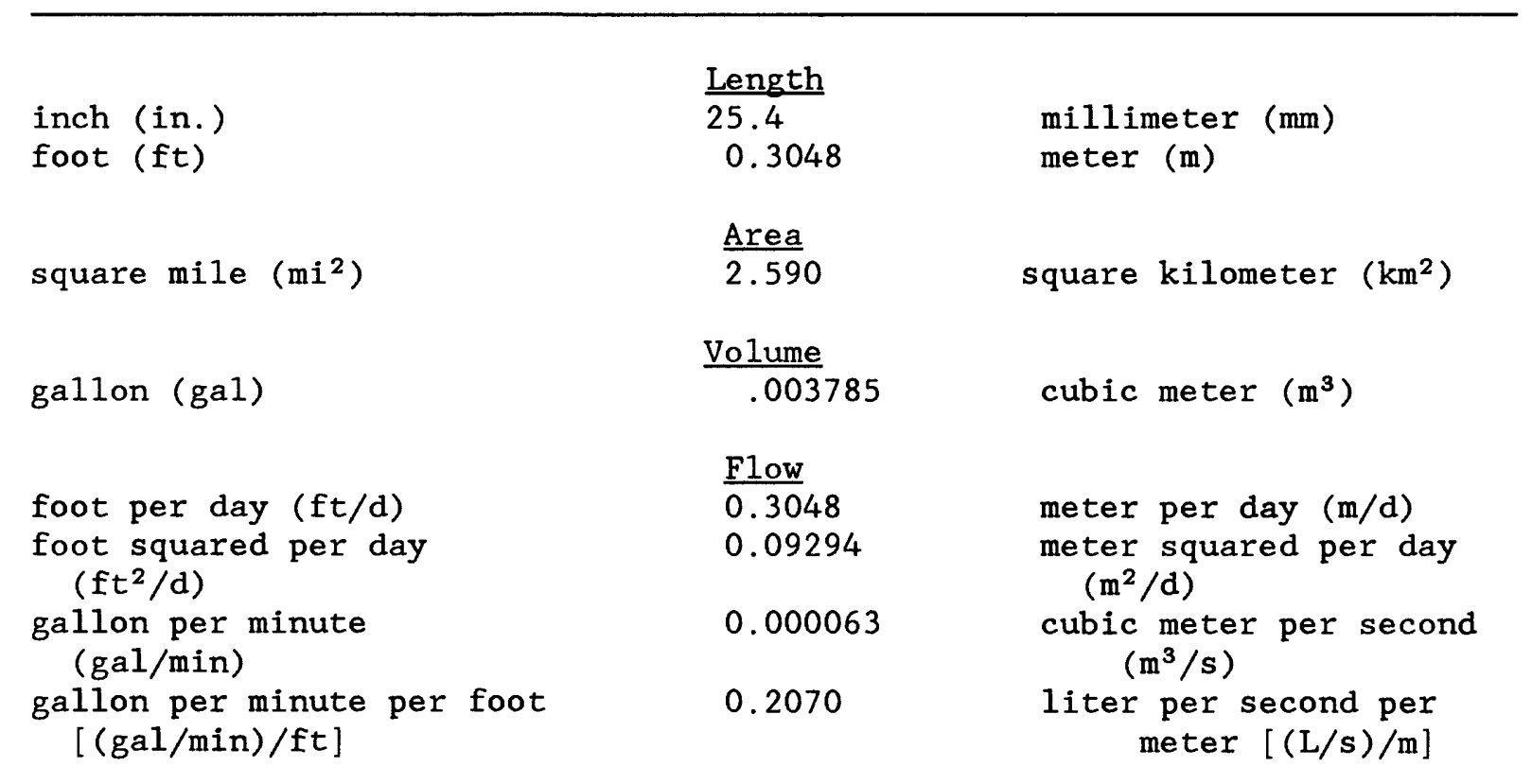




\title{
PREPROCESSOR AND POSTPROCESSOR COMPUTER PROGRAMS FOR A RADIAL-FLOW, FINITE-ELEMENT MODEL
}

By Amleto A. Pucci, Jr. and Daryll A. Pope

\begin{abstract}
Preprocessing and postprocessing computer programs that enhance the utility of the U.S. Geological Survey radial-flow model have been developed. The preprocessor program (1) generates a triangular finite-element mesh from minimal data input, (2) produces graphical displays and tabulations of data for the mesh, and (3) prepares an input data file to use with the radialflow model.

The postprocessor program is a version of the radial-flow model, which was modified to (1) produce graphical output for simulation and field results, (2) generate a statistic for comparing the simulation results with observed data, and (3) allow hydrologic properties to vary in the simulated region.

Examples of the use of the processor programs for a hypothetical aquifer test are presented. Instructions for the data files, format instructions, and a listing of the preprocessor and postprocessor source codes are given in the appendixes.

\section{INTRODUCTION}

\section{Background}

Reilly (1984) developed a Galerkin Finite-Element Model (RADFLOW) to simulate ground-water flow in a radially-symmetric aquifer. The model can be used to simulate the response of an aquifer to pumping (Lindner and Reilly, 1983). Finite-element and node data are input manually, and output data are created as arrays by the RADFLOW model. This approach can be tedious and can introduce errors into the spatial discretization (finiteelement mesh). In this report, new procedures are introduced to minimize data-entry errors and output manipulation.
\end{abstract}

\section{Purpose and Scope}

The purpose of this report is to present the preprocessor and postprocessor algorithms and computer programs that have been written for the radial, ground-water flow model, and to demonstrate the use of these computer programs. The preprocessor, called MESH, is a Fortran computer code, that contains algorithms for generating a triangular mesh, and creates and formats input data files for the ground-water flow model. The postprocessor program, named RADFLOW-S, is a modification of the Reilly (1984) code. Post-processing operations produce graphical displays and statistical evaluations of water-level changes in observation wells in the simulated region. This report includes (1) a general explanation of the 
preprocessor and postprocessor concepts and algorithms; (2) a general summary of the MESH, and RADFLOW-S codes, as well as a listing of these codes; and(3) descriptions of how to use the preprocessors and postprocessors with input and output examples.

\section{RADIAL FLOW MODEL}

The user needs to have some familiarity with the geometry of the radial-flow regions, and the assumptions and requirements imposed on the preprocessing by the original radial-flow model to understand the preprocessor program. The flow region is radially symmetric, with a discharging well at the center of the region. Pumping is assumed to have little effect on water levels at large distances from the pumping well. This condition is approximated in the numerical simulation as a constanthead boundary at the lateral boundary of the flow region. The lower boundary of the flow region must be a no-flow boundary. The upper boundary may be either an impermeable boundary (no-flow boundary), or a free surface (water-table condition) (Reilly, 1984). Because of the radial symmetry, the hydrogeologic units in the radial-flow system are modeled as layers with uniform hydrologic properties. A conceptual model of such a region is shown in figure 1. Reilly (1984) describes the model assumptions and the geometric configuration of the region in more detail in the original program documentation.

The original radial-flow model code of Reilly (1984), requires the user to manually discretize the radial-aquifer region into three-node triangular elements, each with uniform hydraulic properties. The computer code simulates the radial flow in the discretized region by generating a system of algebraic equations derived from the Galerkin finite-element approximation of the differential equations of two-dimensional, radiallysymmetric ground-water flow (Reilly, 1984; p. 5, eq. 13). Input data required to solve the system of equations include a number for each triangular finite-element, the finite-element node numbers, the location of each node in the region, and the hydraulic properties associated with each element. 


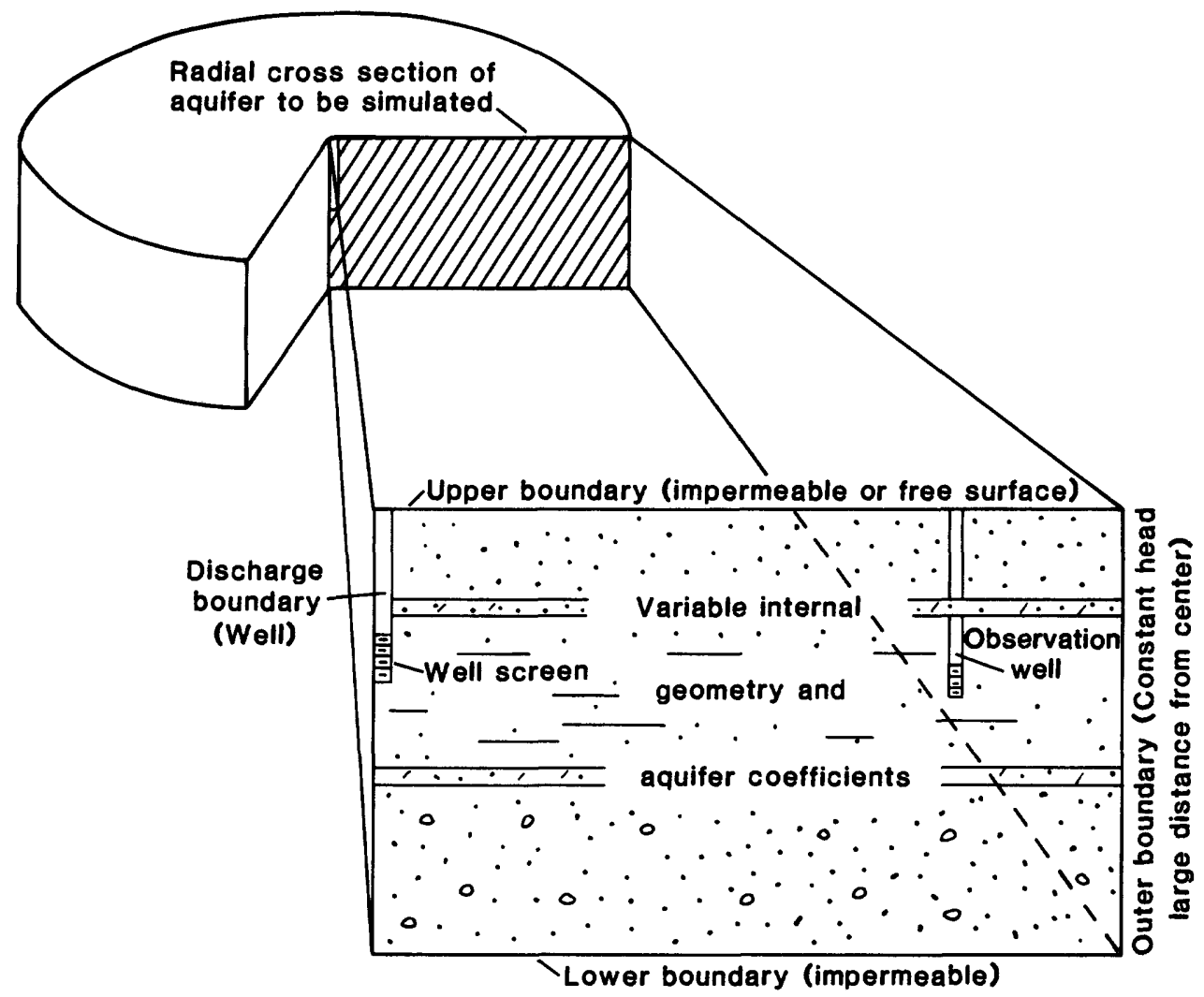

Figure 1.--Conceptual model for a radially symmetric ground-water flow system. (Modified from Linder and Reilly, 1983, fig. 6, p. 21) 


\section{PREPROCESSOR PROGRAM}

The preprocessor program, MESH, automatically generates the finiteelements for the radial-flow finite-element program, RADFLOW-S. It generates a finite-element mesh from a minimum amount of information supplied by the user. Figure 2 is a representative example of a groundwater flow region that has been divided into triangular elements using MESH. The user inputs data that (1) defines zones of different hydraulic properties; (2) identifies sources or sinks, and the flow boundaries of the radial ground-water region; (3) creates a finite-element mesh of the dimensions needed to meet the required simulation accuracy; (4) generates triangular shapes of reasonable form that do not cause numerical difficulties; and (5) automatically numbers nodes for the region. Reilly (1984) gives a description of constraints in designing a mesh for a radial flow system, which is beyond the scope of this report. Pinder and Gray (1977), Steinmueller (1974) and many other authors discuss numerical stability and design of meshes used for finite-element analysis. A listing of the preprocessor code is given in appendix 1. 


\section{Preprocessor Concepts}

The automatic, mesh-generating algorithm uses eight-node, quadratic, rectangular, finite elements. These rectangular finite elements are a family of two-dimensional finite elements that are different from the triangular finite elements that are generated for the numerical computations of the radial-flow model. Each rectangular finite element is defined by the program user as a subregion, which represents a radial section in the ground-water flow region. The horizontal and vertical extent of the subregions are determined from the hydrogeologic units in the radial-flow region. Generally, one or more rows of subregions are assigned to each hydrogeologic unit.

Examples of how rectangular elements are used to represent subregions is schematically shown for the simple region in figure $3(a)$. This region is divided into six rectangular, finite-elements. The node positions for the quadratic, rectangular elements in figure $3(a)$ are in the global reference frame, $r, z$, where " $r$ " represents the radial distance from the well, and " $z$ " the vertical elevation in relation to datum. In this example, the rectangular element that represents subregion 5 in the global reference frame has a range in " $r$ " from 0 feet to 200 feet, and for " $z$ " the range is 0 feet to 100 feet.

The mesh-generating program uses a local reference frame in the algorithm that divides each rectangular element representing a subregion into triangular finite elements. Zienkiewicz (1977) and Segerlind (1976) cover the concept of local reference frame in detail. The rectangular element, which represents the subregion in the $r, z$ (global) reference frame, is transformed to a square element in the $u, v$ (local) reference frame, where both $u$ and $v$ range from -1 to 1 . This reference frame is centered within the boundaries of each subregion, as shown in figure 3(b). Once a subregion is divided, the coordinates are transformed back to the global coordinates that are required to solve the numerical equation for radial flow (Reilly, 1984; p.5, eq. 13). The local reference frame is used for the dividing operations because of the convenience of the identical geometry for each subregion. The tranformation is done automatically using quadratic rectangular basis functions. The equations to transform a point " $k$ " from the local reference frame coordinates, $u, v$, to the global reference frame, $r, z$, are:

$$
R_{i}=\sum_{j=1}^{8} N_{j} \times R_{j},
$$

and

$$
z_{i}=\sum_{j=1}^{8} N_{j} \times z_{j},
$$

where $R_{j_{h}}, z_{j}$ are the global coordinates for the eight nodes, $j=1, \ldots, 8$, for

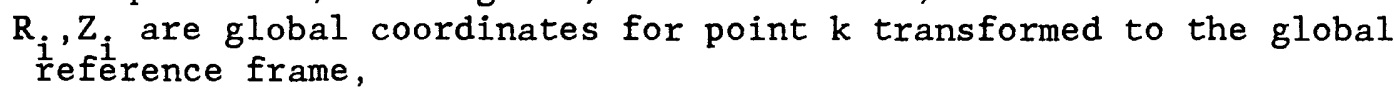


$N_{j}$ are the quadratic, rectangular basis functions for the eight nodes, and $j=1, \ldots, 8$ for the quadratic, rectangular, finite element in the local reference frame in counter-clockwise order, beginning with the lower left corner node.

Figure 4 shows a radial-flow region of 4 hydrogeologic units, 50 subregions, and 181 global nodes. These subregions were divided into the 480 finite-element, 273 finite-element node mesh in figure 2. (For sake of clarity, the eight nodes in each rectangular element that represents a subregion are referred to as global nodes. The nodes the program generates in the triangular mesh are called the finite-element nodes.) In this example, alternating layers of sand and clay are delineated into rows of subregions using rectangular elements. The subregion discretization is much coarser than the generated finite-element mesh. The algorithm requires the identification of a primary hydrogeologic unit, and in this example it is the lower sand unit. Note that the discretization intervals between nodes along the horizontal sides of each rectangular finite element is centered in the logarithmic scale, and is not centered in a linear scale. This consideration adds to the numerical stability of the radial-flow model solver (Reilly, 1984).

\section{Preprocessor Algorithms}

\section{Division of Subregions}

The preprocessor algorithm proceeds by dividing a subregion into simple rectangles, then into triangular finite elements as in fig. 3(b) through 3 (d). These operations are completed for each subregion before numbering finite-element nodes and then proceeding to the next subregion. The algorithm requires: (1) the global locations of the eight nodes of the rectangular, finite element that represent each subregion, and (2) the number of row and column increments to be made for each subregion. The transformed subregion in figure $3(\mathrm{c})$ is divided into eight simple rectangles, by specifying five column increments along the $u$-axis and three row increments along the $\mathrm{v}$-axis. The intersection of each row and column in the divided subregion is the location of a finite-element node, which is given a node number and assigned to a triangular finite element in subsequent operations in the code. Zienkiewicz and Phillips (1971) originated this algorithm, which Segerlind (1976) also used.

\section{Node Numbering}

The node numbering algorithm begins when the user discretizes the flow region into subregions. The radial-flow solver requires the lowest triangular finite-element node numbers to be along the constant-head boundary (Reilly, 1984). Because the automatic finite-element nodenumbering algorithm is based on the sequence of subregions, constraints are made on the numbering of subregions by the user. The numbering algorithm requires the lowest subregion numbers to be in sequence, top to bottom, along the constant-head boundary. As an example, subregion 1 and 2 are the two subregions on the constant-head boundary in figure 3(a). A number for each subregion, and a global node number for each of the eight nodes in the 


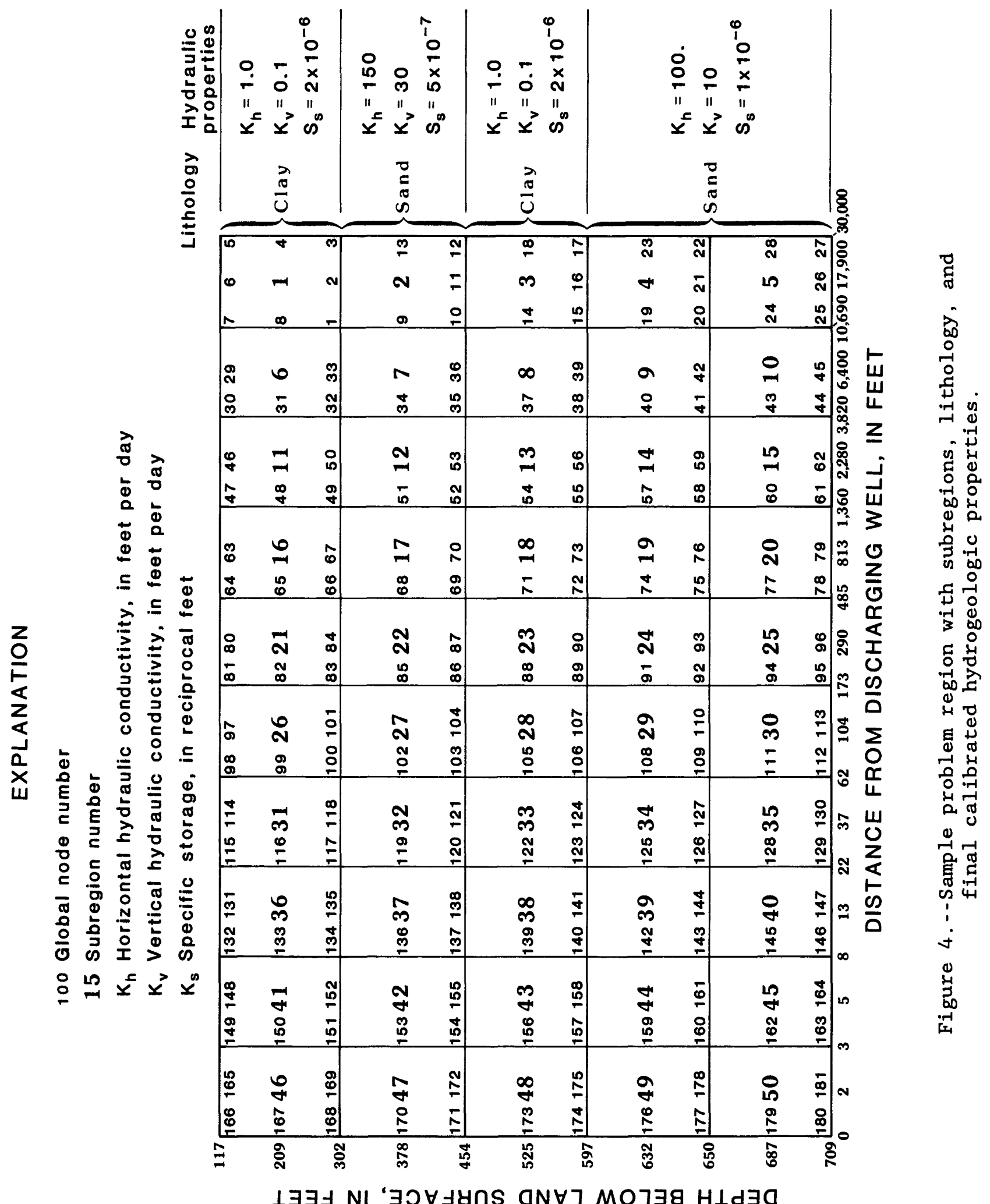


rectangular element representing that subregion, are assigned by the user. Table 1 illustrates the assignment of global node numbers for the subregions in figure 3(a). Global node numbers can be in any order and are not the same as the triangular finite-element numbers to be generated by the algorithm.

The algorithm determines the number of finite-element nodes created in a subregion from the number of row and column increments specified by the user in each subregion. Each subregion must be divided into the same number of rows, if the subregions share a boundary along a vertical side, or divided into the same number of columns, if the shared boundary is along a horizontal side. Columns 2 and 3 in table 1 list these values for the example given in figures 3(a)-3(e). For example, subregion 1 has three rows of increments, and subregion 2 has five rows of increments.

The user must assign finite-element node numbers to finite-element nodes on the constant-head boundary. The number of finite-element nodes on this boundary is equal to the total number of row increments for each subregion along the constant-head boundary minus the number of shared rows. For the region shown in figure $3(a)$, three-row increments are assigned for subregion 1, and five-row increments are assigned for subregion 2; these subregions share one boundary. Therefore, seven finite-element nodes are located along this boundary $(5+3$ row increments - 1 row shared between subregion 1 and 2). For the example in figure 3, nodes 1 through 7 are assigned on the constant-head boundary.

Automatic numbering is done by the code after a subregion is divided into columns and rows, before creating the triangular finite elements in the subregion, and before proceeding to the next subregion to repeat the series of operations. Information on the spatial arrangement of the subregions is needed for the algorithm to avoid renumbering the finite-element nodes along shared subregion boundaries. This information is stored in the "connectivity matrix".

The numerical function of the connectivity matrix is demonstrated by example. Assembly of the connectivity matrix for the region in figure 3(a) is shown in table 2. This region consists of six subregions, numbered 1 through 6. Each subregion can have one neighboring subregion on each of its four sides. The orientation of each of the four sides is numbered 1 through 4. Side 1 is below, and sides 2,3 , and 4 are numbered counter-clockwise. The connectivity matrix identifies the subregion number on each shared side for each subregion, as shown in table 2 for figure 3(a). A zero is used where the subregion side is not shared. As indicated by table 2, subregion 5 in figure $3(\mathrm{a})$ is bounded by subregion 3 to the right (side 2), and by subregion 6 below (side 1 ); sides 3 and 4 are not shared.

The algorithm assigns node numbers to the corners of the simple rectangles formed from the intersection of the columns and rows in each divided subregion, row by row, from left to right, and top to bottom. The algorithm searches the connectivity matrix for each subregion to determine if nodes along its boundaries have been numbered previously. For subregion 5 in figure $3(a)$ and in table 2, the numbering algorithm proceeds through the subregions in numerical order and the search of the connectivity matrix determines that subregion 3 is divided and numbered, and that the 
Table 1.-Global node numbers, and number of column and row increments for each subregion in figure $3(a)$.

\begin{tabular}{|c|c|c||cccccccc|}
\hline $\begin{array}{l}\text { Subregion } \\
\text { number }\end{array}$ & $\begin{array}{l}\text { Number } \\
\text { of row } \\
\text { increments }\end{array}$ & $\begin{array}{l}\text { Number } \\
\text { of column } \\
\text { increment }\end{array}$ & $\begin{array}{l}\text { Global node numbers } \\
\text { associated with each subregion }\end{array}$ \\
\hline 1 & 3 & 3 & 1 & 2 & 3 & 4 & 5 & 6 & 7 & 8 \\
2 & 5 & 3 & 10 & 11 & 12 & 13 & 3 & 2 & 1 & 9 \\
3 & 3 & 3 & 17 & 18 & 1 & 8 & 7 & 14 & 15 & 16 \\
4 & 5 & 20 & 21 & 10 & 9 & 1 & 18 & 17 & 19 \\
5 & 3 & 25 & 26 & 17 & 16 & 15 & 22 & 23 & 24 \\
6 & 5 & 5 & 28 & 29 & 20 & 19 & 17 & 26 & 25 & 27 \\
\hline
\end{tabular}

Table 2.--Connectivity matrix for the subregions shown in figure $3(a)$.

\begin{tabular}{|c|c|c|c|c|}
\hline $\begin{array}{l}\text { Subregion } \\
\text { number }\end{array}$ & $\begin{array}{l}\text { Shared } \\
\text { Side } 1\end{array}$ & $\begin{array}{l}\text { Dundary } \\
\text { Side } 2\end{array}$ & $\begin{array}{l}\text { Abregior } \\
\text { Side } 3\end{array}$ & $\begin{array}{l}\text { number } \\
\text { Side } 4\end{array}$ \\
\hline 1 & 2 & 0 & 0 & 3 \\
\hline 2 & 0 & 0 & 1 & 4 \\
\hline 3 & 4 & 1 & 0 & 5 \\
\hline 4 & 0 & 2 & 3 & 6 \\
\hline 5 & 6 & 3 & 0 & 0 \\
\hline 6 & 0 & 4 & 5 & 0 \\
\hline
\end{tabular}


nodes shared by subregion 5 and subregion 3 are numbered. Therefore, these finite-element nodes are not renumbered. However, because subregion 6 has not been divided and numbered, the nodes it shares along the boundary with subregion 5 are assigned. Node numbers on each boundary of the subregion are stored in an array. Segerlind (1976) and Collins (1973) discuss node numbering and illustrate the use of the connectivity matrix in more detail.

\section{Division into Triangles}

After numbering finite-element nodes and before the next subregion is divided, the algorithm divides each simple rectangle formed from the intersection of columns and rows in each subregion into two triangles as illustrated in figure $3(\mathrm{~d})$. The creation of triangles, proceeds left-toright, top-to-bottom, through all the simple rectangles in each subregion. The algorithm determines the proper numbering for diagonals from the simple rectangle, assigns the node sequence for each triangular element to produce the consistent counter-clockwise order needed to assemble the matrices in the numerical radial-flow equation (Reilly, 1984; p. 5, eq. 13), and gives each triangle a finite-element number. Reilly (1984) discusses the nodenumbering conventions. Global coordinates for each node are calculated for each triangular finite-element node using the transformation operation described in the section on preprocessor concepts. The bandwidth is determined for each triangular-element. If it is the largest bandwidth in the region, it is recorded and printed in the final tabulation of results.

In summary, the preprocessor algorithms generate the finite-element mesh, one subregion at a time. The algorithm to divide each subregion into simple rectangles uses the geometry of a local reference frame. The user determines the resolution of the mesh by specifying the number of row and column increments. The number of simple rectangles produced for each subregion is determined from the number of assigned rows and columns for each subregion. The corners of these simple rectangles become the finiteelement nodes, and each node is numbered. Each simple rectangle is divided into two triangular finite elements, and then each triangular element is numbered. The global locations of the finite-element nodes are determined by transforming the coordinates from local to global coordinates. These finite-element-mesh data are assembled with hydrogeologic data as described in the following section for input to the radial-flow model.

\section{Preprocessor Input and Output}

The MESH program can be used in two different modes, the " $P$ " and " $R$ " modes. The "P" mode is used to produce a plot of the finite-element mesh at a graphics terminal or to create a plotfile, which can be plotted. It also produces a descriptive output file called OUTPUT, which can be used instead of, or in conjunction with, a plotter to evaluate the generated finiteelement mesh. It is not necessary to use either a graphics terminal or plotter to run the MESH program. Once the mesh geometry has been evaluated by the user, the " $R$ " mode can be used to automatically create the properly formatted input data file to run RADFLOW-S. 
The MESH program requires input from the BASIC DATA FILE in either the " $P$ " or " $R$ " mode. Following the order that data are input, the BASIC DATA FILE includes data on (1) the number of subregions and total number of global nodes in the modeled region, (2) the radial distance from the well head to the global nodes, (3) the vertical distance of the global nodes relative to a datum elevation, (4) subregion numbers and the connoctivity matrix data, (5) the number of subregions and finite-element node numbers along the constant-head boundary, (6) the number of row increments for each subregion along the constant-head boundary, and (7) the global node numbers in each subregion and the number of row and column increments for each subregion.

A description of the input-data variables and formats for the BASIC DATA FILE is given in appendix 2. Sample input data, which produced the finite-element mesh shown in figure $3(e)$ from the subregions shown in figure $3(a)$, is presented in appendix 3. The BASIC DATA FILE for the region in figure 4 is presented in appendix 4, section $A$. This data set was used to produce the 480 finite-element mesh shown in figure 2.

\section{"P" Operation Mode and Output}

In "P" operation, the program prompts the user to choose the output device. The program uses the graphics device utility (GDIU) to facilitate graphical output. A graphics terminal compatible to the TAB $132 / 15-G^{1}$ or TEKTRONICS 4010 terminals or plotting devices at the users installation may be chosen, or a plotfile can be created for input to another graphics plotter. Visual examination of the graphical output of the finite-element mesh can quickly show problems in the global-mesh data. Errors in the input data set can be corrected by referring to the OUTPUT file descriptions and by examining the graphical output.

The descriptive file OUTPUT is created in the " $P$ " operation mode. The OUTPUT file includes (1) a tabulation of the connectivity matrix for all the subregions, (2) a list of the number of row and column increments in which each subregion is divided, (3) the finite-element node numbers for each subregion, and (4) the finite-element numbers and the associated finiteelement node numbers, and the global coordinates of these finite-element nodes. The program prompts the user at the terminal to enter the maximum length of the " $r$ "and " $z$ " axes, and a choice of either an arithmetic or logarithmic plotting scale along the " $r$ " axis. An example of the OUTPUT file containing mesh data for the simple region shown in figures $3(e)$ is given in appendix 5 .

\section{"R" Operation Mode and Output}

The PROPERTIES data file and the BASIC DATA FILE are required input to run MESH in the " $R$ " mode. The BASIC DATA FILE was previouly described.

1 "Use of brand names in this report is for identification purposes only and does not constitute endorsement by the U.S. Geological Survey." 
PROPERTIES data are formatted in four sections. The first data section contains control data for setting up the simulation input data file. It contains (1) a simulation identifier, (2) identification of the hydraulic properties of the primary hydrogeologic unit in the region, (3) the number of hydrogeologic units that are distinct from the primary hydrogeologic unit, (4) the number of finite-element nodes along the screen in the discharging well (must be more than 1), and (5) the number of pumping periods. The second data section specifies the finite-element node numbers along the screen of the discharging well, and, therefore, is determined after evaluating the output on the mesh from " $P$ " mode operation. The third data section assigns the hydraulic properties for those hydrogeologic units that the user has identified as distinct from the primary hydrogeologic unit. For the example shown in figure 4, one primary hydrogeologic unit and three distinct units were identified. The fourth data section gives information on the test-well discharge rate and duration.

A description of the PROPERTIES data-file input variables and their formats is given in appendix 2, section B. Further discussion of the function of these hydraulic properties to simulate a radial-flow system is described in the original RADFLOW report (Reilly, 1984).

MESH produces the RADFLOW. INPUT data file as output, which is used by the RADFLOW-S radial-flow model. The RADFLOW. INPUT data file is identical to the input file documented by Reilly (1984). The RADFLOW. INPUT file must be manually modified as described in the original report to simulate an aquifer test of an unconfined system (Reilly, 1984).

\section{POSTPROCESSOR and MODIFIED PROGRAM}

This section summarizes the concepts and modifications that are in the RADFLOW-S version but are not included in the original code radial-flow model. The original RADFLOW model determined water levels at each finiteelement node at each time step in a summary output file. RADFLOW-S retains the summary output file as part of the output from the radial-flow simulations. The modified code is presented in appendix 6 .

\section{Postprocessor Concepts}

The summary output file from the original model consists of a printout of large matrices from simulations, which can be can be unwieldly. To improve this, the innovation used in the RADFLOW-S program was to focus on only that portion of the computed results that are typically used in the analysis--that is, the computed drawdown in observation wells within the radial-flow region.

The postprocessor performs two functions: (1) it creates standard logarithmic plots from the observation-well water-level changes from the finite-element simulation and from the field data, and (2) it evaluates a Gaussian-norm statistic that compares the simulation results and field data at each observation well. An example of the logarithmic plot produced by the program is given in figure 5. Modifications to the hydrogeologic data and mesh can be made as iterative feedback to improve the match of simulation and field data. 


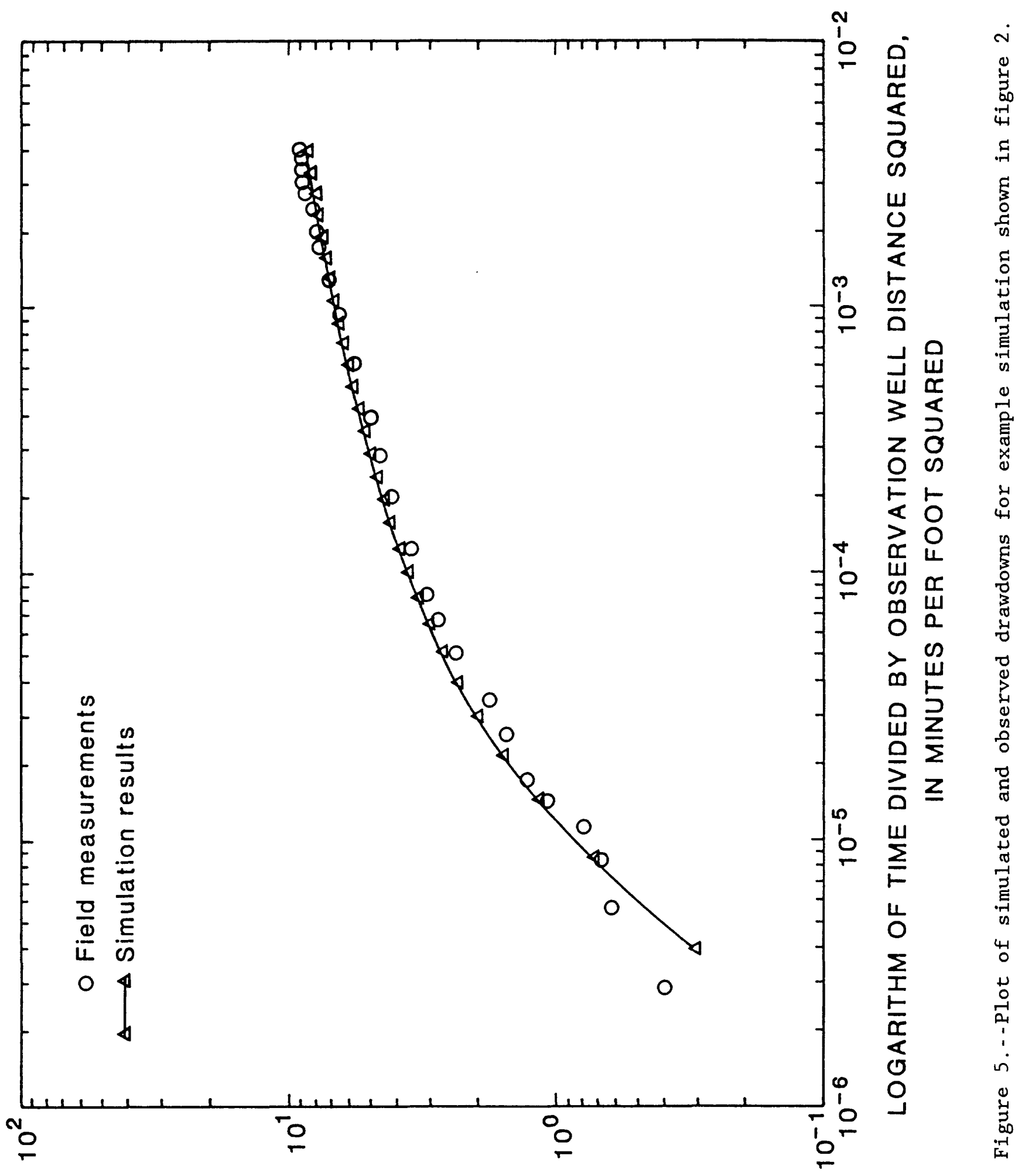

$\perp \exists \exists \exists \mathrm{NI}$ 'S 'NMOQM 


\section{Postprocessor Algorithms}

\section{Calculation of Observation-we11 Drawdowns}

As in the original model, the RADFLOW-S model calculates the groundwater potential, or head, for each triangular finite-element node in the mesh for each time step of the simulation period (Reilly, 1984). The postprocessor program uses triangular basis functions of the same type as in the numerical solution to the radial-flow equation (Reilly, 1984; p.4, eq. 7) to interpolate heads in observation wells from the node heads. The method of numerical interpolation using linear-triangular basis functions is basic and is described in detail in Segerlind (1976) and Zienkiewicz (1977).

Calculation of the Gaussian Norm

The Gaussian-norm statistic, "e", is a general comparison of the adequacy of the simulated drawdown and the observed drawdown for each observation for the entire period of simulation. It is expressed by the formula:

$$
\mathrm{e}=\sum_{\mathrm{i}=1}^{\mathrm{n}} \frac{\mathrm{h}_{\mathrm{i}}-\mathrm{h}^{\prime}{ }_{i}}{\mathrm{~h}_{\mathrm{i}}}
$$

where $h_{i}=$ is the observed head at the observation well point, $i$, at time $t$.

$h^{\prime}{ }_{i}=$ is the calculated head at the observation well point, $i$, at $\mathrm{n}=$ number of observed head values at the observation well point.

For example, where the observed and calculated heads are approximately the same value, the Gaussian-norm statistic will approach zero, indicating that the field and simulation results are in good agreement. This comparison is done once for each observation well. Because the simulated values usually are calculated for times that are different from the times of the observed field data, the algorithm does a linear interpolation to determine a simulated value at the same time as the field data.

\section{General Postprocessor Input and Output Description}

The program, RADFLOW-S, is a modified version of the radial-flow finite-element program code, RADFLOW, with the addition of postprocessing subroutines, which are called PTPLOT, PMPLT, and EPSILON. PTPLOT and PMPLOT subroutines generate logarithmic graphs of water-level changes versus time, and EPSILON calculates the Gaussian-norm statistic. PTPLOT prompts the user for input to control the plotting routines for water-level plots of each observation well, and calls the PMPLOT and EPSILON subroutines. PMPLOT prompts the user to name the input file that contains the drawdown data for each observation well, then reads these data files and generates plots of 
corresponding field and simulated drawdown data. More detailed descriptions of these subroutines and data files follows.

\section{Postprocessor Input}

The RADFLOW-S program reads data both through user responses to prompts at the terminal and by reading data files. Subroutine PTPLOT prompts the user at the terminal for (1) the name of the file containing the field water-level data, (2) the headings for the logarithmic water-level graphs, and (3) axes limits for the graph. The graph axes limits must be given as log values that span the range of the data as shown in figure 5 . The $x$-axis is in units of time per length squared, (time per square of the radial distance of the observation well from the pumped we11), and the y-axis is in feet. Subroutine PTPLOT calls the GDIU and prompts the user to specify an output device to either output directly to a graphics terminal, or to create a plotfile for a plotter. The program plots the simulated water-level data in the order that the observation wells are included in the OB.WELL data file; therefore, the user follows the same order when responding to prompts for field data and plotting control.

The three datafiles required to run the program are: (1) the RADFLOW. INPUT data file, previously described in the section on the ' $R$ ' option for the preprocessor, MESH; (2) the OB. WELL data file, which contains data on the number of observation wells and their screen locations; and (3) user generated data files containing measured field data for each of the observation wells.

The OB.WELL data file lists the number of observation wells in the region, the location of the midpoint of the screen of each observation well, and the finite-element number in the mesh that contains the observation-well screen. The location of the observation well(s) in the finite-element mesh is determined by the user after running and reviewing the graphics output and the output tabulation file OUTPUT generated by MESH in "P" mode. The observation well location is assumed to be the midpoint of the total screen length. Drawdowns in up to five observation wells can be calculated. The requirement for observation-well data to run RADFLOW-S can be overridden by creating an empty data file. Further descriptions of the data file variables and the data formats are presented in appendix 1 , section $C$. The $O B$.WELL data file used to create the plot shown in figure 5 is presented in appendix 4 , section $C$.

Data files of field data on each observation well must be separate and must be given a label by the user. Each data file lists the number of water-level measurements for the observation well, the distance of the observation well from the pumped we11, a prepumping reference water level (optional), and the water-level measurement and recorded time at each observation we11. A dummy reference water-level value is used in place of a prepumping water-level if water-level measurements are entered as the drawdown (or recovery) value. Appendix 2, section $D$ describes the input formats for these data. The data file for the observation well example shown in figure 5 is given in appendix 4, section $D$. 
Postprocessor output of logarithmic graphs of water-level changes may be plotted to a terminal screen or to another device by creating a plot file. The value of the Gaussian-norm statistic is shown on the user's terminal at the completion of the logarithm plot for each observation well. The code creates a summary output file in the format originally documented by Reilly (1984).

\section{Summary}

Preprocessing and postprocessing computer programs have been developed that simplify and enhance the utility of the U.S. Geological Survey radialflow model. Principals of automatic mesh generation and data manipulation have been used in the programming. Features of the preprocessor include: (1) reduced user input for generating the finite-element mesh for the radial-flow model, (2) use of global and local reference-frame geometry to discretize the flow region, (3) a capability for the user to simply describe the spatial variation of hydrologic properties (horizontal and vertical hydraulic conductivity, and specific storage or specific yield) of subregions in the flow region, (4) automatic division of the flow region into triangular finite-elements, (5) automatic numbering of the finiteelement nodes in the discretized region, and (6) generation of an input file to run the radial-flow model, RADFLOW-S.

The postprocessing program is part of the simulation code for the radial-flow system. The postprocessor features (1) interpolation of the water-level changes at observation wells for the simulated region; (2) plotting simulated water-level changes and field data from observation wells together for as many as five observation wells; and (3) calculation of a Gaussian-norm statistic, which compares the simulation to field results.

In addition to the program descriptions, discussion of the concepts in these processors and examples of their use for a hypothetical aquifer test are presented. Appendixes provide format instructions for the data files, example data files, and a listing of the preprocessor and postprocessor source codes. 


\section{SELECTED REFERENCES}

Collins, R.J., 1973, Bandwidth reduction by automatic renumbering: International Journal for Numerical Methods in Engineering, Vo1. 6, p. 345-356.

Lindner, J.B., and Reilly, T.E., 1983, Analysis of Three Tests of the unconfined aquifer in Southern Nassau County, Long Island New York: U.S. Geological Survey Water-Resources Investigations Report 82-4021, 46 p.

Pinder, G.F。, and Gray, W.G., 1977, Finite element simulation in surface and subsurface hydrology: Academic Press, New York, 295 p.

Reilly, T.E., 1984, A Galerkin finite-element flow model for the transient response of a radially symmetric aquifer: U.S. Geological Survey Water-Supply Paper 2198, 60 p.

Segerlind, L.J., 1976, Applied Finite Element Analysis: John Wiley \& Sons, New York, 422 p.

Steinmueller, G., 1974, Restrictions in the Application of Automatic Mesh Generation Schemes by 'Isoparametric' Co-ordinates:

International Journal for Numerical Methods in Engineering, Vol. 8, p. 289-294.

Zienkiewicz, O.C., 1977, The Finite Element Method: 3rd. Ed., McGraw-Hill Book Company (UK) Limited, London, U.K. 787 p.

Zienkiewicz, O.C., and Phillips, D.V., 1971, An Automatic Mesh Generation Scheme for Plane and Curved Surfaces by 'Isoparametric' coordinates: International Journal for Numerical Methods in Engineering, v. 3, p. 519-528. 
APPENDIXES

22 Dage 25 follow. 


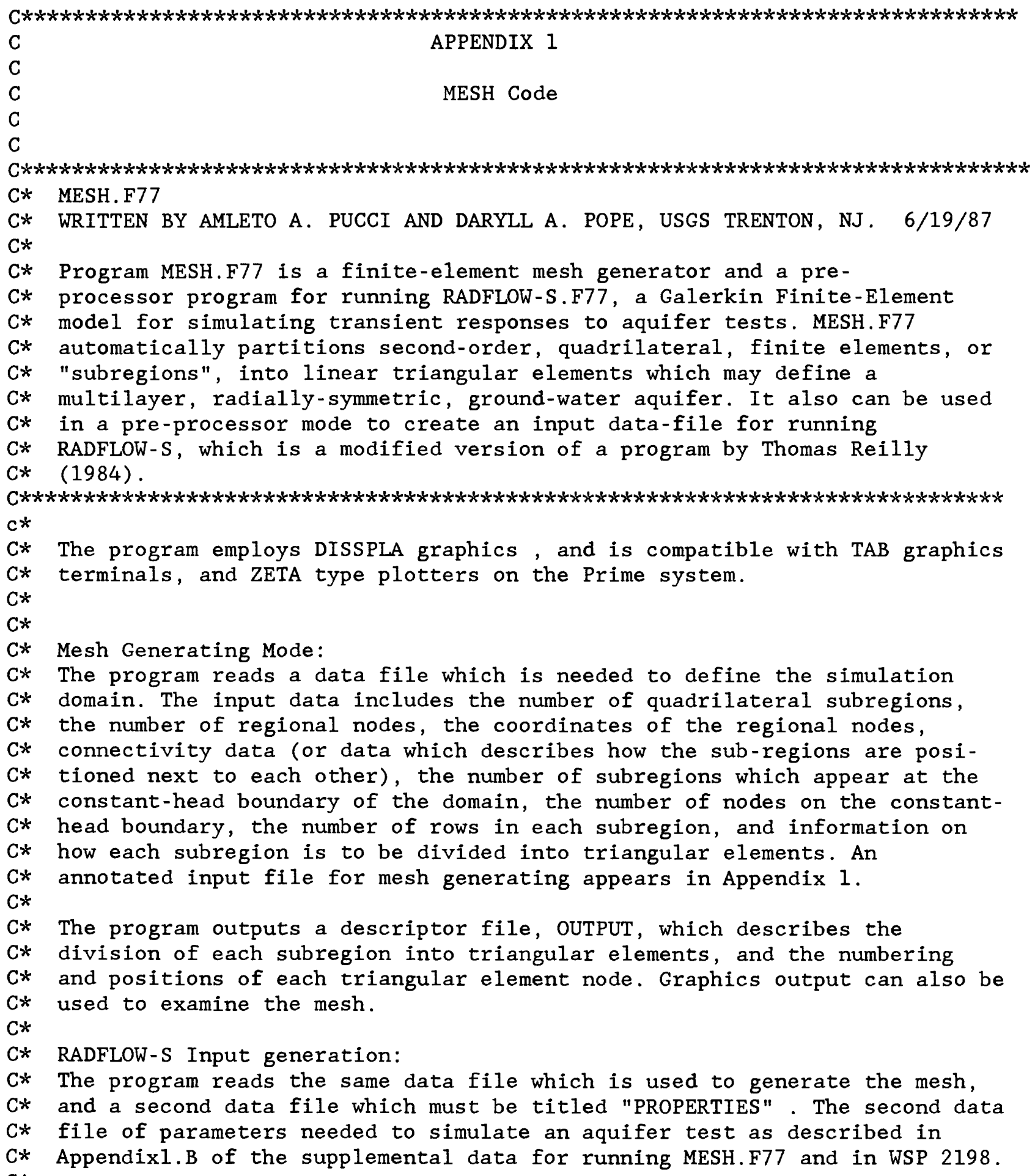

C*

$C *$ 


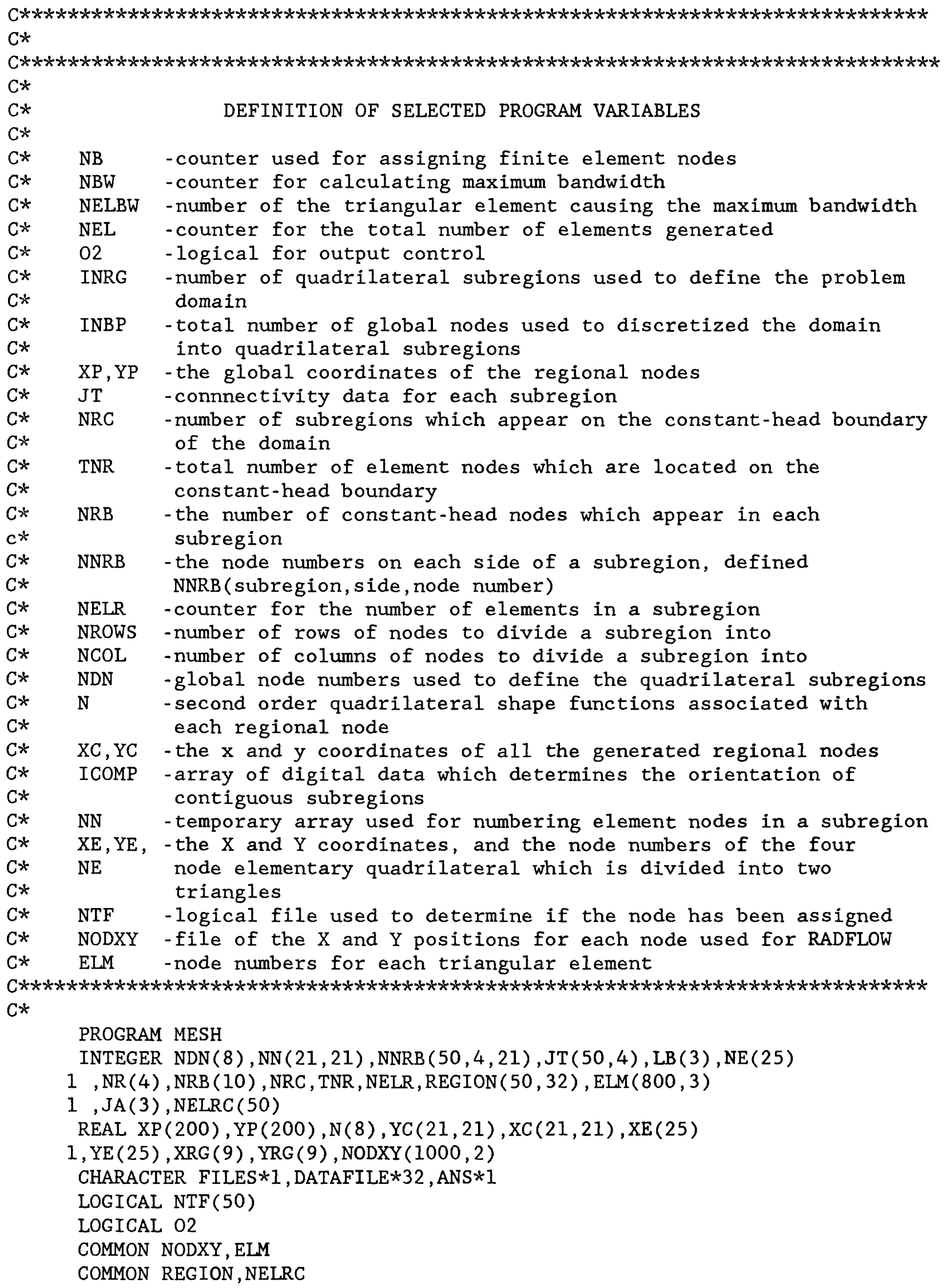




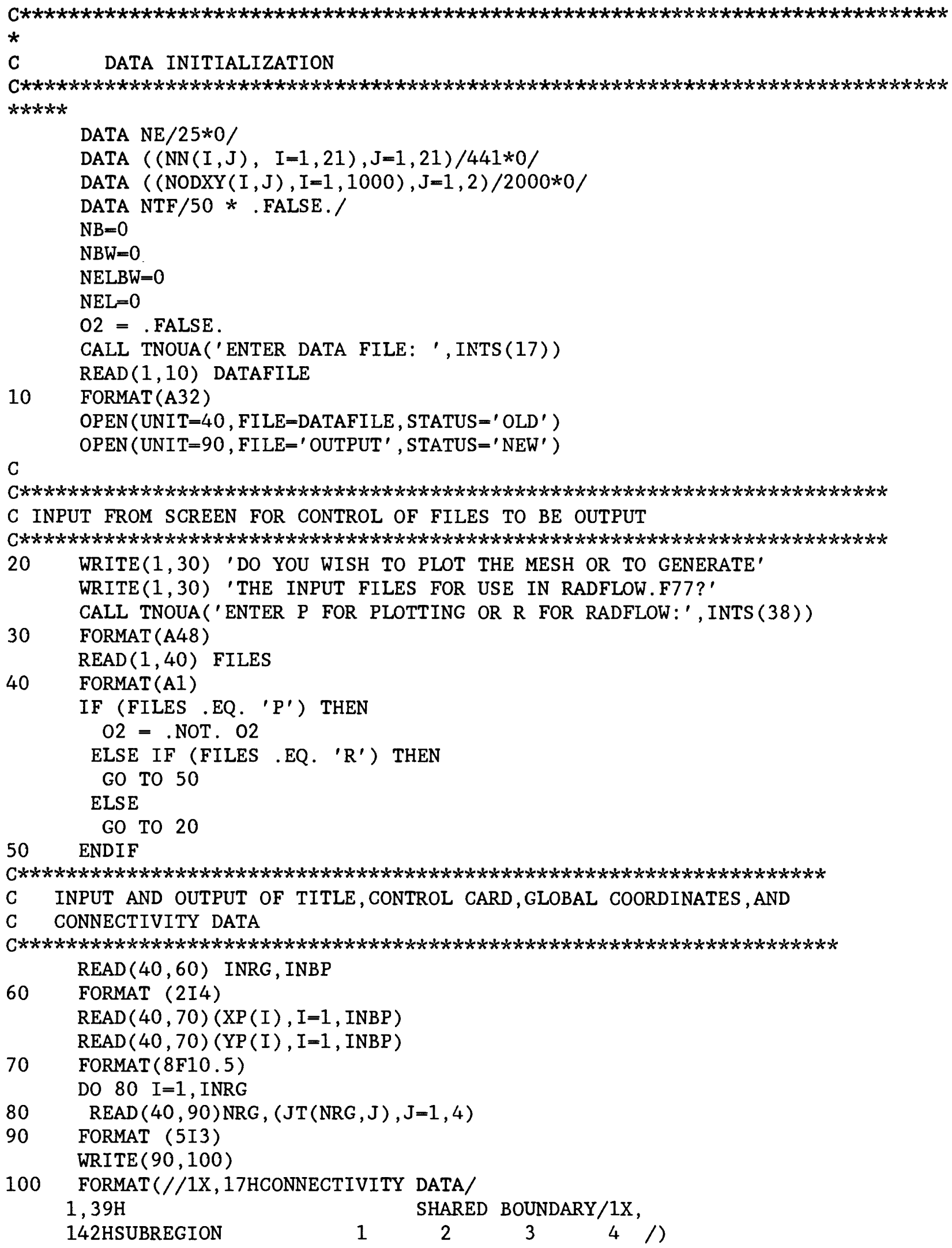


C100 FORMAT $(/ / 1 \mathrm{X}, 39 \mathrm{HCONNECTIVITY} \mathrm{DATA}$

C

$\begin{array}{lll}1 & 2\end{array}$
143HSUB REGION

DO 110 I=1, INRG

110

$\operatorname{WRITE}(90,120) \mathrm{I},(\mathrm{JT}(\mathrm{I}, \mathrm{J}), \mathrm{J}=1,4)$

120 FORMAT $(2 \mathrm{X}, \mathrm{I} 3,16 \mathrm{X}, 4(\mathrm{I} 2,5 \mathrm{X}))$

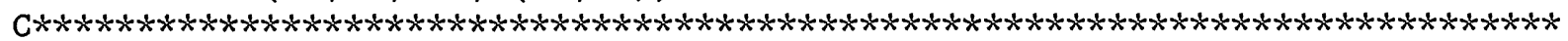

C INPUT OF NODE NUMBERS ALONG CONSTANT-HEAD BOUNDARY

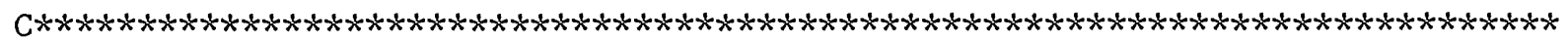

130

$\operatorname{READ}(40,130)$ NRC, TNR

DO $140 \quad I=1$, NRC

$140 \quad \operatorname{READ}(40,150) \operatorname{NRB}(I)$

150 FORMAT (I3)

$\mathrm{NB}=\mathrm{TNR}$

$\mathrm{K}=2$

DO $160 \mathrm{I}=1$, NRC

IM $=\mathrm{I}-1$

$\operatorname{NNRB}(I, 2,1)=\operatorname{NNRB}($ IM $, 2, \operatorname{NRB}($ IM) $)$

DO $160 \mathrm{~J}=2, \mathrm{NRB}(\mathrm{I})$

$\operatorname{NNRB}(I, 2, J)=K$

$\mathrm{K}=\mathrm{K}+1$

160 CONTINUE

$\operatorname{NNRB}(1,2,1)=1$

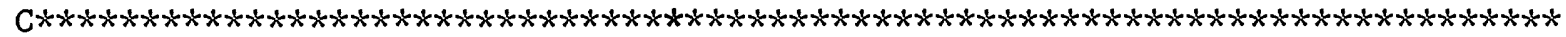

C LOOP ON THE SUBREGIONS TO GENERATE THE ELEMENTS

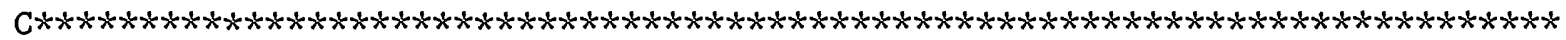

DO $420 \mathrm{KK}=1$, INRG

NELR $=0$

READ $(40,170)$ NRG, NROWS , NCOL , (NDN $(I), I=1,8)$

170 FORMAT (11I4)

IF (NRG .NE. 1) THEN

WRITE $(90,175)$

175 FORMAT $(/ 30 \mathrm{X}, 41 \mathrm{H} *$ NOTE: COORDINATES ARE MULTIPLIED BY .001)

ENDIF

WRITE $(90,180)$ NRG, NROWS , NCOL, $(\operatorname{NDN}(I), I=1,8)$

180 FORMAT (1H1///1X,

164H***** ARRANGEMENT OF GLOBAL NODE AND FINITE ELEMENT NODE NUMBERS

$1,13 \mathrm{H}$ IN SUBREGION

$1,12,6 \mathrm{H} \quad * * * * / / 22 \mathrm{HNUMBER}$ OF INCREMENTS $=/ / 10 \mathrm{X}, \mathrm{I} 2,11 \mathrm{H}$ ROWS AND $4 \mathrm{X}$

$1, \mathrm{I} 2,8 \mathrm{H}$ COLUMNS//10X,19HGLOBAL NODE NUMBERS , 10X, 8I5)

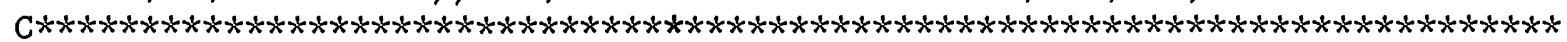

C GENERATION OF THE ELEMENT NODAL COORDINATES

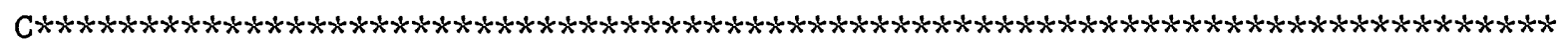

DO $190 \quad I=1,8$

$I I=N D N(I)$

$\mathrm{XRG}(\mathrm{I})=\mathrm{XP}(\mathrm{II})$

$190 \quad$ YRG (I) $=$ YP (II)

$\mathrm{XRG}(9)=\mathrm{XP}(1)$

$\mathrm{YRG}(9)=\mathrm{YP}(1)$

TR=NROWS -1

DETA $=2$. $/ \mathrm{TR}$

$\mathrm{TR}=\mathrm{NCOL}-1$

$\mathrm{DSI}=2$. / TR

DO $200 \mathrm{I}=1$, NROWS 


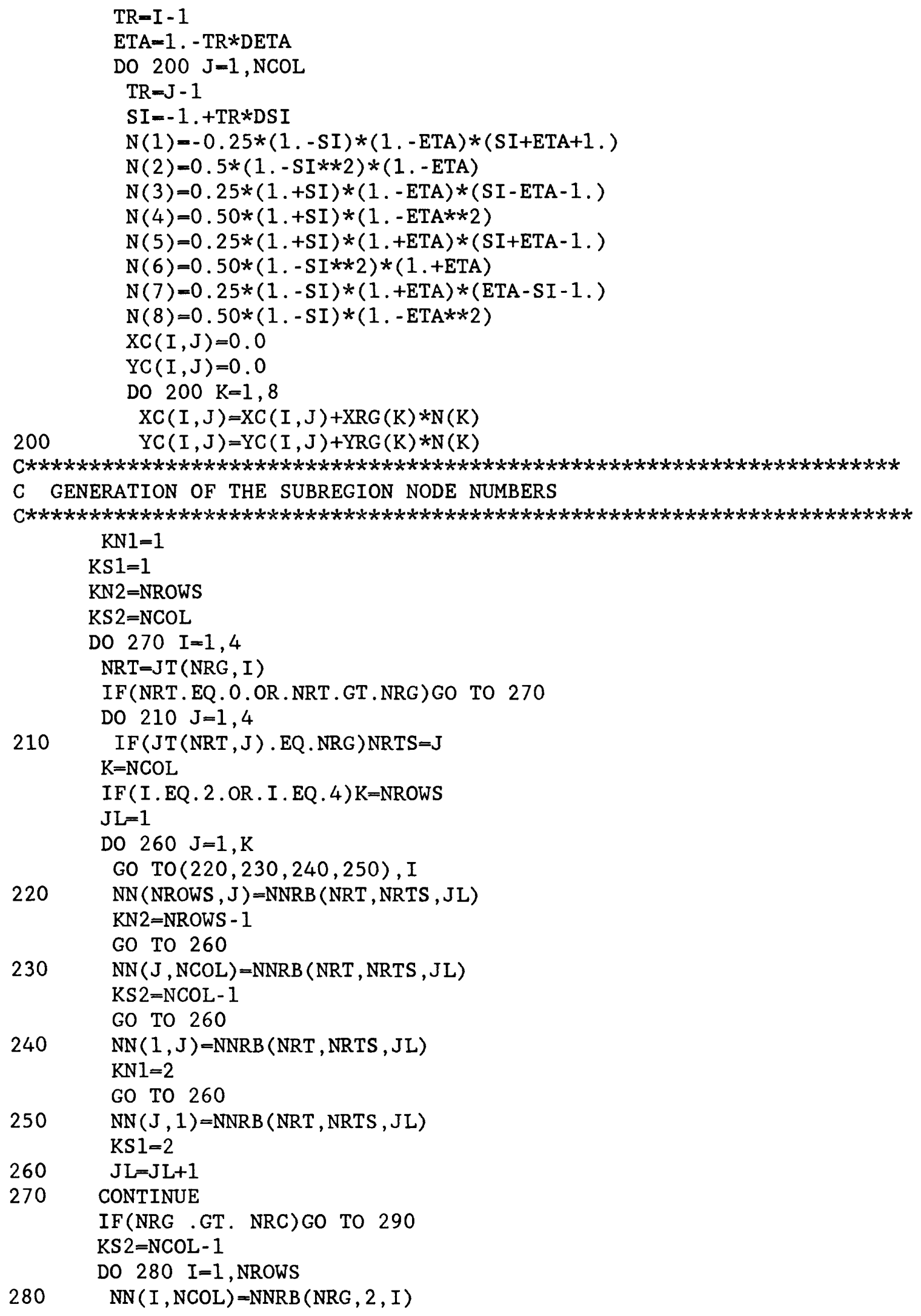




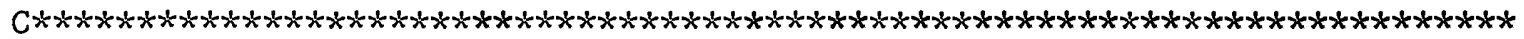
C STORAGE OF THE BOUNDARY NUMBERS

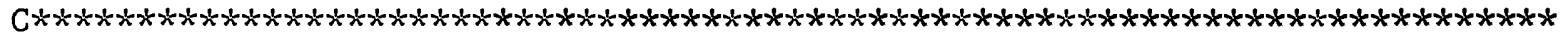
DO $310 \quad I=1$, NCOL

NNRB (NRG , $1, I)=$ NN (NROWS , I) 


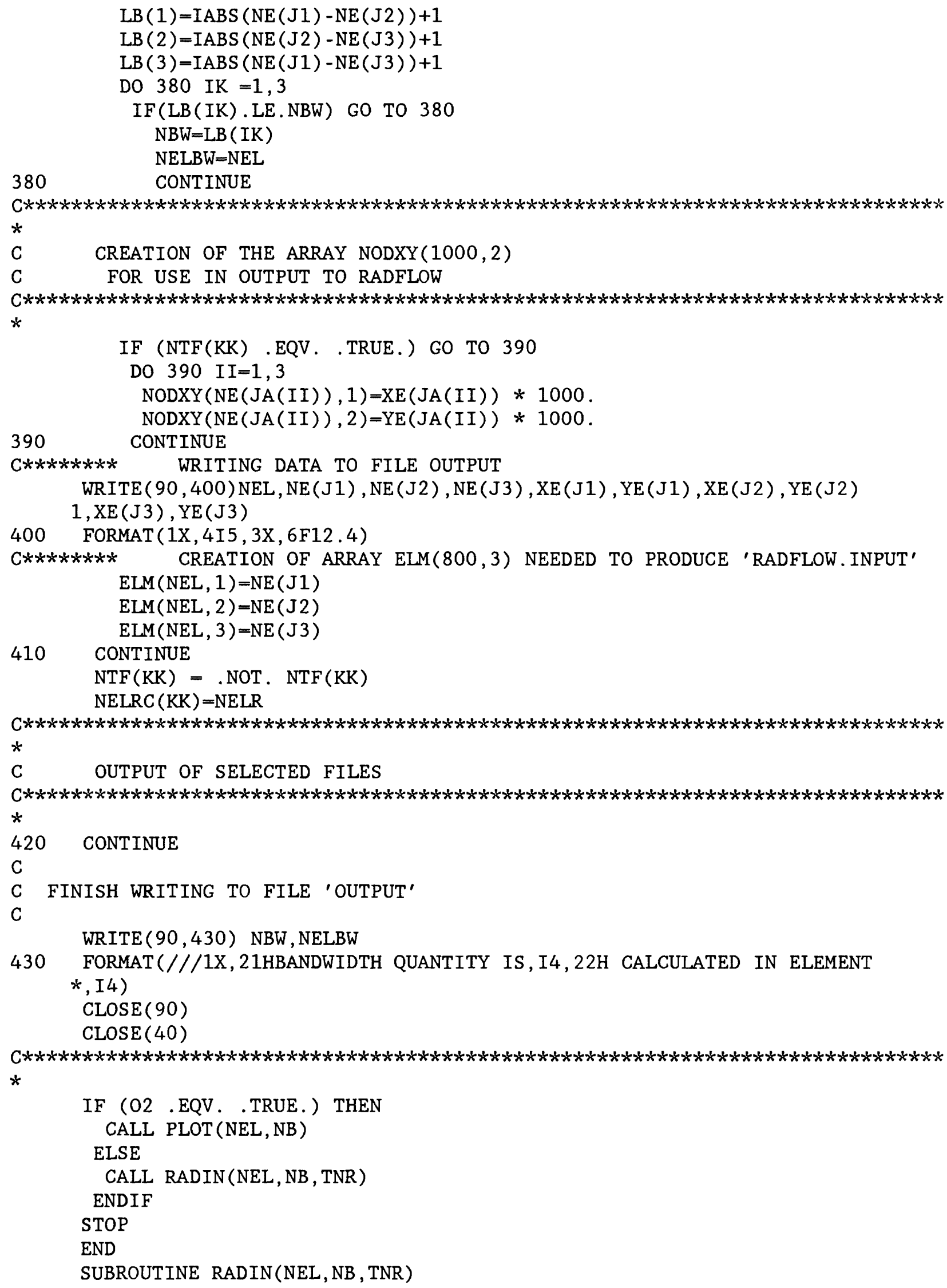




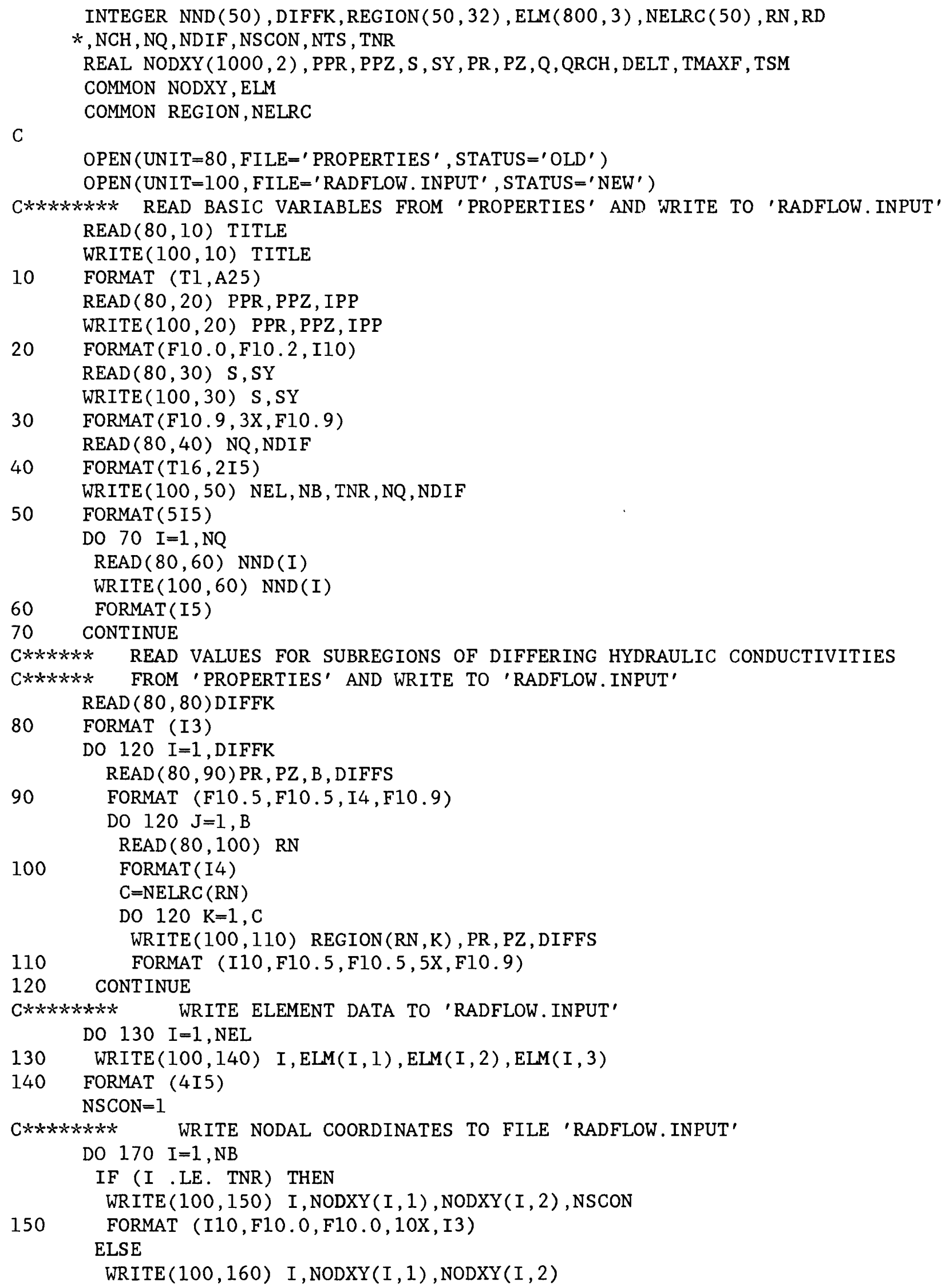




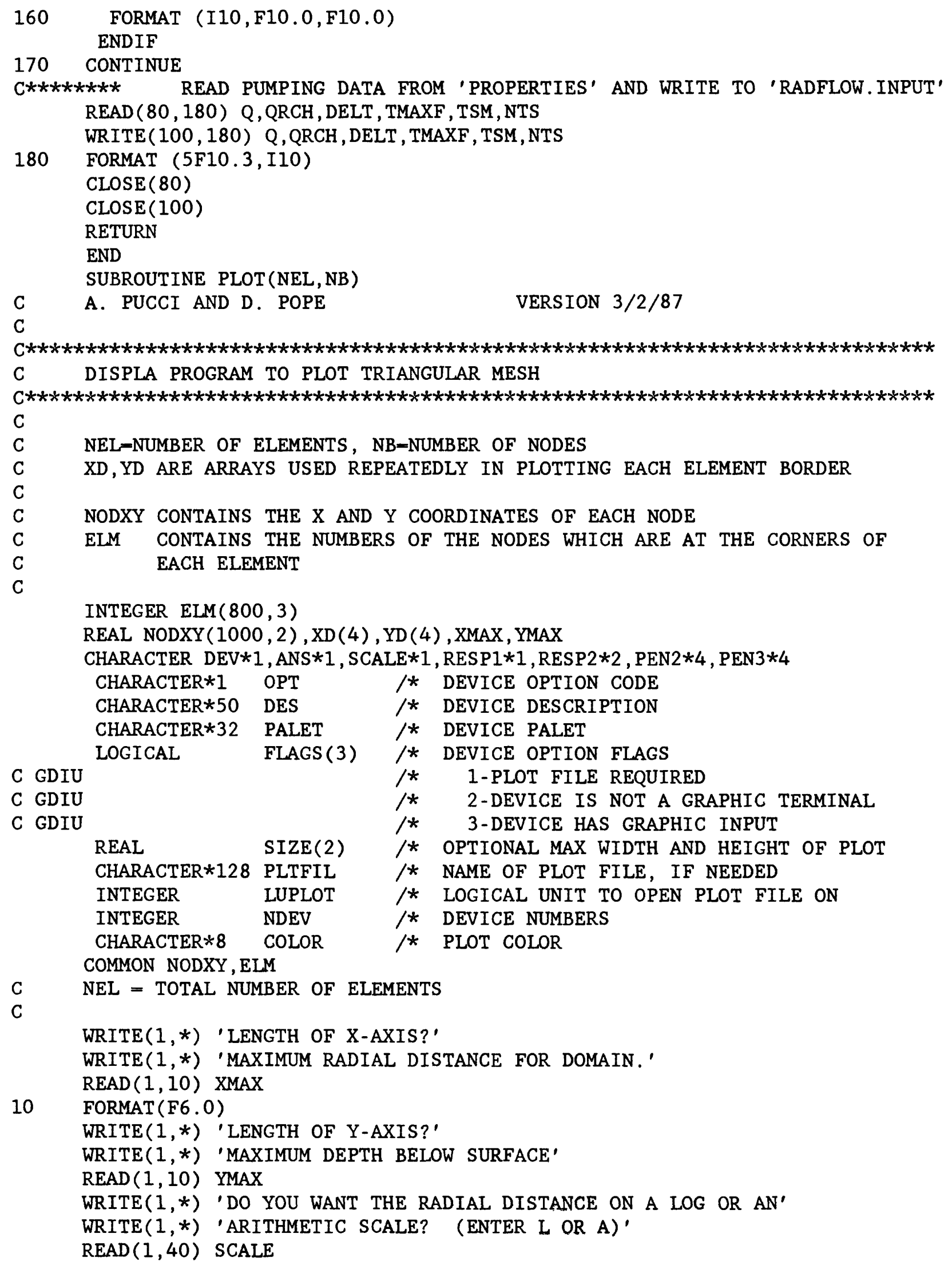




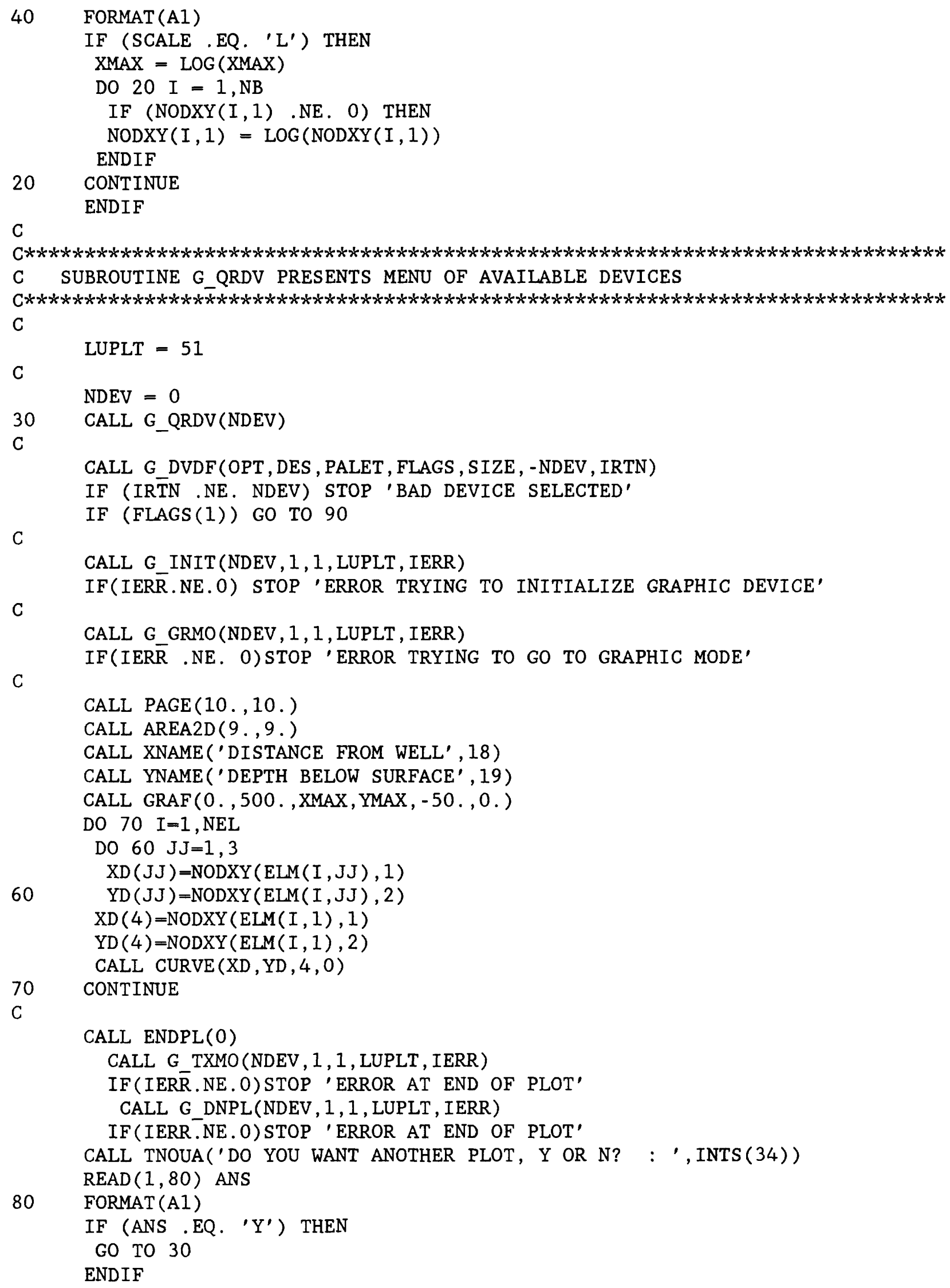


GO TO 100

C

90 OPEN(LUPLT, FILE-' FEM. PLOT', STATUS=' NEW' )

C

CALL G INIT(NDEV , 1, 1, LUPLT, IERR)

IF (IERR.NE.0) STOP 'ERROR TRYING TO INITIALIZE GRAPHIC DEVICE'

C

CALL G GRMO(NDEV , 1, 1, LUPLT, IERR)

IF(IERR .NE. O)STOP 'ERROR TRYING TO GO TO GRAPHIC MODE'

C

CALL PAGE $(30,30$.

CALL AREA2D (28.,28.)

CALL XNAME('DISTANCE FROM WELL', 18)

CALL YNAME('DEPTH BELOW SURFACE',19)

CALL GRAF $(0,50, \mathrm{XMAX}, \mathrm{YMAX},-50,0)$

DO $120 \mathrm{I}=1$, NEL

DO $110 \mathrm{JJ}=1,3$

$\mathrm{XD}(\mathrm{JJ})=\operatorname{NODXY}(\operatorname{ELM}(\mathrm{I}, \mathrm{JJ}), 1)$

$110 \quad \mathrm{YD}(\mathrm{JJ})=\operatorname{NODXY}(\operatorname{ELM}(\mathrm{I}, \mathrm{JJ}), 2)$

$\operatorname{XD}(4)=\operatorname{NODXY}(\operatorname{ELM}(I, 1), 1)$

$\mathrm{YD}(4)=\operatorname{NODXY}(\operatorname{ELM}(I, 1), 2)$

CALL CURVE(XD, YD , 4, 0)

120 CONTINUE

C

IF (PALET .NE. ' ' ) THEN

PEN2 = PALET $(9: 12)$

PEN3 = PALET (13:16)

ENDIF

C

C LABEL TRIANGULAR ELEMENTS

CALL TNOUA ('DO YOU WANT TO LABEL THE ELEMENT NUMBERS? ', INTS(42)) $\operatorname{READ}(1,125) \operatorname{RESP} 1$

IF (RESP1 .EQ. ' $N$ ') GO TO 135

125 FORMAT(A1)

CALL HEIGHT (0.08)

IF (PALET .NE. ' ') CALL SETCLR(PEN2)

DO $130 \mathrm{~J}=1$, NEL

$X=(\operatorname{NODXY}(\operatorname{ELM}(J, 1), 1)+\operatorname{NODXY}(\operatorname{ELM}(J, 2), 1)+\operatorname{NODXY}(\operatorname{ELM}(J, 3), 1)) / 3.0$

$Y=(\operatorname{NODXY}(\operatorname{ELM}(J, 1), 2)+\operatorname{NODXY}(\operatorname{ELM}(J, 2), 2)+\operatorname{NODXY}(\operatorname{ELM}(J, 3), 2)) / 3.0$

130 CALL RLINT $(J, X, Y)$

C LABEL NODE NUMBERS ON PLOT

135 CALL TNOUA('DO YOU WANT TO LABEL THE NODE NUMBERS? ', INTS(39))

$\operatorname{READ}(1,125) \operatorname{RESP} 2$

IF (RESP2 .EQ. ' $N$ ') GO TO 150

CALL HEIGHT ('RESET')

CALL HEIGHT (0.05)

IF (PALET .NE. ' ' ) CALL SETCLR(PEN3)

CALL MSHIFT $(0.0,-0.05)$

DO $140 \mathrm{~K}=1$, NB

IF (SCALE .EQ. 'A') THEN

$\mathrm{XSP}=\operatorname{NODXY}(\mathrm{K}, 1)+5$.

ELSE

$\mathrm{XSP}=\operatorname{NODXY}(K, 1)+.4$

ENDIF 


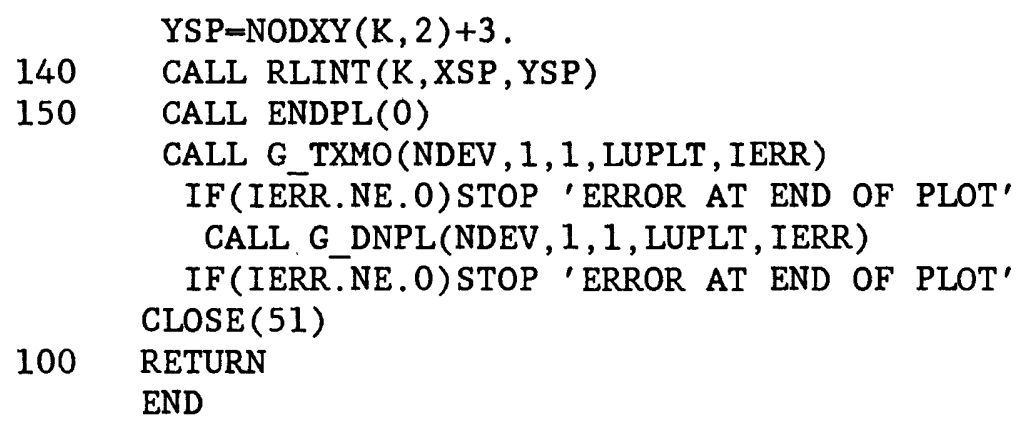


APPENDIX 2

Formats for input files

SECTION A

BASIC DATA FILE

Group 1

$\underline{\text { Card Columns Format Variable }}$

1 I4 14 INRG = Number of subregions in mesh

5-8 I4 INBP $=$ Number of global-mesh nodes

Group 2: Coordinates of boundary points

Number of cards depends on number of boundary points

Card Columns Format Variable Definition

$$
\begin{aligned}
& \text { - } \quad 1-80 \quad 8(\mathrm{~F} 10.5) \quad \mathrm{XP}=\mathrm{X} \text {-coordinates of global-mesh } \\
& \text { nodes. Number of values }=\text { INBP. } \\
& \text { Origin is pumping well } \\
& \text { (feet/1000). } \\
& \begin{array}{lll}
1-80 & 8(\mathrm{~F} 10.5) \quad Y P
\end{array}
\end{aligned}
$$

\section{Group 3: Connectivity data}

INRG number of cards

Card Columns Format Variable Definition

1-INRG 1-3 I3 NRG = subregion number.

$$
\begin{aligned}
& \text { 4-15 } 4 \text { (I3) JT(NRG,K) }=\text { Number of the subregion which } \\
& \text { shares side } K \text { with subregion NRG, } \\
& \mathrm{K}=1 \text { to } 4 \text {. }
\end{aligned}
$$

Group 4: Data on subregions along constant head boundary

TNR +1 number of cards

$\underline{\text { Card Columns Format Variable Definition }}$
$1 \quad 1-3$
I3
NRC
$=$ Number of subregions along the constant-head boundary.


4-6

I3

2 - INRG

$1-3$

I3

Group 5: subregion Data

INRG number of cards

1 - INRG

$1-4$

I4

$5-8$

I4

$9-12$

I4

$13-44$

$8(I 4)$
TNR

$\mathrm{NRB}(I)$

Variable

Definition
- Total number of rows along the constant-head boundary.

Number of rows in each subregion in order from top to bottom. $I=1$ to NRC.
NRG $=$ subregion number.

NROWS $=$ Number of rows in subregion.

NCOL $=$ Number of columns in subregion.

NDN(I) = Numbers of the boundary points which define the subregion, $I=1$ to 8 . 
SECTION B

PROPERTIES

GROUP 1: Title and problem setup

\begin{tabular}{|c|c|c|c|c|}
\hline$\underline{\text { Card }}$ & Columns & Format & Variable & Definition \\
\hline 1 & $1-80$ & $20 A 4$ & TITLE & Any title the user wishes. \\
\hline \multirow[t]{3}{*}{2} & $1-10$ & F10.0 & PPR & $\begin{array}{l}\text { Primary radial hydraulic } \\
\text { conductivity in feet per day } \\
(\mathrm{ft} / \mathrm{d}) \text {. }\end{array}$ \\
\hline & $11-20$ & F10.0 & $\mathrm{PPZ}$ & $\begin{aligned}= & \text { Primary vertical hydraulic } \\
& \text { conductivity }(\mathrm{ft} / \mathrm{d}) .\end{aligned}$ \\
\hline & $21-30$ & I10 & IPP & Number of pumping periods. \\
\hline \multirow[t]{2}{*}{3} & $1-10$ & F10.0 & $\mathrm{S}$ & $\begin{array}{l}\text { Coefficient of compressive } \\
\text { storage (Ss) in } 1 / \mathrm{ft} .\end{array}$ \\
\hline & $11-20$ & F10.0 & SY & Specific Yield (unitless). \\
\hline \multirow[t]{2}{*}{4} & $16-20$ & I5 & NQ & $\begin{array}{l}=\text { Number of nodes associated } \\
\text { with well screen. }\end{array}$ \\
\hline & $21-25$ & I5 & NDIF & $\begin{array}{l}=\text { Number of elements having } \\
\text { different hydraulic conduc- } \\
\text { tivities than the primary ones } \\
\text { on card } 2 \text {. }\end{array}$ \\
\hline
\end{tabular}

Group 2: Nodes along the well screen

NQ number of cards

Card Columns Format Variable Definition

- $1-5$ I5 NND(I) = Node along well screen. 
Group 3: Data to assign secondary hydrologic properties to user defined sets of subregions

\begin{tabular}{|c|c|c|c|c|}
\hline$\underline{\text { Card }}$ & Columns & Format & Variable & Definition \\
\hline 1 & $1-3$ & I3 & DIFFK & $\begin{array}{l}=\text { Number of subsets of subregions } \\
\text { to be assigned secondary } \\
\text { properties. }\end{array}$ \\
\hline
\end{tabular}

Subgroups: This section will be repeated for each subset of subregions

$1 \quad 1-10 \quad$ F10.0 PR $\quad=$ Radial hydraulic conductivity assigned to all elements contained in the subregions in this subset $(\mathrm{ft} / \mathrm{d})$.

$\begin{array}{cccl}11-20 & \text { F10.0 } & \text { PZ } & =\begin{array}{l}\text { Vertical hydraulic conductivity } \\ \text { (ft/d). }\end{array} \\ 21-24 & \text { I4 } & \text { B } & \begin{array}{l}\text { Number of subregions in this } \\ \text { subset of subregions. }\end{array} \\ 25-34 & \text { F10.9 } & \text { DIFFS } & =\begin{array}{l}\text { Coefficient of compressive } \\ \text { storage (Ss) in feet } .\end{array} \\ 2-B \quad 1-4 & \text { I4 } & \text { RN } & =\begin{array}{l}\text { subregion number to be included } \\ \text { in this subset. }\end{array}\end{array}$

Group 4: Pumping period information used in RADFLOW-S.F77

\begin{tabular}{|c|c|c|c|c|}
\hline$\underline{\text { Card }}$ & $\underline{\text { Columns }}$ & Format & Variable & Definition \\
\hline & $1-10$ & F10.0 & Q & $\begin{aligned}= & \text { Pumping rate in cubic feet } \\
& \text { per second }\left(\mathrm{ft}^{3} / \mathrm{sec}\right) .\end{aligned}$ \\
\hline & $11-20$ & F10.0 & $\mathrm{QRCH}$ & Recharge rate $(f t / d)$. \\
\hline & $21-30$ & F10.0 & DELT & $=$ Initial time step (Days). \\
\hline & $31-40$ & F10.0 & TMAXF & $\begin{array}{l}=\text { Maximum length of pumping } \\
\text { Period (Days). }\end{array}$ \\
\hline & $41-50$ & F10.0 & TSM & $\begin{array}{l}=\text { Time step multiplier (each time } \\
\text { step after DELT is multiplied } \\
\text { by TSM. }\end{array}$ \\
\hline & $51-60$ & I10 & NTS & $\begin{array}{l}=\text { Number of time steps in } \\
\text { Pumping period. }\end{array}$ \\
\hline
\end{tabular}

For more information on RADFLOW options for pumping period simulations see Reilly (1984 pg. 27). 
SECTION C

OB. WELL

Group 1: Number of observation wells you have data for

$\underline{\text { Card Columns Format Variable Definition }}$

$1 \quad 1-4 \quad$ I4 NNO $\quad$ - Number of observation we11s you wish to use.

Group 2: Location of midpoint of screen for each observation wel1

NNO number of cards

\begin{tabular}{|c|c|c|c|c|c|}
\hline Card & Columns & Format & Variable & Definition & \\
\hline - & $2-7$ & F6. 0 & $\operatorname{XBAR}(I)$ & $\begin{aligned} &= X \text {-coordinate (in feet) } \\
& \text { midpoint of the screen } \\
& \text { observation well, } \quad I=1\end{aligned}$ & $\begin{array}{l}\text { of the } \\
\text { for each } \\
\text { to NNO. }\end{array}$ \\
\hline$\cdots$ & $9-14$ & F6. 0 & $\operatorname{YBAR}(I)$ & $\begin{array}{l}\text { Y-coordinate (in feet) } \\
\text { midpoint of the screen } \\
\text { observation well, } \quad I=1\end{array}$ & $\begin{array}{l}\text { of the } \\
\text { for each } \\
\text { to NNO. }\end{array}$ \\
\hline
\end{tabular}

Group 3: Element numbers that contain the screen for each observation wel1

NNO number of cards

$\underline{\text { Card Columns Format Variable Definition }}$

- $1-4 \quad$ I4 $\operatorname{NNE}(I)=$ Element number that contains the midpoint of the screen for each observation we11, $\mathrm{I}=1$ to NNO. 
SECTION D

Observation well data file

\section{Group 1}

One card

\begin{tabular}{|c|c|c|c|c|}
\hline$\underline{\text { Card }}$ & Columns & Format & Variable & Definition \\
\hline 1 & $2-4$ & I3 & $\mathrm{N}$ & $\begin{array}{l}=\text { Number of observed data points } \\
\text { in file. }\end{array}$ \\
\hline & $5-9$ & F5. 0 & $\mathrm{R}$ & $\begin{array}{l}=\text { Distance of observed well from } \\
\text { pumping well (in feet). }\end{array}$ \\
\hline & $11-15$ & F5. 1 & $\mathrm{RE}$ & $\begin{array}{l}\text { Reference elevation. Will be } \\
\text { zero if the data is drawdown data. } \\
\text { If the data is water level data } \\
\text { this should be the elevation of } \\
\text { the measuring point of the well. }\end{array}$ \\
\hline
\end{tabular}

Group 2: Time-drawdown or Time-water-1eve1 data

$\mathrm{N}$ number of cards

\begin{tabular}{|c|c|c|c|c|}
\hline$\underline{\text { Card }}$ & Columns & Format & Variable & Definition \\
\hline - - & $1-10$ & F10.0 & $T(I)$ & $\begin{array}{l}=\text { Time of measurement in minutes. } \\
I=1, N .\end{array}$ \\
\hline & $11-20$ & F10.3 & $S(I)$ & $\begin{array}{l}=\text { Drawdown or water-level data in } \\
\text { feet, } I=1 \text { to } \mathrm{N} .\end{array}$ \\
\hline
\end{tabular}




\section{APPENDIX 3}

Example of BASIC DATA FILE for the six subregion example mesh shown in figure 3. The description of the input data file format is given in appendix 2 , section $A$. 629

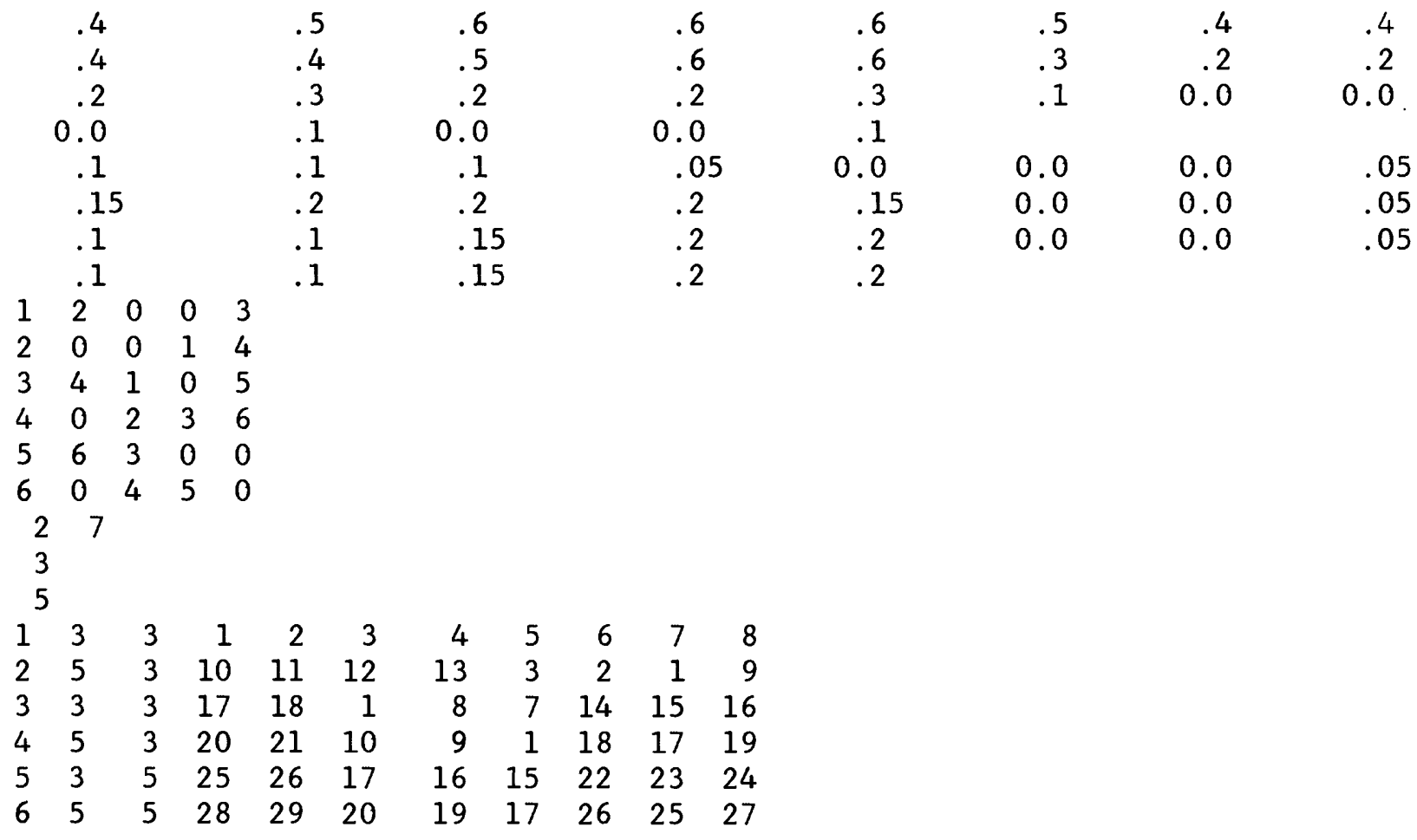


Data files used for example simulation shown in figure 4 .

SECTION A

BASIC DATA FILE for generating figure 4.

The description of the input data file format is given in appendix 2 , section A.

\begin{tabular}{|c|c|c|c|c|c|c|c|}
\hline 50 & 181 & & & & & & \\
\hline 10.69 & 17.9 & 30. & 30. & 30. & 17.9 & 10.69 & 10.69 \\
\hline 10.69 & 10.69 & 17.9 & 30. & 30 & 10.69 & 10.69 & 17.9 \\
\hline 30. & 30. & 10.69 & 10.69 & 17.9 & 30. & 30. & 10.69 \\
\hline 10.69 & 17.9 & 30. & 30. & 6.40 & 3.82 & 3.82 & 3.82 \\
\hline 6.40 & 3.82 & 3.82 & 6.40 & 3.82 & 3.82 & 6.40 & 3.82 \\
\hline 3.82 & 6.40 & 3.82 & 3.82 & 6.40 & 2.28 & 1.36 & 1.36 \\
\hline 1.36 & 2.28 & 1.36 & 1. 36 & 2.28 & 1.36 & 1.36 & 2.28 \\
\hline 1.36 & 1.36 & 2.28 & 1.36 & 1.36 & 2.28 & .813 & .485 \\
\hline .485 & .485 & .813 & .485 & .485 & .813 & .485 & .485 \\
\hline .813 & .485 & .485 & .813 & .485 & .485 & .813 & .290 \\
\hline .173 & .173 & .173 & .290 & .173 & .173 & .290 & .173 \\
\hline .173 & .290 & .173 & .173 & .290 & .173 & .173 & .290 \\
\hline .104 & .062 & .062 & .062 & .104 & .062 & .062 & .104 \\
\hline .062 & .062 & .104 & .062 & .062 & .104 & .062 & .062 \\
\hline .104 & .037 & .022 & .022 & .022 & .037 & .022 & .022 \\
\hline .037 & .022 & .022 & .037 & .022 & .022 & .037 & .022 \\
\hline .022 & .037 & .013 & .008 & .008 & .008 & .013 & .008 \\
\hline .008 & .013 & .008 & .008 & .013 & .008 & .008 & .013 \\
\hline .008 & .008 & .013 & .005 & .003 & .003 & .003 & .005 \\
\hline .003 & .003 & .005 & .003 & .003 & .005 & .003 & .003 \\
\hline .005 & .003 & .003 & .005 & .002 & 0.0 & 0.0 & 0.0 \\
\hline .002 & 0.0 & 0.0 & .002 & 0.0 & 0.0 & .002 & 0.0 \\
\hline 0.0 & .002 & 0.0 & 0.0 & .002 & & & \\
\hline 0.302 & 0.302 & 0.302 & 0.209 & 0.117 & 0.117 & 0.117 & 0.209 \\
\hline 0.378 & 0.454 & 0.454 & 0.454 & 0.378 & 0.525 & 0.597 & 0.597 \\
\hline 0.597 & 0.525 & 0.632 & 0.650 & 0.650 & 0.650 & 0.632 & 0.687 \\
\hline 0.709 & 0.709 & 0.709 & 0.687 & 0.117 & 0.117 & 0.209 & 0.302 \\
\hline 0.302 & 0.378 & 0.454 & 0.454 & 0.525 & 0.597 & 0.597 & 0.632 \\
\hline 0.650 & 0.650 & 0.687 & 0.709 & C. 709 & 0.117 & 0.117 & 0.209 \\
\hline 0.302 & 0.302 & 0.378 & 0.454 & 0.454 & 0.525 & 0.597 & 0.597 \\
\hline 0.632 & 0.650 & 0.650 & 0.687 & 0.709 & 0.709 & 0.117 & 0.117 \\
\hline 0.209 & 0.302 & 0.302 & 0.378 & 0.454 & 0.454 & 0.525 & 0.597 \\
\hline 0.597 & 0.632 & 0.650 & 0.650 & 0.687 & 0.709 & 0.709 & 0.117 \\
\hline 0.117 & 0.209 & 0.302 & 0.302 & 0.378 & 0.454 & 0.454 & 0.525 \\
\hline 0.597 & 0.597 & 0.632 & 0.650 & 0.650 & 0.687 & 0.709 & 0.709 \\
\hline 0.117 & 0.117 & 0.209 & 0.302 & 0.302 & 0.378 & 0.454 & 0.454 \\
\hline 0.525 & 0.597 & 0.597 & 0.632 & 0.650 & 0.650 & 0.687 & 0.709 \\
\hline 0.709 & 0.117 & 0.117 & 0.209 & 0.302 & 0.302 & 0.378 & 0.454 \\
\hline 0.454 & 0.525 & 0.597 & 0.597 & 0.632 & 0.650 & 0.650 & 0.687 \\
\hline 0.709 & 0.709 & 0.117 & 0.117 & 0.209 & 0.302 & 0.302 & 0.378 \\
\hline 0.454 & 0.454 & 0.525 & 0.597 & 0.597 & 0.632 & 0.650 & 0.650 \\
\hline 0.687 & 0.709 & 0.709 & 0.117 & 0.117 & 0.209 & 0.302 & 0.302 \\
\hline .378 & .454 & .454 & .525 & .597 & .597 & .632 & .650 \\
\hline
\end{tabular}




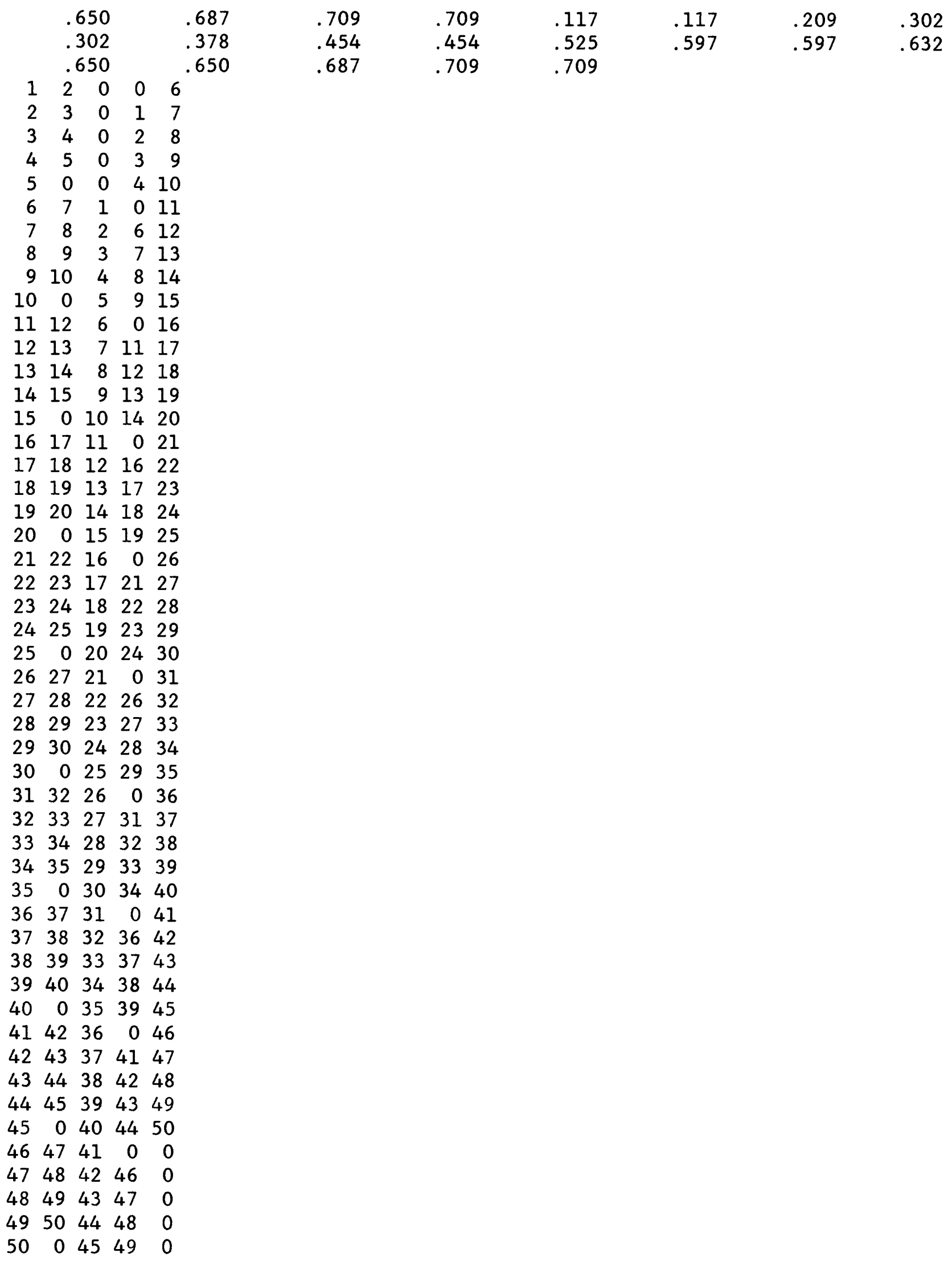


$\begin{array}{lllllllllll}11 & 3 & 3 & 49 & 50 & 32 & 31 & 30 & 46 & 47 & 48\end{array}$

$\begin{array}{lllllllllll}12 & 3 & 3 & 52 & 53 & 35 & 34 & 32 & 50 & 49 & 51\end{array}$

$\begin{array}{lllllllllll}13 & 3 & 3 & 55 & 56 & 38 & 37 & 35 & 53 & 52 & 54\end{array}$

$\begin{array}{lllllllllll}14 & 3 & 3 & 58 & 59 & 41 & 40 & 38 & 56 & 55 & 57\end{array}$

$\begin{array}{lllllllllll}15 & 5 & 3 & 61 & 62 & 44 & 43 & 41 & 59 & 58 & 60\end{array}$

$\begin{array}{lllllllllll}16 & 3 & 3 & 66 & 67 & 49 & 48 & 47 & 63 & 64 & 65\end{array}$

$\begin{array}{lllllllllll}17 & 3 & 3 & 69 & 70 & 52 & 51 & 49 & 67 & 66 & 68\end{array}$

$\begin{array}{lllllllllll}18 & 3 & 3 & 72 & 73 & 55 & 54 & 52 & 70 & 69 & 71\end{array}$

$\begin{array}{lllllllllll}19 & 3 & 3 & 75 & 76 & 58 & 57 & 55 & 73 & 72 & 74\end{array}$

$\begin{array}{lllllllllll}20 & 5 & 3 & 78 & 79 & 61 & 60 & 58 & 76 & 75 & 77\end{array}$

$\begin{array}{lllllllllll}21 & 3 & 3 & 83 & 84 & 66 & 65 & 64 & 80 & 81 & 82\end{array}$

$\begin{array}{lllllllllll}22 & 3 & 3 & 86 & 87 & 69 & 68 & 66 & 84 & 83 & 85\end{array}$

$\begin{array}{lllllllllll}23 & 3 & 3 & 89 & 90 & 72 & 71 & 69 & 87 & 86 & 88\end{array}$

$\begin{array}{lllllllllll}24 & 3 & 3 & 92 & 93 & 75 & 74 & 72 & 90 & 89 & 91\end{array}$

$\begin{array}{lllllllllll}25 & 5 & 3 & 95 & 96 & 78 & 77 & 75 & 93 & 92 & 94\end{array}$

$\begin{array}{rrrrrrrrrrr}26 & 3 & 3 & 100 & 101 & 83 & 82 & 81 & 97 & 98 & 99\end{array}$

$\begin{array}{lllllllllll}27 & 3 & 3 & 103 & 104 & 86 & 85 & 83 & 101 & 100 & 102\end{array}$

$\begin{array}{lllllllllll}28 & 3 & 3 & 106 & 107 & 89 & 88 & 86 & 104 & 103 & 105\end{array}$

$\begin{array}{lllllllllll}29 & 3 & 3 & 109 & 110 & 92 & 91 & 89 & 107 & 106 & 108\end{array}$

$\begin{array}{lllllllllll}30 & 5 & 3 & 112 & 113 & 95 & 94 & 92 & 110 & 109 & 111\end{array}$

$\begin{array}{lllllllllll}31 & 3 & 3 & 117 & 118 & 100 & 99 & 98 & 114 & 115 & 116\end{array}$

$\begin{array}{lllllllllll}32 & 3 & 3 & 120 & 121 & 103 & 102 & 100 & 118 & 117 & 119\end{array}$

$\begin{array}{lllllllllll}33 & 3 & 3 & 123 & 124 & 106 & 105 & 103 & 121 & 120 & 122\end{array}$

$\begin{array}{lllllllllll}34 & 3 & 3 & 126 & 127 & 109 & 108 & 106 & 124 & 123 & 125\end{array}$

$\begin{array}{lllllllllll}35 & 5 & 3 & 129 & 130 & 112 & 111 & 109 & 127 & 126 & 128\end{array}$

$\begin{array}{lllllllllll}36 & 3 & 3 & 134 & 135 & 117 & 116 & 115 & 131 & 132 & 133\end{array}$

$\begin{array}{lllllllllll}37 & 3 & 3 & 137 & 138 & 120 & 119 & 117 & 135 & 134 & 136\end{array}$

$\begin{array}{lllllllllll}38 & 3 & 3 & 140 & 141 & 123 & 122 & 120 & 138 & 137 & 139\end{array}$

$\begin{array}{lllllllllll}39 & 3 & 3 & 143 & 144 & 126 & 125 & 123 & 141 & 140 & 142\end{array}$

$\begin{array}{lllllllllll}40 & 5 & 3 & 146 & 147 & 129 & 128 & 126 & 144 & 143 & 145\end{array}$

$\begin{array}{lllllllllll}41 & 3 & 3 & 151 & 152 & 134 & 133 & 132 & 148 & 149 & 150\end{array}$

$\begin{array}{lllllllllll}42 & 3 & 3 & 154 & 155 & 137 & 136 & 134 & 152 & 151 & 153\end{array}$

$\begin{array}{lllllllllll}43 & 3 & 3 & 157 & 158 & 140 & 139 & 137 & 155 & 154 & 156\end{array}$

$\begin{array}{lllllllllll}44 & 3 & 3 & 160 & 161 & 143 & 142 & 140 & 158 & 157 & 159\end{array}$

$\begin{array}{lllllllllll}45 & 5 & 3 & 163 & 164 & 146 & 145 & 143 & 161 & 160 & 162\end{array}$

$\begin{array}{lllllllllll}46 & 3 & 3 & 168 & 169 & 151 & 150 & 149 & 165 & 166 & 167\end{array}$

$\begin{array}{lllllllllll}47 & 3 & 3 & 171 & 172 & 154 & 153 & 151 & 169 & 168 & 170\end{array}$

$\begin{array}{lllllllllll}48 & 3 & 3 & 174 & 175 & 157 & 156 & 154 & 172 & 171 & 173\end{array}$

$\begin{array}{lllllllllllll}49 & 3 & 3 & 177 & 178 & 160 & 159 & 157 & 175 & 174 & 176\end{array}$

$\begin{array}{lllllllllll}50 & 5 & 3 & 180 & 181 & 163 & 162 & 160 & 178 & 177 & 179\end{array}$ 
SECTION B

PROPERTIES data file for region shown in figure 4.

Description of input data set for PROPERTIES is given in appendix 2 , section $B$.

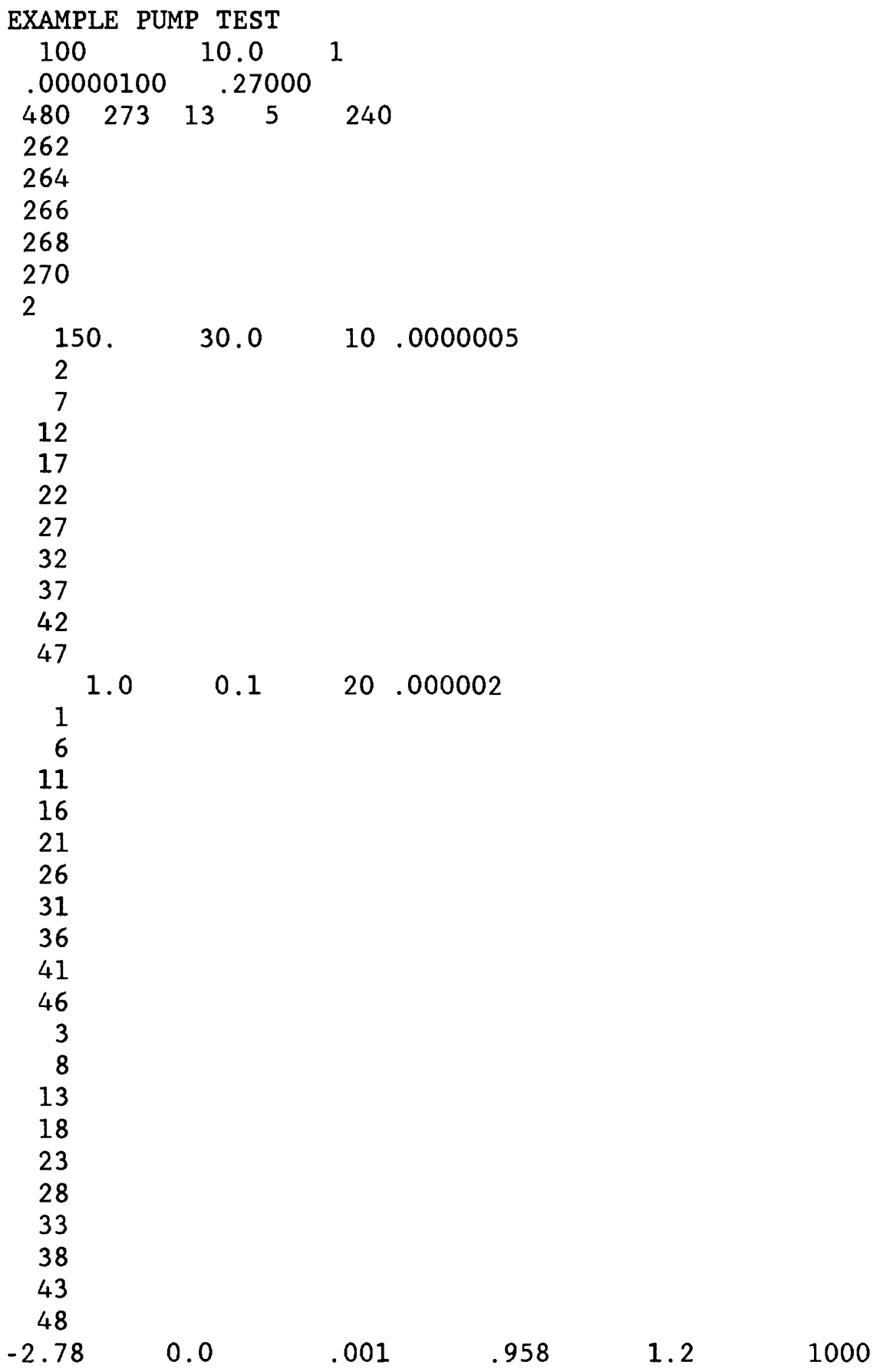


SECTION C

OB.WELL data file used to generate figure 5.

Description of input data set for OB.WELL is given in appendix 2 , section $C$.

1

$600 \quad 682.0$

181

SECTION D

Observed field-data file used to generate figure 5.

Description of input data set for actual pump test data files is given in appendix 2, section $D$.

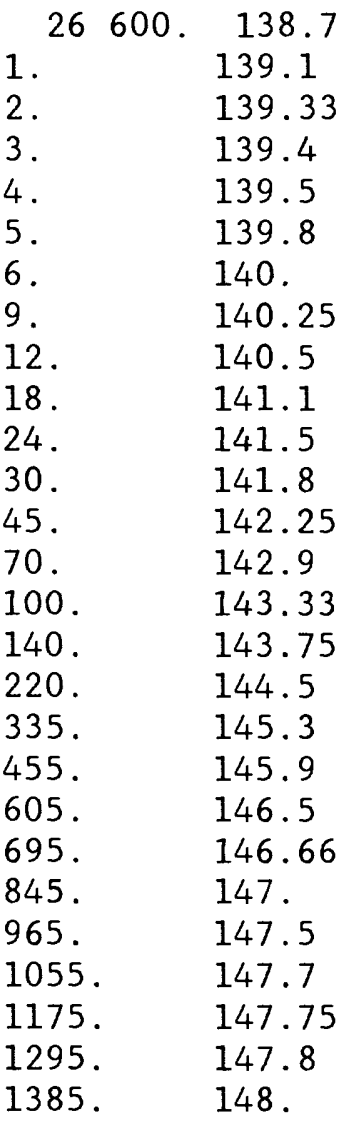


Example of 'OUTPUT' file from MESH 'P' mode for example shown in figure 3.

\begin{tabular}{ccccc} 
CONNECTIVITY DATA & \multicolumn{4}{c}{ SHARED BOUNDARY } \\
SUBREGION & 1 & 2 & 3 & 4 \\
1 & 2 & 0 & 0 & 3 \\
2 & 0 & 0 & 1 & 4 \\
3 & 4 & 1 & 0 & 5 \\
4 & 0 & 2 & 3 & 6 \\
5 & 0 & 3 & 0 & 0 \\
6 & 0 & 4 & 5 & 0
\end{tabular}

1

**** ARRANGement OF GLOBAL NODE AND FINITE ELEMENT NODE NUMBER, IN SUBREgION $1 * * * *$ NUMBER OF INCREMENTS =

$\begin{array}{lllllllllll}3 \text { ROWS AND } 3 \text { COLUMNS } & & & & & & & & \\ \text { GLOBAL NODE NUMBERS } & 1 & 2 & 3 & 4 & 5 & 6 & 7 & 8\end{array}$

FINITE-ELEMENT NOOE NUMBERS

$\begin{array}{rrr}8 & 9 & 1 \\ 10 & 11 & 2 \\ 12 & 13 & 3\end{array}$

ELEMENT NUMBERS, FINITE-ELEMENT NODE NUMBERS, AND NODE COORDINATES

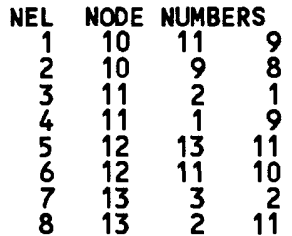

1

$\begin{array}{cccccc}X(1) & Y(1) & X(2) & Y(2) & X(3) & Y(3) \\ 0.4000 & 0.0500 & 0.5000 & 0.0500 & 0.5000 & 0.0000 \\ 0.4000 & 0.0500 & 0.5000 & 0.0000 & 0.4000 & 0.0000 \\ 0.5000 & 0.0500 & 0.6000 & 0.0500 & 0.6000 & 0.0000 \\ 0.5000 & 0.0500 & 0.6000 & 0.0000 & 0.5000 & 0.0000 \\ 0.4000 & 0.1000 & 0.5000 & 0.1000 & 0.5000 & 0.0500 \\ 0.4000 & 0.1000 & 0.5000 & 0.0500 & 0.4000 & 0.0500 \\ 0.5000 & 0.1000 & 0.6000 & 0.1000 & 0.6000 & 0.0500 \\ 0.5000 & 0.1000 & 0.6000 & 0.0500 & 0.5000 & 0.0500\end{array}$

*NOTE: COORDINATES ARE MULTIPLIED BY .001

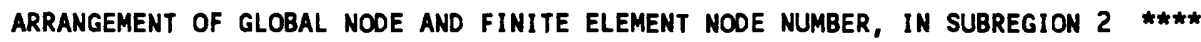
NUMBER OF INCREMENTS =

$\begin{array}{lllllllllll}5 \text { ROWS AND } 3 \text { COLUMNS } & & & & & & & & & & \\ \text { GLOBAL NODE NUMBERS } & 10 & 11 & 12 & 13 & 3 & 2 & 1 & 9\end{array}$

FINITE-ELEMENT NODE NUMBERS

$\begin{array}{lll}12 & 13 & 3 \\ 14 & 15 & 4 \\ 16 & 17 & 5 \\ 18 & 19 & 6 \\ 20 & 21 & 7\end{array}$

ELEMENT NUMBERS, FINITE-ELEMENT NOOE NUMBERS, AND NODE COORDINATES

$\begin{array}{rrrrrrrrrr}\text { NEL } & \text { MODE } & \text { MUMBERS } & x(1) & Y(1) & x(2) & Y(2) & X(3) & Y(3) \\ 99 & 14 & 15 & 13 & 0.4000 & 0.1250 & 0.5000 & 0.1250 & 0.5000 & 0.1000 \\ 10 & 14 & 13 & 12 & 0.4000 & 0.1250 & 0.5000 & 0.1000 & 0.4000 & 0.1000 \\ 11 & 15 & 4 & 3 & 0.5000 & 0.1250 & 0.6000 & 0.1250 & 0.6000 & 0.1000 \\ 12 & 15 & 3 & 13 & 0.5000 & 0.1250 & 0.6000 & 0.1000 & 0.5000 & 0.1000 \\ 13 & 16 & 17 & 15 & 0.4000 & 0.1500 & 0.5000 & 0.1500 & 0.5000 & 0.1250\end{array}$




$\begin{array}{rrrrllllll}14 & 16 & 15 & 14 & 0.4000 & 0.1500 & 0.5000 & 0.1250 & 0.4000 & 0.1250 \\ 15 & 17 & 5 & 4 & 0.5000 & 0.1500 & 0.6000 & 0.1500 & 0.6000 & 0.1250 \\ 16 & 17 & 4 & 15 & 0.5000 & 0.1500 & 0.6000 & 0.1250 & 0.5000 & 0.1250 \\ 17 & 18 & 19 & 17 & 0.4000 & 0.1750 & 0.5000 & 0.1750 & 0.5000 & 0.1500 \\ 18 & 18 & 17 & 16 & 0.4000 & 0.1750 & 0.5000 & 0.1500 & 0.4000 & 0.1500 \\ 19 & 19 & 6 & 5 & 0.5000 & 0.1750 & 0.6000 & 0.1750 & 0.6000 & 0.1500 \\ 20 & 19 & 5 & 17 & 0.5000 & 0.1750 & 0.6000 & 0.1500 & 0.5000 & 0.1500 \\ 21 & 20 & 21 & 19 & 0.4000 & 0.2000 & 0.5000 & 0.2000 & 0.5000 & 0.1750 \\ 22 & 20 & 19 & 18 & 0.4000 & 0.2000 & 0.5000 & 0.1750 & 0.4000 & 0.1750 \\ 23 & 21 & 7 & 6 & 0.5000 & 0.2000 & 0.6000 & 0.2000 & 0.6000 & 0.1750 \\ 24 & 21 & 6 & 19 & 0.5000 & 0.2000 & 0.6000 & 0.1750 & 0.5000 & 0.1750\end{array}$

*NOTE: COORDINATES ARE MULTIPLIED BY .001

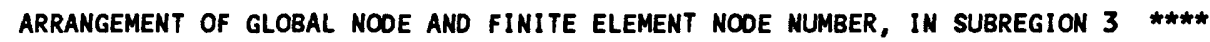
NUMBER OF INCREMENTS =

$\begin{array}{lllllllllll}3 \text { ROWS AND } 3 \text { COLUMNS } & & & & & & & & \\ \text { GLOBAL NODE NUMBERS } & 17 & 18 & 1 & 8 & 7 & 14 & 15 & 16\end{array}$

FINITE-ELEMENT NODE NUMBERS

$\begin{array}{rrr}22 & 23 & 8 \\ 24 & 25 & 10 \\ 26 & 27 & 12\end{array}$

ELEMENT NUMBERS, FINITE-ELEMENT NODE NUMBERS, AND NOOE COORDINATES

$\begin{array}{rrrr}\text { NEL } & \text { NOOE } & \text { NUMBERS } \\ 25 & 24 & 25 & 23 \\ 26 & 24 & 23 & 22 \\ 27 & 25 & 10 & 8 \\ 28 & 25 & 8 & 23 \\ 29 & 26 & 27 & 25 \\ 30 & 26 & 25 & 24 \\ 31 & 27 & 12 & 10 \\ 32 & 27 & 10 & 25\end{array}$

$\begin{array}{cccccc}X(1) & Y(1) & X(2) & Y(2) & x(3) & Y(3) \\ 0.2000 & 0.0500 & 0.3000 & 0.0500 & 0.3000 & 0.0000 \\ 0.2000 & 0.0500 & 0.3000 & 0.0000 & 0.2000 & 0.0000 \\ 0.3000 & 0.0500 & 0.4000 & 0.0500 & 0.4000 & 0.0000 \\ 0.3000 & 0.0500 & 0.4000 & 0.0000 & 0.3000 & 0.0000 \\ 0.2000 & 0.1000 & 0.3000 & 0.1000 & 0.3000 & 0.0500 \\ 0.2000 & 0.1000 & 0.3000 & 0.0500 & 0.2000 & 0.0500 \\ 0.3000 & 0.1000 & 0.4000 & 0.1000 & 0.4000 & 0.0500 \\ 0.3000 & 0.1000 & 0.4000 & 0.0500 & 0.3000 & 0.0500\end{array}$

*NOTE: COORDINATES ARE MULTIPLIED BY .001

**** ARRANGEMENT OF GLOBAL NOOE AND FINITE ELEMENT NOOE NUMBER, IN SUBREgION 4 **** NUMBER OF INCREMENTS =

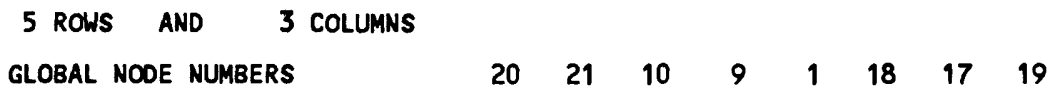

FINITE-ELEMENT NODE NUMBERS

$\begin{array}{lll}26 & 27 & 12 \\ 28 & 29 & 14 \\ 30 & 31 & 16 \\ 32 & 33 & 18 \\ 34 & 35 & 20\end{array}$

ELEMENT NUMBERS, FINITE-ELEMENT NOOE NUMBERS, AND NODE COORDINATES

$\begin{array}{cccccccccc}\text { NEL } & \text { NODE } & \text { NUMBERS } & x(1) & Y(1) & x(2) & Y(2) & x(3) & Y(3) \\ 33 & 28 & 29 & 27 & 0.2000 & 0.1250 & 0.3000 & 0.1250 & 0.3000 & 0.1000 \\ 34 & 28 & 27 & 26 & 0.2000 & 0.1250 & 0.3000 & 0.1000 & 0.2000 & 0.1000 \\ 35 & 29 & 14 & 12 & 0.3000 & 0.1250 & 0.4000 & 0.1250 & 0.4000 & 0.1000 \\ 36 & 29 & 12 & 27 & 0.3000 & 0.1250 & 0.4000 & 0.1000 & 0.3000 & 0.1000 \\ 37 & 30 & 31 & 29 & 0.2000 & 0.1500 & 0.3000 & 0.1500 & 0.3000 & 0.1250 \\ 38 & 30 & 29 & 28 & 0.2000 & 0.1500 & 0.3000 & 0.1250 & 0.2000 & 0.1250 \\ 39 & 31 & 16 & 14 & 0.3000 & 0.1500 & 0.4000 & 0.1500 & 0.4000 & 0.1250\end{array}$




$\begin{array}{llllll}0.3000 & 0.1500 & 0.4000 & 0.1250 & 0.3000 & 0.1250 \\ 0.2000 & 0.1750 & 0.3000 & 0.1750 & 0.3000 & 0.1500 \\ 0.2000 & 0.1750 & 0.3000 & 0.1500 & 0.2000 & 0.1500 \\ 0.3000 & 0.1750 & 0.4000 & 0.1750 & 0.4000 & 0.1500 \\ 0.3000 & 0.1750 & 0.4000 & 0.1500 & 0.3000 & 0.1500 \\ 0.2000 & 0.2000 & 0.3000 & 0.2000 & 0.3000 & 0.1750 \\ 0.2000 & 0.2000 & 0.3000 & 0.1750 & 0.2000 & 0.1750 \\ 0.3000 & 0.2000 & 0.4000 & 0.2000 & 0.4000 & 0.1750 \\ 0.3000 & 0.2000 & 0.4000 & 0.1750 & 0.3000 & 0.1750\end{array}$

*NOTE: COORDINATES ARE MULTIPLIED BY .001

**** ARRANGement OF GLOBAL NOOE AND FINITE ELEMENT NODE NUMBER, IN SUBRegION $5 * \star \star *$ MUMBER OF INCREMENTS =

3 ROWS AND 5 COLUMNS

$\begin{array}{lllllllll}\text { GLOBAL NODE NUMBERS } & 25 & 26 & 17 & 16 & 15 & 22 & 23 & 24\end{array}$

FINITE-ELEMENT NOOE NUMBERS

$\begin{array}{lllll}36 & 37 & 38 & 39 & 22 \\ 40 & 41 & 42 & 43 & 24 \\ 44 & 45 & 46 & 47 & 26\end{array}$

ELEMENT NUMBERS, FINITE-ELEMENT NODE NUMBERS, AND NODE COORDINATES

\begin{tabular}{rccc} 
NEL & NOOE & \multicolumn{2}{c}{ NUMBERS } \\
49 & 40 & 41 & 37 \\
50 & 40 & 37 & 36 \\
51 & 41 & 42 & 38 \\
52 & 41 & 38 & 37 \\
53 & 42 & 43 & 39 \\
54 & 42 & 39 & 38 \\
55 & 43 & 24 & 22 \\
56 & 43 & 22 & 39 \\
57 & 44 & 45 & 41 \\
58 & 44 & 41 & 40 \\
59 & 45 & 46 & 42 \\
60 & 45 & 42 & 41 \\
61 & 46 & 47 & 43 \\
62 & 46 & 43 & 42 \\
63 & 47 & 26 & 24 \\
64 & 47 & 24 & 43
\end{tabular}
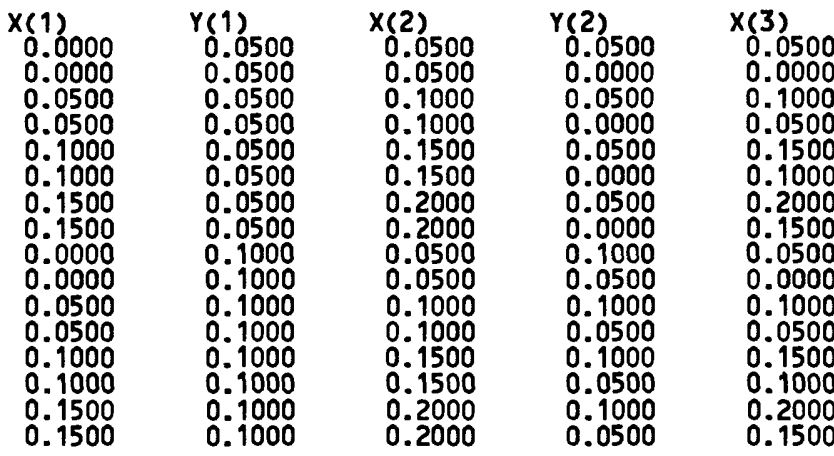

$Y(3)$

0.0000

0.0000

0.0000

0.0000

0.0000

0.0000

0.0000

0.0000

0.0500

0.0500

0.0500

0.0500

0.0500

0.0500

0.0500

*NOTE: COORDINATES ARE MULTIPLIED BY .001

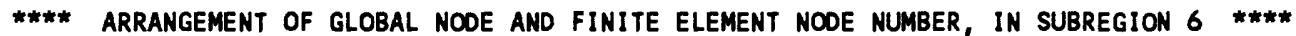
NUMBER OF INCREMENTS $=$

5 ROWS AND 5 COLUMNS

$\begin{array}{lllllllll}\text { GLOBAL NOOE NUMBERS } & 28 & 29 & 20 & 19 & 17 & 26 & 25 & 27\end{array}$

FINITE-ELEMENT NOOE NUMBERS

$\begin{array}{lllll}44 & 45 & 46 & 47 & 26 \\ 48 & 49 & 50 & 51 & 28 \\ 52 & 53 & 54 & 55 & 30 \\ 56 & 57 & 58 & 59 & 32 \\ 60 & 61 & 62 & 63 & 34\end{array}$

\section{ELEMENT NUMBERS, FINITE-ELEMENT NOOE NUMBERS, AND NOOE COORDINATES}

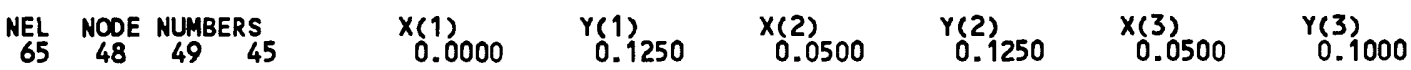




$\begin{array}{llllllllll}66 & 48 & 45 & 44 & 0.0000 & 0.1250 & 0.0500 & 0.1000 & 0.0000 & 0.1000 \\ 67 & 49 & 50 & 46 & 0.0500 & 0.1250 & 0.1000 & 0.1250 & 0.1000 & 0.1000 \\ 68 & 49 & 46 & 45 & 0.0500 & 0.1250 & 0.1000 & 0.1000 & 0.0500 & 0.1000 \\ 69 & 50 & 51 & 47 & 0.1000 & 0.1250 & 0.1500 & 0.1250 & 0.1500 & 0.1000 \\ 70 & 50 & 47 & 46 & 0.1000 & 0.1250 & 0.1500 & 0.1000 & 0.1000 & 0.1000 \\ 71 & 51 & 28 & 26 & 0.1500 & 0.1250 & 0.2000 & 0.1250 & 0.2000 & 0.1000 \\ 72 & 51 & 26 & 47 & 0.1500 & 0.1250 & 0.2000 & 0.1000 & 0.1500 & 0.1000 \\ 73 & 52 & 53 & 49 & 0.0000 & 0.1500 & 0.0500 & 0.1500 & 0.0500 & 0.1250 \\ 74 & 52 & 49 & 48 & 0.0000 & 0.1500 & 0.0500 & 0.1250 & 0.0000 & 0.1250 \\ 75 & 53 & 54 & 50 & 0.0500 & 0.1500 & 0.1000 & 0.1500 & 0.1000 & 0.1250 \\ 76 & 53 & 50 & 49 & 0.0500 & 0.1500 & 0.1000 & 0.1250 & 0.0500 & 0.1250 \\ 77 & 54 & 55 & 51 & 0.1000 & 0.1500 & 0.1500 & 0.1500 & 0.1500 & 0.1250 \\ 78 & 54 & 51 & 50 & 0.1000 & 0.1500 & 0.1500 & 0.1250 & 0.1000 & 0.1250 \\ 79 & 55 & 30 & 28 & 0.1500 & 0.1500 & 0.2000 & 0.1500 & 0.2000 & 0.1250 \\ 80 & 55 & 28 & 51 & 0.1500 & 0.1500 & 0.2000 & 0.1250 & 0.1500 & 0.1250 \\ 81 & 56 & 57 & 53 & 0.0000 & 0.1750 & 0.0500 & 0.1750 & 0.0500 & 0.1500 \\ 82 & 56 & 53 & 52 & 0.0000 & 0.1750 & 0.0500 & 0.1500 & 0.0000 & 0.1500 \\ 83 & 57 & 58 & 54 & 0.0500 & 0.1750 & 0.1000 & 0.1750 & 0.1000 & 0.1500 \\ 84 & 57 & 54 & 53 & 0.0500 & 0.1750 & 0.1000 & 0.1500 & 0.0500 & 0.1500 \\ 85 & 58 & 59 & 55 & 0.1000 & 0.1750 & 0.1500 & 0.1750 & 0.1500 & 0.1500 \\ 86 & 58 & 55 & 54 & 0.1000 & 0.1750 & 0.1500 & 0.1500 & 0.1000 & 0.1500 \\ 87 & 59 & 32 & 30 & 0.1500 & 0.1750 & 0.2000 & 0.1750 & 0.2000 & 0.1500 \\ 88 & 59 & 30 & 55 & 0.1500 & 0.1750 & 0.2000 & 0.1500 & 0.1500 & 0.1500 \\ 89 & 60 & 61 & 57 & 0.0000 & 0.2000 & 0.0500 & 0.2000 & 0.0500 & 0.1750 \\ 90 & 60 & 57 & 56 & 0.0000 & 0.2000 & 0.0500 & 0.1750 & 0.0000 & 0.1750 \\ 91 & 61 & 62 & 58 & 0.0500 & 0.2000 & 0.1000 & 0.2000 & 0.1000 & 0.1750 \\ 92 & 61 & 58 & 57 & 0.0500 & 0.2000 & 0.1000 & 0.1750 & 0.0500 & 0.1750 \\ 93 & 62 & 63 & 59 & 0.1000 & 0.2000 & 0.1500 & 0.2000 & 0.1500 & 0.1750 \\ 94 & 62 & 59 & 58 & 0.1000 & 0.2000 & 0.1500 & 0.1750 & 0.1000 & 0.1750 \\ 95 & 63 & 34 & 32 & 0.1500 & 0.2000 & 0.2000 & 0.2000 & 0.2000 & 0.1750 \\ 96 & 63 & 32 & 59 & 0.1500 & 0.2000 & 0.2000 & 0.1750 & 0.1500 & 0.1750\end{array}$

BANDWIDTH QUANTITY IS 32 CALCULATED IN ELEMENT 95 
C

C C

DIMENSION NG(480,3), PR(480), PZ(480), RE(273), ZE(273), IFLUX(273MAN 20 1), IQ(273), IRCH(273), $\operatorname{NSCON}(273), F(273), S 1(273), S 3(260), S 5(26 \mathrm{MAN} 30$ 20), F2(260), WG1 $(260,59), \operatorname{WTRA} 1(260,59), \mathrm{R}(3), \mathrm{Z}(3), \mathrm{ZI}(3), \mathrm{RI}(3), \mathrm{MAN} 40$ $3 \mathrm{~L}(3), \mathrm{W}(3,3), \mathrm{WR}(3,3), \mathrm{WZ}(3,3), \mathrm{WW}(3,3), \operatorname{WST}(3,3), \mathrm{NND}(50)$, TITLEMAN 50 4(20), SS $(480)$

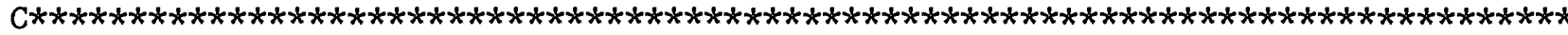

C ARRAYS THAT ARE INTRODUCED IN THE RADFLOW-S VERSION

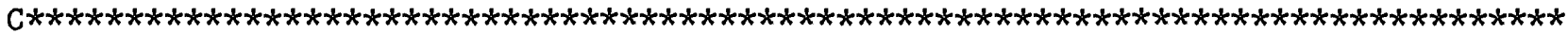
DIMENSION NNE (5)

REAL N1,N2,N3,XBAR(5), YBAR(5), PHI(5) 
REAL POB $(5,100), \operatorname{TOB}(5,100), \operatorname{EPSI}(5)$

COMMON /PT/ POB, TOB

C NNE= OBSERVATION WELL ELEMENT NUMBERS

COMMON /ELEM/NG, PR, PZ

COMMON /NODES /RE, ZE, IFLUX, IQ, IRCH, NSCON , F, SI

COMMON /GLOBAL/WG1, WTRA1

COMMON /EPS/EPSI

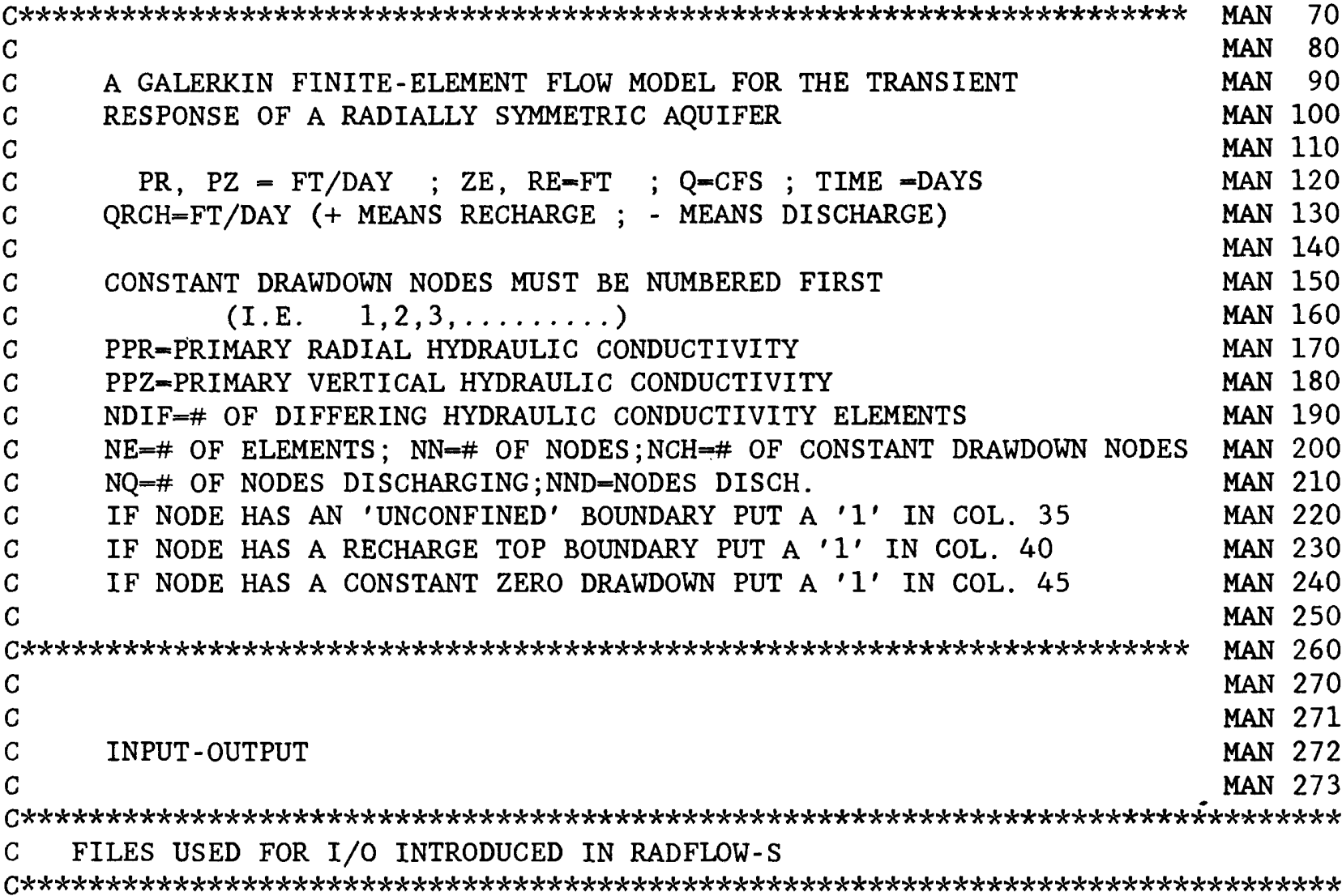

OPEN (UNIT=55, FILE=' RADFLOW. INPUT' , STATUS=' OLD' )

OPEN (UNIT $=56$, FILE = ' RAD . OUTPUT' , STATUS = ' NEW' $)$

OPEN $($ UNIT $=57$, FILE $=$ ' OB. WELL' , STATUS $=$ ' OLD' $)$

C

C CALCULATE CONSTANTS

MAN 276

MAN 280

$\mathrm{TPI}=3.1416 * 2$

$\operatorname{CONV} 1=1440 * 60$.

MAN 290

MAN 300

C

READ $(55,11)$ TITLE

MAN 310

MAN 320

MAN 330

11 FORMAT (20A4)

WRITE $(56,12)$ TITLE

12 FORMAT (1H1, 10X, 20A4)

READ $(55,13)$ PPR, PPZ, IPP

MAN 340

MAN 350

MAN 360

MAN 370

13 FORMAT (2F10.0,I10)

MAN 380

READ $(55,14)$ S, SY

MAN 390

14 FORMAT (2F10.0)

MAN 400

WRITE $(56,15) \mathrm{S}$

MAN 410

15 FORMAT (1HO,36H COEFFICIENT OF SPECIFIC STORAGE=,E12.5,5H 1/FT) MAN 420 WRITE $(56,16)$ SY

MAN 430 
16 FORMAT (1H0,17H SPECIFIC YIELD $=$, F10.4)

MAN 440 WRITE $(56,17)$ PPR, PPZ

MAN 450

17 FORMAT ( 1 HO, 38H THE PRIMARY HYDRAULIC CONDUCTIVITY - ,F10.3,12H RMAN 460 IADIALLY \&,F10.3,21H VERTICALLY (FT/DAY))

READ $(55,18) \quad \mathrm{NE}, \mathrm{NN}, \mathrm{NCH}, \mathrm{NQ}, \mathrm{NDIF}$

18 FORMAT (5I5)

WRITE $(56,19)$ NE, NN, NCH, NQ, NDIF

MAN 470

MAN 480

MAN 490

MAN 500

19 FORMAT ( $1 \mathrm{HO}, \mathrm{I5}, 13 \mathrm{H}$ ELEMENTS, I5,9H NODES , I5,22H CONSTANT VAMAN 510

ILUE NODES, I5, 18H NODES DISCHARGING, I5, 23H ELEMENTS OF DIFF. H.C.) MAN 520

IF (NQ.EQ.0) GO TO 24

MAN 530

WRITE $(56,20)$

20 FORMAT ( 1 HO, 17HDISCHARGING NODES)

DO $23 \quad I=1$, NQ

$\operatorname{READ}(55,21) \quad \operatorname{NND}(I)$

21 FORMAT (I5)

WRITE $(56,22)$ NND (I)

22 FORMAT (1X, I9)

23 CONTINUE

24 DO $25 \mathrm{I}=1$, NE

$P R(I)=P P R$

$\mathrm{PZ}(\mathrm{I})=\mathrm{PPZ}$

MAN 540

MAN 550

MAN 560

MAN 570

MAN 580

MAN 590

MAN 600

MAN 610

MAN 620

MAN 630

MAN 640

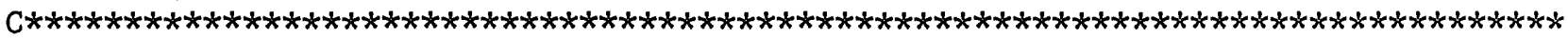

C INITIALIZE SPECIFIC STORAGE IN EACH TRIANGULAR ELEMENT

$\mathrm{C} * * * * * * * * * * * * * * * * * * * * * * * * * * * * * * * * * * * * * * * * * * * * * * * * * * * * * * * * * * * * * * * * * * * * * * * * * * * * * * * * * * * 4$ $\mathrm{SS}(I)=\mathrm{S}$

25 CONTINUE

MAN 650

C

MAN 660

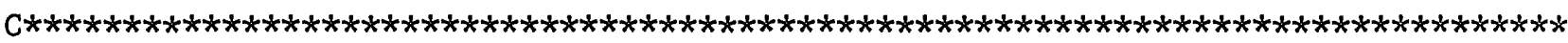

C DEFINE ELEMENTS OF DIFFERENT CONDUCTIVITIES

MAN 670

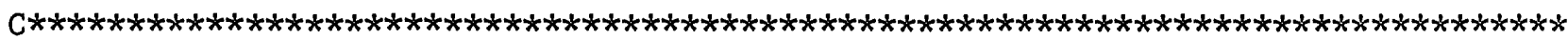
C

IF (NDIF.EQ.0) GO TO 31

MAN 680

MAN 690

$\mathrm{C} * * * * * * * * * * * * * * * * * * * * * * * * * * * * * * * * * * * * * * * * * * * * * * * * * * * * * * * * * * * * * * * * * * * * * * * * * * * * * * * * * * * * * * * * * * * 4$

C SOME SECTION OF THE ORIGINAL RADFLOW SOURCE CODE HAVE BEEN COMMENTED

C OUT WITH AN 'CS' IN RADFLOW-S BECAUSE OF REDUNDANCIES WITH THE MESH

C PRE-PROCESSOR. THEY REMAIN AS COMMENTED STATEMENTS TO HELP THE

C PROGRAM REVIEWER

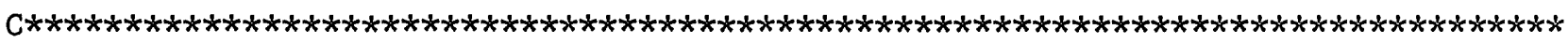

C WRITE $(56,26)$

CS26 FORMAT ( 1 HO, 1X,39H, ELEMENTS WITH DIFFERENT CONDUCTIVITIES)

CS WRITE $(56,27)$

MAN 720

CS 27 FORMAT (1H0,1X, 7HELEMENT, 5X, 11HRADIAL H.C. , 5X, 13HVERTICAL H.C.) DO $30 \mathrm{~K}=1$, NDIF

READ $(55,28)$ IE, PR (IE), PZ (IE), SS (IE)

MAN 730

MAN 740

MAN 750

28 FORMAT (I10, 2F10.0, 5X, F10.0)

MAN 760

CS WRITE $(56,29)$ IE, PR(IE), PZ(IE)

MAN 770

CS 29 FORMAT (1X, I5, 10X, F10.3, 10X, F10.3)

MAN 780

30 CONTINUE

MAN 790

MAN 800

C

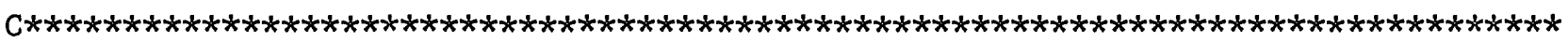

C READ NODAL ORDER OF EACH ELEMENT

MAN 810

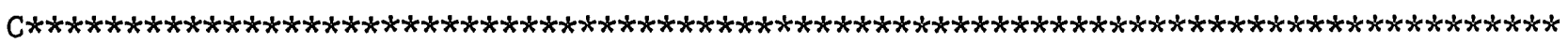

$\mathrm{C}$

CS 31 WRITE $(56,32)$

MAN 820

MAN 830 


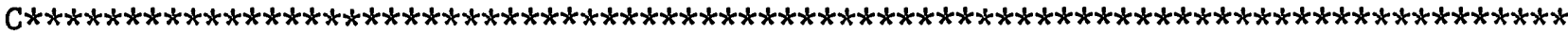

C READ \# OF OBSERVATION WELLS

C MAXIMUM OF 5 OBSERVATION WELLS

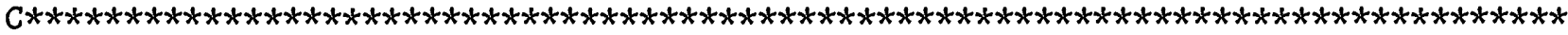
$\operatorname{READ}(57,221) \mathrm{NNO}$

221 FORMAT $(5(1 \mathrm{X}, \mathrm{I} 4))$

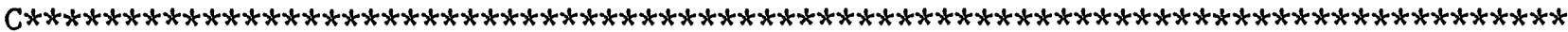

\section{READ LOCATION FOR OBSERVATION WELLS IN EACH ELEMENT}

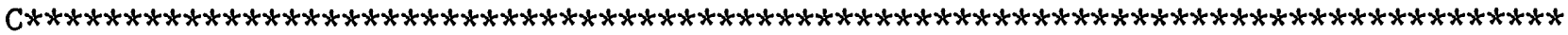
DO $223 \mathrm{I}=1$, NNO $\operatorname{READ}(57,222) \operatorname{XBAR}(I), \operatorname{YBAR}(I)$

222 FORMAT $(2(1 \mathrm{X}, \mathrm{F} 6.0))$

223 CONTINUE

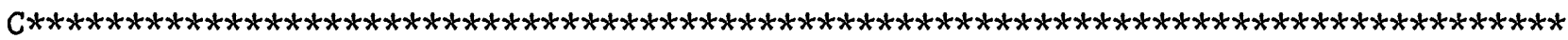

C READ ELEMENT NUMBERS FOR OB. WELLS

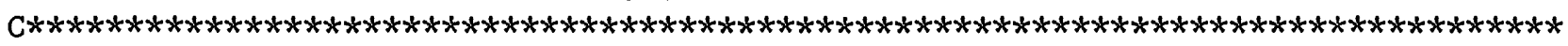
DO $224 \mathrm{I}=1$, NNO $\operatorname{READ}(57,225) \operatorname{NNE}(I)$

225 FORMAT $(5(1 \mathrm{X}, \mathrm{I} 4))$

224 CONTINUE

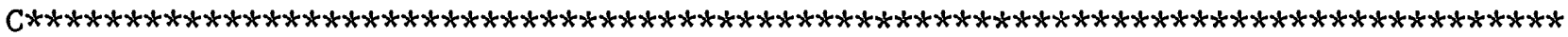

C

C READ NODAL COORDINATES FOR EACH NODE

MAN 910

C

$C * * * * * * * * * * * * * * * * * * * * * * * * * * * * * * * * * * * * * * * * * * * * * * * * * * * * * * * * * * * * * * * * * * * * * * * * * * * * * * * * * * * * * * * * * * * 4)$

CS WRITE $(56,36)$

CS 36 FORMAT (1HO,17HNODAL INFORMATION) MAN 950
CS
WRITE $(56,37)$

37 FORMAT (1X , 4HNODE , 10X, 1HR , 10X, 1HZ, 10X , 10HUNCONFINED , 10X, 16HSURFACEMAN 970

CS 1 RECHARGE, 10X,13HCONSTANT HEAD)

MAN 980

DO $40 \mathrm{~J}=1$, NN

MAN 990

$\mathrm{IQ}(\mathrm{J})=0$

MAN1000

READ (55, 38) IND, RE(IND), ZE (IND), IFLUX(IND), IRCH(IND), NSCON(IND) MAN1010

38 FORMAT (I10,2F10.0,3I5)

MAN1020

CS WRITE $(56,39)$ IND, RE (IND), ZE(IND), IFLUX (IND), IRCH (IND), NSCON(IND) MAN1030

CS 39 FORMAT (1X, I5, 2F10.2,3(15X, I5)) MAN1040 40 CONTINUE

MAN1050

C

MAN1060

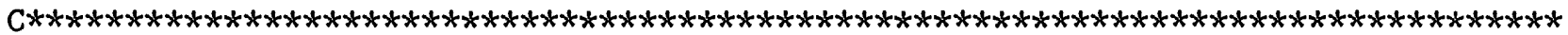

C CHECK INPUT DATA FOR CONSISTENCY

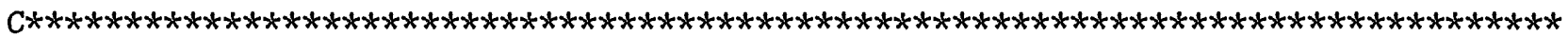

C

CALL CHECK (NE, NN, NCH, NG, RE, ZE, NSCON, IERR)

MAN1080

IF (IERR. EQ. 1) GO TO 91

MAN1090

C

MAN1100

MAN1110

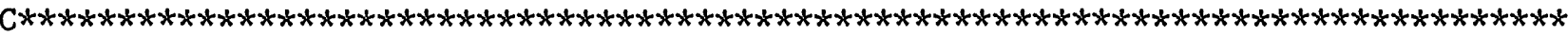

C DEFINE DISCHARGING NODES

MAN1120 
C

IF (NQ.EQ.0) GO TO 46

MAN1130

DO $41 \mathrm{~K}=1$, NQ

MAN1140

$\mathrm{IQ}(\mathrm{NND}(\mathrm{K}))=1$

MAN1150

41 CONTINUE

MAN1160

C

MAN1170

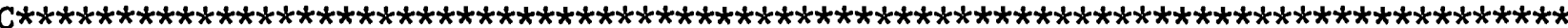

C DEFINE TOTAL TRANSMISSIVITY OF SCREEN LENGTH

MAN1190

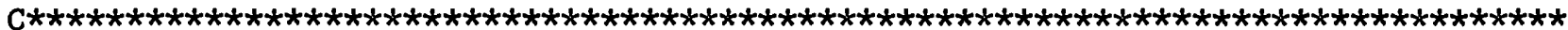

C

TRTOT 0 .

MAN1200

DO $45 \mathrm{~J}=1, \mathrm{NE}$

DO $44 \mathrm{I}=1,3$

IF (IQ (NG $(J, I))$.NE.1) GO TO 44

MAN1210

IF (I.EQ.1) GO TO 42

IF (IQ (NG(J,I-1)).NE. 1) GO TO 44

$\mathrm{TI}=\mathrm{PR}(\mathrm{J}) * \operatorname{ABS}(\mathrm{ZE}(\mathrm{NG}(\mathrm{J}, \mathrm{I}))-\mathrm{ZE}(\mathrm{NG}(\mathrm{J}, \mathrm{I}-\mathrm{I})))$

GO TO 43

42 IF (IQ $(N G(J, 3))$.NE.1) GO TO 44

$\mathrm{TI}=\mathrm{PR}(\mathrm{J}) * \operatorname{ABS}(\mathrm{ZE}(\mathrm{NG}(\mathrm{J}, 1))-\mathrm{ZE}(\mathrm{NG}(\mathrm{J}, 3)))$

43 TRTOT $=$ TRTOT+TI

44 CONTINUE

45 CONTINUE

MAN1220

MAN1230

MAN1240

MAN1250

MAN1260

MAN1270

MAN1280

MAN1290

MAN1300

MAN1310

MAN1320

MAN1330

MAN1340

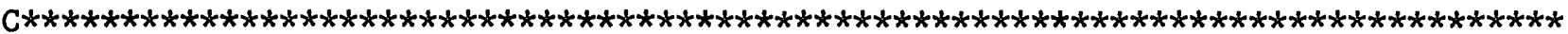

C DETERMINE HALF BAND WIDTH AND NEEDED MATRIX WIDTH

MAN1350

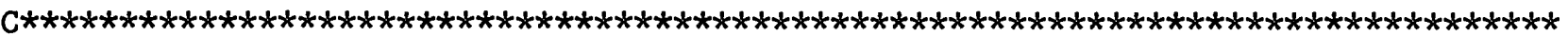

C

46 IHBW $1=0$

MAN1360

DO $50 \quad I=1, N E$

MAN1370

DO $49 \mathrm{~J}=1,3$

MAN1380

IF (J.EQ.1) GO TO 47

MAN1390

IF (NSCON(NG(I,J-1)).EQ.1) GO TO 49

MAN1400

IF (NSCON(NG(I,J)).EQ.1) GO TO 49

MAN1410

$I H B W=I A B S(N G(I, J)-N G(I, J-1))$

MAN1420

GO TO 48

47 IF (NSCON(NG(I,1)).EQ.1) GO TO 49

MAN1430

MAN1440

IF (NSCON(NG $(I, 3))$. EQ. 1) GO TO 49

MAN1450

$\operatorname{IHBW}=\operatorname{IABS}(\mathrm{NG}(I, 1)-\mathrm{NG}(I, 3))$

MAN1460

MAN1470

48 IF (IHBW. LT. IHBW1) GO TO 49

MAN1480

IHBW $1=$ IHBW

MAN1490

49 CONTINUE

MAN1500

50 CONTINUE

MAN1510

$\mathrm{M}=2 * I \mathrm{IBBW} 1+1$

MAN1520

WRITE $(56,51)$ IHBWL, M

MAN1530

51 FORMAT (1H0,22HTHE HALF BAND WIDTH IS, I5,32H AND THE WIDTH OF THEMAN1540

1 MATRIX IS, I5)

MAN1550

DO 52 II $=1$, NN

MAN1560

$\mathrm{S} 1(\mathrm{II})=0.0$

MAN1570

52 CONTINUE

MAN1580

$\mathrm{MM}=\mathrm{NN}-\mathrm{NCH}$

MAN1590

C

SET UP PUMPING PERIOD

MAN1600

MAN1610 
TITO $=0.0$

MAN1630

DO $90 \mathrm{NPP}=1$, IPP

MAN1640

DO 53 II $=1$, NN

MAN1650

$F(I I)=0.0$

MAN1660

53 CONTINUE

MAN1670

READ $(55,54)$ Q, QRCH, DELT , TMAXF , TSM, NTS

MAN1680

54 FORMAT (5F10.0, I10)

DT=DELT

MAN1690

$\mathrm{TM}=0.0$

MAN1700

DO $55 I=1$, NTS

MAN1710

$\mathrm{TM}=\mathrm{TM}+\mathrm{DT}$

MAN1720

IF (TM.GE.TMAXF) GO TO 56

MAN1730

$\mathrm{DT}=\mathrm{TSM} * \mathrm{DT}$

MAN1740

55 CONTINUE

MAN1750

GO TO 57

MAN1760

MAN1770

56 DELT $=$ TMAXF $/ \mathrm{TM} * \mathrm{DELT}$

MAN1780

NTS $=I$

MAN1790

57 WRITE $(56,58)$ NPP, DELT, NTS

MAN1800

58 FORMAT (1H1,14HPUMPING PERIOD, I10,/,20H INITIAL TIME STEP $=$, F10.5, MAN1810

15H DAYS, /,46H NUMBER OF TIME STEPS IN THIS PUMPING PERIOD =,I10) WRITE $(56,59)$ Q

59 FORMAT (1H0,11HDISCHARGE $=, E 12.5,6 \mathrm{H} \quad$ CFS $)$ WRITE $(56,60)$ QRCH

60 FORMAT (1HO, 1OHRECHARGE $=, F 7.2,8 \mathrm{H} \quad \mathrm{FT} / \mathrm{DAY})$ $\mathrm{Q}=\mathrm{Q} *$ CONV1

MAN1820

MAN1830

MAN1840

MAN1850

MAN1860

MAN1870

C

VALUE OF SINK MATRIX

MAN1880

MAN1890

MAN1900

QTOT $=0.0$

MAN1910

DO $65 \mathrm{~K}=1$, NE

MAN1920

DO $61 \mathrm{~J}=1,3$

MAN1930

$\mathrm{L}(\mathrm{J})=\mathrm{NG}(\mathrm{K}, \mathrm{J})$

MAN1940

$R(J)=R E(L(J))$

MAN1950

$\mathrm{Z}(\mathrm{J})=\mathrm{ZE}(\mathrm{L}(\mathrm{J}))$

MAN1960

MAN1970

MAN1980

DO $64 \mathrm{I}=1,3$

MAN1990

DO $63 \mathrm{~J}=1,3$

MAN2000

IF (IQ (L(J)).NE.1) GO TO 62

MAN2010

IF (IQ (L(I)).NE.1) GO TO 62

MAN2020

$B L E N=S Q R T((A B S(R(I)-R(J))) * * 2+(A B S(Z(I)-Z(J))) * * 2)$

MAN2030

$\mathrm{F}(\mathrm{L}(\mathrm{I}))=\mathrm{Q} * \mathrm{PR}(\mathrm{K}) * \mathrm{BLEN} /(2 . * \mathrm{TRTOT})+\mathrm{F}(\mathrm{L}(\mathrm{I}))$

MAN2040

$\mathrm{QTOT}=\mathrm{Q} * \mathrm{PR}(\mathrm{K}) * \mathrm{BLEN} /(2 . * \mathrm{TRTOT})+\mathrm{QTOT}$

62 IF (IRCH(L(J)).NE.1) GO TO 63

MAN2050

IF (IRCH(L(I)).NE.1) GO TO 63

MAN2060

$A R E A=3.1416 * A B S(R(J) * * 2-R(I) * * 2)$

MAN2070

$\mathrm{F}(\mathrm{L}(\mathrm{I}))=\mathrm{QRCH} * \mathrm{AREA} / 2 .+\mathrm{F}(\mathrm{L}(\mathrm{I}))$

63 CONTINUE

64 CONTINUE

MAN2080

MAN2090

65 CONTINUE

MAN2100

DO $66 I=1, M M$

MAN2110

$\mathrm{F} 2(\mathrm{I})=\mathrm{F}(\mathrm{I}+\mathrm{NCH})$

MAN2120

66 CONTINUE

MAN2130

MAN2140

C

MAN2150 
C

67 FORMAT (1H0,28H CALCULATED WELL DISCHARGE $=, F 10.2,4 \mathrm{H}$ CFS)

MAN2200

C START TIME LOOP

MAN2210

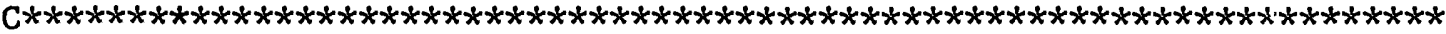

TIME $=0.0$

MAN2220

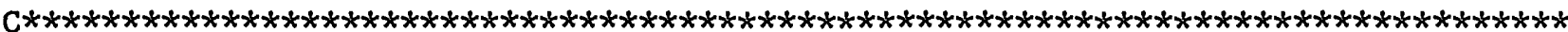

C NIT= IS COUNTER FOR PRINT ROUTINE

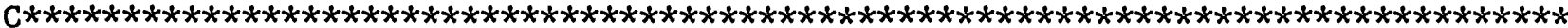
NIT $=0$

DO $89 \mathrm{IT}=1$, NTS

MAN2250

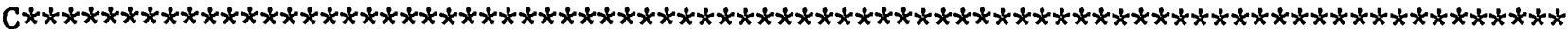
C INITIALIZE VARIABLES

MAN2270

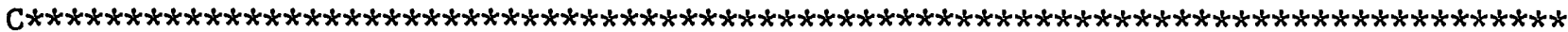
C

MAN2280

DO $69 \mathrm{I}=1, \mathrm{MM}$

MAN2290

DO $68 \mathrm{~J}=1, \mathrm{M}$

MAN2300

WTRA1 $(I, J)=0.0$

MAN2310

$\operatorname{WGI}(\mathrm{I}, \mathrm{J})=0.0$

MAN2320

68 CONTINUE

MAN2330

69 CONTINUE

MAN2340

DO $79 \mathrm{~K}=1, \mathrm{NE}$

MAN2350

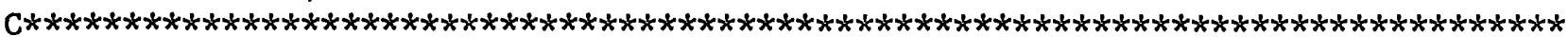

C ASSIGN SPECIFIC STORAGE FOR EACH ELEMENT DURING CONDUCTIVITY

C MATRIX ASSEMBLY

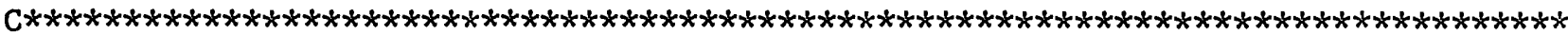
$\mathrm{S}=\mathrm{SS}(\mathrm{K})$

DO $70 \mathrm{~J}=1,3$

MAN2360

$\mathrm{L}(\mathrm{J})=\mathrm{NG}(\mathrm{K}, \mathrm{J})$

MAN2370

$R(J)=R E(L(J))$

MAN2380

$\mathrm{Z}(\mathrm{J})=\mathrm{ZE}(\mathrm{L}(\mathrm{J}))$

MAN2 390

70 CONTINUE

MAN2400

C

AVERAGE DISTANCE R OF ELEMENT

MAN2410

C

$R B A R=(R(1)+R(2)+R(3)) / 3$.

MAN2420

MAN2430

MAN2440

C

DO $72 \mathrm{I}=1,3$

MAN2450

MAN2460

DO $71 \mathrm{~J}=1,3$

MAN2470

$W(I, J)=0.0$

MAN2480

71 CONTINUE

MAN2490

72 CONTINUE

MAN2500

$\mathrm{ZI}(1)=\mathrm{Z}(2)-\mathrm{Z}$ (3)

MAN2510

$\mathrm{ZI}(2)=Z(3)-Z(1)$

MAN2520

$Z I(3)=Z(1)-Z(2)$

MAN2530

$R I(1)=R(3)-R(2)$

MAN2540

$R I(2)=R(1)-R(3)$

MAN2550

$R I(3)=R(2)-R(1)$

MAN2560

$\mathrm{DEL}=(\mathrm{ZI}(1) * \mathrm{R}(1)+\mathrm{ZI}(2) * \mathrm{R}(2)+\mathrm{ZI}(3) * \mathrm{R}(3)) / 2$.

MAN2570

C

CALCULATE ELEMENT MATRICIES

MAN2580

MAN2590 
Do $78 \mathrm{I}=1,3$

MAN2610

DO $77 \mathrm{~J}=1,3$

MAN2620

$\mathrm{WR}(\mathrm{I}, \mathrm{J})=\mathrm{TPI} * \mathrm{RBAR} * \mathrm{PR}(\mathrm{K}) * \mathrm{ZI}(\mathrm{I}) * \mathrm{ZI}(\mathrm{J}) /(4 *$ DEL $)$

MAN2630

$\mathrm{WZ}(\mathrm{I}, \mathrm{J})=\mathrm{TPI} * \mathrm{RBAR} * \mathrm{PZ}(\mathrm{K}) * \mathrm{RI}(\mathrm{I}) * \mathrm{RI}(\mathrm{J}) /(4$ * *DEL $)$

MAN2640

IF (I.EQ.J) GO TO 73

MAN2650

WST $(I, J)=S * T P I * R(I) * D E L /(D E L T * 12$.

MAN2660

GO TO 74

MAN2670

$73 \operatorname{WST}(\mathrm{I}, \mathrm{J})=\mathrm{S} * \mathrm{TPI} * \mathrm{R}(\mathrm{I}) * \mathrm{DEL} /(\mathrm{DELT} * 6$.

MAN2680

$74 \mathrm{WW}(\mathrm{I}, \mathrm{J})=\mathrm{WR}(\mathrm{I}, \mathrm{J})+\mathrm{WZ}(\mathrm{I}, \mathrm{J})$

MAN2690

IF (I.NE.J) GO TO 76

IF (IFLUX(L(I)).NE.1) GO TO 76

MAN2700

AREA $=0.0$

DO $75 \mathrm{KK}=1,3$

IF (KK.EQ.I) GO TO 75

IF (IFLUX (L(KK)).NE.1) GO TO 75

$A R E A=3.1416 * A B S(R(I) * R(I)-R(K K) * R(K K))$

75 CONTINUE

$W(I, J)=-S Y * A R E A /(2 . * D E L T)$

C

C

C

ASSEMBLE ELEMENT MATRICIES INTO GLOBAL

76 IF (NSCON(L(J)).EQ.1) GO TO 77

IF (NSCON(L(I)).EQ.1) GO TO 77

$\mathrm{I} I=\mathrm{NG}(\mathrm{K}, \mathrm{I})-\mathrm{NCH}$

$\mathrm{JJ}=\mathrm{NG}(\mathrm{K}, \mathrm{J})-\mathrm{NCH}$

MAN2710

MAN2720

MAN2730

MAN2740

MAN2750

MAN2760

MAN2770

MAN2780

MAN2790

MAN2800

MAN2810

MAN2820

MAN2830

MAN2840

MAN2850

MTRAN $=\mathrm{JJ}-\mathrm{II}+(\mathrm{M}+1) / 2$

MAN2860

MAN2870

GLOBAL TRANSIENT MATRIX

MAN2880

MAN2890

WTRA1 (II , MTRAN) $=W S T(I, J)+W(I, J)+W T R A 1$ (II , MTRAN)

MAN2900

MAN2910

GLOBAL MATRIX

MAN2920

MAN2930

MAN2940

WGI (II , MTRAN) $=W W(I, J)+W G I$ (I I , MTRAN)

MAN2950

MAN2960

78 CONTINUE

MAN2970

79 CONTINUE

MAN2980

MAN2990

MAN3000

SUM OF GLOBAL AND TRANSIENT COEFFICIENT MATRICIES

MAN3010 ON LEFT HAND SIDE

MAN3020

DO $81 \mathrm{I}=1, \mathrm{MM}$

MAN3030

DO $80 \mathrm{~J}=1, \mathrm{M}$

MAN3040

WG1 $(I, J)=W T R A 1(I, J)+W G 1(I, J)$

MAN3050

80 CONTINUE

MAN3060

81 CONTINUE

MAN3070

MAN3080

MULT. OF MATRICIES ON RIGHT HAND SIDE

MAN3090

MAN3100

DO $82 \quad I=1, M M$

MAN3110

$\mathrm{S} 3(\mathrm{I})=\mathrm{S} 1(\mathrm{I}+\mathrm{NCH})$

MAN3120

$\mathrm{S} 5(\mathrm{I})=0.0$

MAN3130 
82 CONTINUE

MAN3140

CALL MLTBM(WTRA1, S3, S5, MM , M)

MAN3150

DO $83 \mathrm{I}=1, \mathrm{MM}$

MAN3160

$\mathrm{S} 5(\mathrm{I})-\mathrm{S} 5(\mathrm{I})+\mathrm{F} 2(\mathrm{I})$

MAN3170

83 CONTINUE

MAN3180

C

SOLUTION

MAN3190

MAN3200

MAN3210

CALL SOLVE (1, WG1 , S5, MM , IHBW1 , MM , M)

MAN3220

CALL SOLVE ( 2 , WG1 , S5, MM, IHBW1, MM, M)

MAN3230

$\mathrm{NNN}=\mathrm{NCH}+1$

DO $84 I=\mathrm{NNN}$, NN

$\mathrm{S} 1(\mathrm{I})=\mathrm{S} 5(\mathrm{I}-\mathrm{NCH})$

MAN3240

MAN3250

MAN3260

84 CONTINUE

MAN3270

C

TIME-TIME+DELT

MAN3280

TIMM $=$ TIME $* 1440$.

MAN3290

ACTT-TIME+TITO

MAN3300

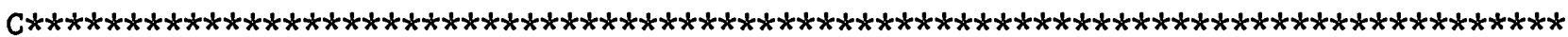

C WRITE OUT OBSERVATION WELL RESULTS AFTER EACH ITERATION

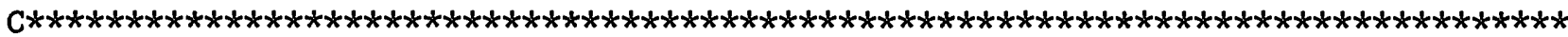

DO $801 \mathrm{KK}=1$, NNO

$\mathrm{LN}=\mathrm{NNE}(\mathrm{KK})$

XBARE $=X B A R(K K)$

YBARE-YBAR (KK)

DO $802 \mathrm{JJ}=1,3$

$\mathrm{L}(\mathrm{JJ})=\mathrm{NG}(\mathrm{LN}, \mathrm{JJ})$

$R(J J)=R E(L(J J))$

$802 \quad \mathrm{Z}(\mathrm{JJ})=\mathrm{ZE}(\mathrm{L}(\mathrm{JJ}))$

$A I=R(2) * Z(3)-R(3) * Z(2)$

$A 2=R(3) * Z(1)-R(1) * Z(3)$

$A 3=R(1) * Z(2)-R(2) * Z(1)$

$\mathrm{Bl}=\mathrm{Z}(2)-\mathrm{Z}$ (3)

$B 2=Z(3)-Z(1)$

$\mathrm{B} 3=\mathrm{Z}(1)-\mathrm{Z}(2)$

$C 1=R(3)-R(2)$

$C 2=R(1)-R(3)$

$C 3=R(2)-R(1)$

DELT2 $=(B 1 * R(1)+B 2 * R(2)+B 3 * R(3))$

$\mathrm{N} 1=(\mathrm{A} 1+\mathrm{B} 1 * \mathrm{XBARE}+\mathrm{C} 1 * \mathrm{YBARE}) / \mathrm{DELT} 2$

$\mathrm{N} 2=(\mathrm{A} 2+\mathrm{B} 2 * \mathrm{XBARE}+\mathrm{C} 2 * \mathrm{YBARE}) / \mathrm{DELT} 2$

$\mathrm{N} 3=(\mathrm{A} 3+\mathrm{B} 3 * \mathrm{XBARE}+\mathrm{C} 3 * \mathrm{YBARE}) /(2 * \mathrm{DELT} 2)$

$\mathrm{PHI}(\mathrm{KK})=\mathrm{N} 1 * \mathrm{~S} I(\mathrm{~L}(1))+\mathrm{N} 2 * \mathrm{~S} 1(\mathrm{~L}(2))+\mathrm{N} 3 * \mathrm{~S} 1(\mathrm{~L}(3))$

801 CONTINUE

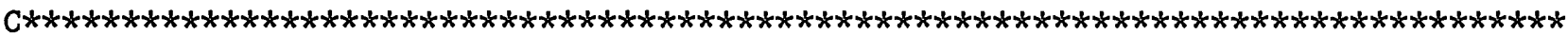

C PRINT OUT OBSERVATION WELL DATA FOR EACH ITERATION

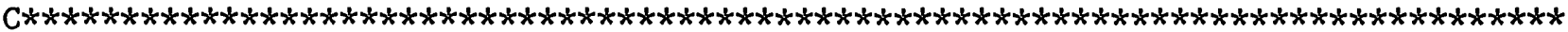

WRITE $(56,850)$ ACTT

850 FORMAT ( $1 \mathrm{X}$, 'THE OBSERVATION WELL DATA AT TIME $=$ ',F10.3,' DAYS')

DO $860 \mathrm{KK}=1$, NNO

WRITE $(56,851)$ KK, PHI (KK)

851 FORMAT ( $1 \mathrm{X}$, 'AT OBS WELL \#', I2, 2X,'THE DRAWDOWN IS ',F6.3,1X,

I'FEET')

$\mathrm{POB}(\mathrm{KK}, \mathrm{IT})=\mathrm{PHI}(\mathrm{KK})$ 


\section{$860 \mathrm{TOB}(\mathrm{KK}, \mathrm{IT})=\mathrm{ACTT} * 1440$}

$\mathrm{C} * * * * * * * * * * * * * * * * * * * * * * * * * * * * * * * * * * * * * * * * * * * * * * * * * * * * * * * * * * * * * * * * * * * * * * * * * * * * * * * * * * * * * * * * * * * 4$

C AN ARITHMETIC LOGICAL TEST FOR PRINTING OUTPUT FOR ENTIRE FLOW FIELD

C EVERY TENTH ITERATION OR LAST ITERATION

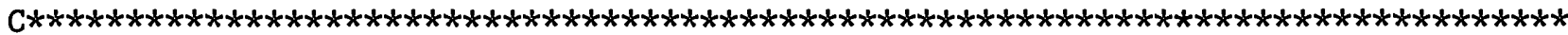
IF (IT .EQ. NTS) GO TO 998

$\mathrm{NIT}=\mathrm{NIT}+1$

$\mathrm{NITT}=\mathrm{NIT} / 10$

NIP $=N I T T * 10$

IF(NIT .NE. NIP) GO TO 999

C

C OUTPUT

MAN3310

$\mathrm{C}$

998 WRITE $(56,85)$ ACTT

85 FORMAT (1H1,30HTOTAL TIME IN THE SIMULATION $=, F 10.3,5 \mathrm{H}$ DAYS) WRITE $(56,86)$ TIME, TIMM

MAN3320

MAN3330

86 FORMAT (1H0,18HTHE DRAWDOWN AFTER, E10.3,9H DAYS OR, E10.3,26HMIN.

IIN THE PUMPING PERIOD)

MAN3340

WRITE $(56,87)$

MAN3350

MAN3360

, 10X, 12H NODE NUMBER, 5X, 8HDRAWDOWN, 10X, 12H NODE NUMBER

15X , 8HDRAWDOWN , 10X , 12H NODE NUMBER , 5X, 8HDRAWDOWN)

WRITE $(56,88)(I, S 1(I), I=1, N N)$

88 FORMAT (10X, I5 , 10X, F10.3 , 10X , I5 , 10X, F10.3 , 10X, I5 , 10X, F10.3)

MAN3410

999 DELT $=$ DELT $*$ TSM

89 CONTINUE

TITO $=$ TIME + TITO

MAN3380

MAN3390

90 CONTINUE

GO TO 93

MAN3430

MAN3440

MAN3450

MAN3460

MAN3470

MAN3480

91 WRITE $(56,92)$

MAN3490

92 FORMAT (1H1,49H**TERMINATION OF PROGRAM DUE TO INPUT DATA ERRORS) MAN3500 GO TO 935

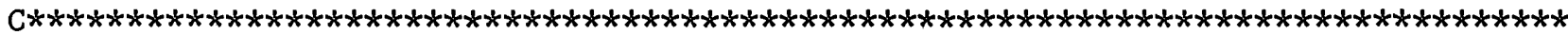

C CALL DRAWDOWN PLOTTING ROUTINE FOR SIMULATION AND FOR TEST

C DATA AT THE OBSERVATION WELL

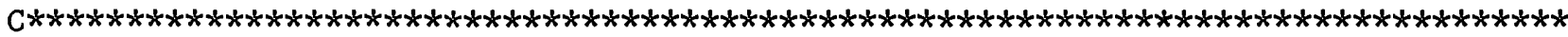

93 DO 931 NPLT $=1$, NNO

931 CALL PTPLOT(NPLT,NTS)

WRITE $(56,993)$ (EPSI (I), I=1, NNO)

993 FORMAT $(1 X, 5(/$, F10.5))

935 STOP

END

MAN3520-

SUBROUTINE CHECK (NE, NN, NCH, NG, RE, ZE, NSCON, IERR)

CHK 010

DIMENSION NG(NE, 3), RE(NN), ZE(NN), NSCON(NN)

C

THIS SUBROUTINE CHECKS THE ELEMENT INPUT DATA FOR CONSISTANCY

CHK 020

CHK 030

CHK 040

CHK 050

IERR $=0$

$\mathrm{NCK}=0$

CHK 060

CHK 070

CHK 080

CHK 090

CHECK NUMBER AND ORDER OF CONSTANT HEAD NODES

CHK 100

FIRST CHECK IF CONSTANT HEAD NODES ARE THE FIRST NODES NUMBERED

CHK 110

CHK 120 
DO $10 \mathrm{I}=1, \mathrm{NCH}$

CHK 130

$\mathrm{NCK}=\mathrm{NSCON}(\mathrm{I})+\mathrm{NCK}$

CHK 140

10 CONTINUE

IF (NCK.EQ.NCH) GO TO 30

CHK 150

IERR=1

CHK 160

$\operatorname{WRITE}(56,20) \mathrm{NCH}, \mathrm{NCK}$

CHK 170

CHK 180

20 FORMAT $(1 \mathrm{H} 1,2 \mathrm{H} * * *$ PROGRAM EXPECTED, I5,39H CONSTANT HEAD NODES BUT CHK 190 1ONLY THE FIRST, I5, 28H NODES WERE FLAGGED AS SUCH)

CHK 200

CHK 210

C

C

THEN CHECK THE TOTAL NUMBER OF CONSTANT HEAD FLAGS

CHK 220

$30 \mathrm{NCK}=0$

DO $40 \quad I=1$, NN

$\mathrm{NCK}=\mathrm{NSCON}(\mathrm{I})+\mathrm{NCK}$

40 CONTINUE

IF(NCK.EQ.NCH) GO TO 60

CHK 230

CHK 240

CHK 250

CHK 260

IERR=1

CHK 270

WRITE $(56,50)$

CHK 280

CHK 290

CHK 300

50 FORMAT $(1$ H0,71H***TOTAL NUMBER OF CONSTANT HEAD FLAGS DOES NOT AGRECHK 310 1E WITH NCH(\# CODED))

CHK 320

CHK 330

NEXT CHECK IS TO INSURE THAT ALL ELEMENTS ARE NUMBERED

CHK 340

COUNTERCLOCKWISE

CHK 350

CHK 360

60 DO $100 \mathrm{~K}=1, \mathrm{NE}$

CHK 370

$\mathrm{L}-\mathrm{NG}(\mathrm{K}, 1)$

$\mathrm{M}=\mathrm{NG}(\mathrm{K}, 2)$

CHK 380

CHK 390

$\mathrm{N}=\mathrm{NG}(\mathrm{K}, 3)$

CHK 400

CHK 410

CHK 420

IF(A.LT.O.) GO TO 100

CHK 430

IERR $=1$

CHK 440

70 FORMAT(1H0,17H***EITHER ELEMENT, I5,23H IS NUMBERED CLOCKWISE,/,11CHK 450

1X,92HOR THE VERTICAL COORDINATES ARE NOT POSITIVE DOWNWARD STARTINCHK 460

$2 G$ WITH ZERO AT THE TOP BOUNDARY)

100 CONTINUE

RETURN

END

SUBROUTINE MLTBM(A, B, R, MM, M)

DIMENSION $A(M M, M), B(M M), R(M M)$

CHK 470

CHK 480

CHK 490

CHK 500 -

MLT 010

MLT 020

MULT. OF A BANDED MATRIX(ORIGINALLY MM*MM)

MLT 030

WITH A VECTOR MATRIX

( COMPACTED BANDED MATRIX OF M*MM AND VECTOR OF $M M * 1$ )

MLT 040

MLT 050

MLT 060

DO $1 \mathrm{I}=1, \mathrm{MM}$

MLT 070

$R(I)=0$.

MLT 080

DO $2 \mathrm{~J}=1, \mathrm{M}$

MLT 090

$\mathrm{K}=\mathrm{J}+\mathrm{I}-(\mathrm{M}+1) / 2$

MLT 100

IF(K.LT.1) GO TO 2

MLT 110

IF (K.GT.MM) GO TO 2

MLT 120

$R(I)=A(I, J) * B(K)+R(I)$

MLT 130

2 CONTINUE

MLT 140

MLT 150

1 CONTINUE

MLT 160 


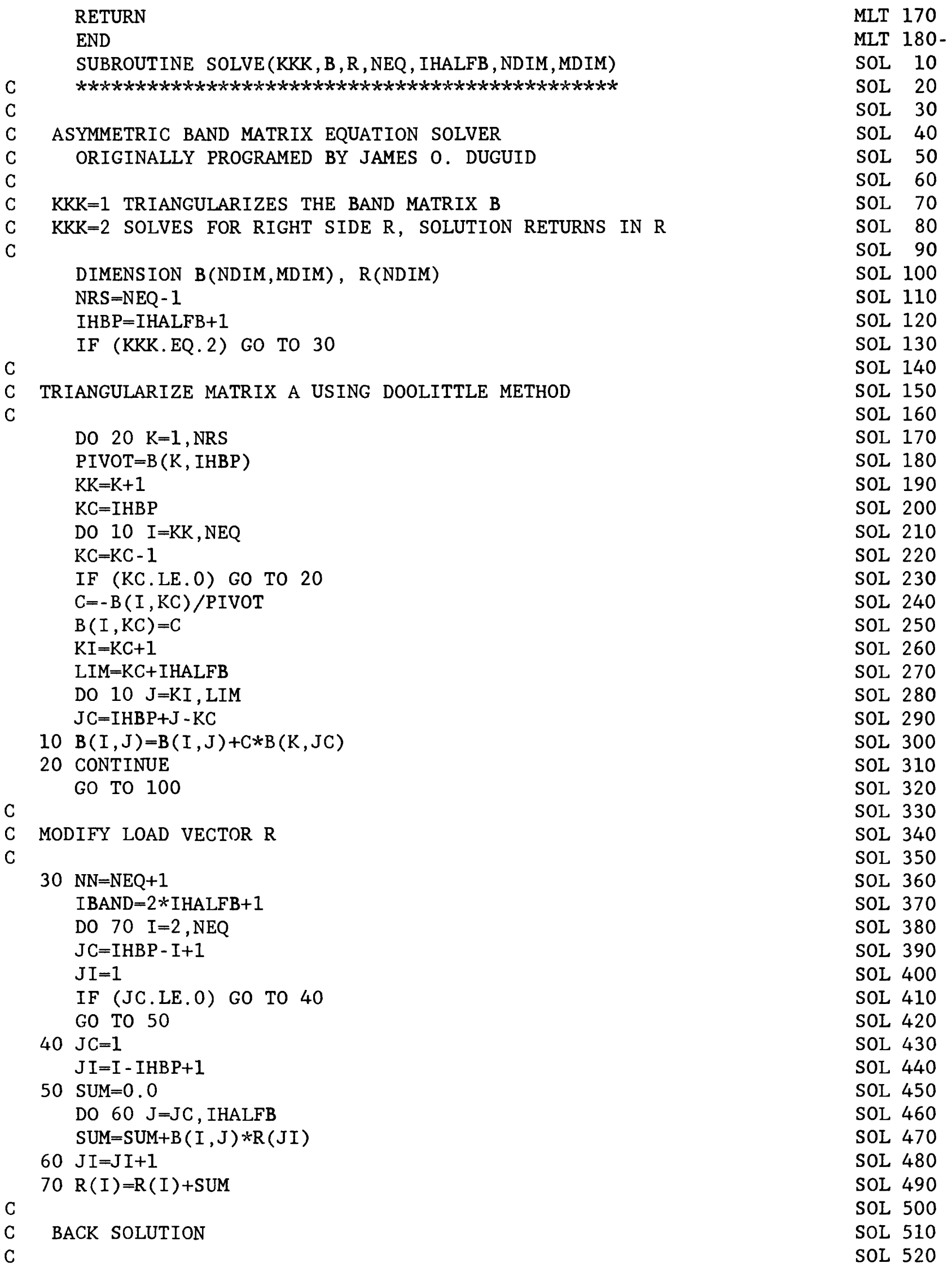




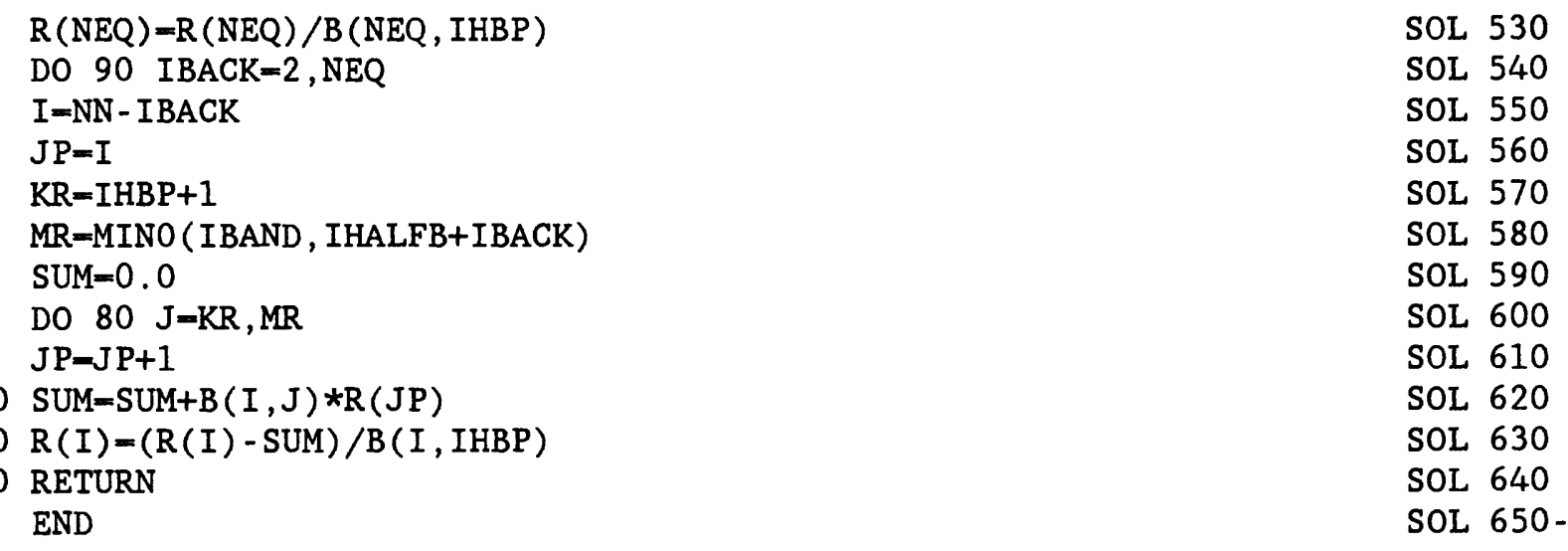

C

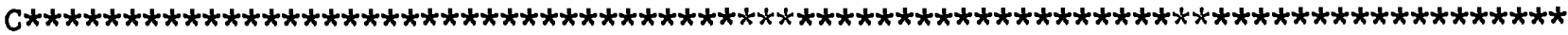

C SUBROUTINE PTPLOT WRITTEN BY A. PUCCI AND D. POPE 1/2/87

C USGS WEST TRENTON, NEW JERSEY

(609) $771-3900$

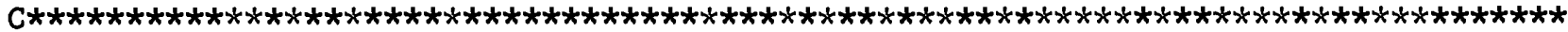
SUBROUTINE PTPLOT(NPLT, NTS)

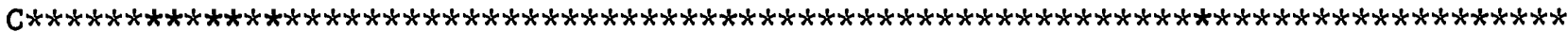

C PROGRAM TO PLOT PUMPING TEST DATA. FROM RADFLOW MODEL OUTPUT AT EACH

C OBSERVATION WELL, AND FROM THE OBSERVATION WELL DATA AT EACH SITE.

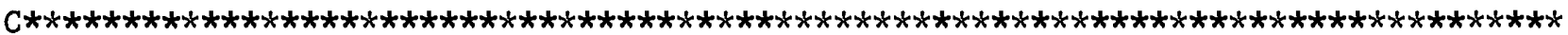

C

GLOSSARY

C

C

GXMAX, GYMAX, GYMIN, GXMIN = USER SUPPLIED LIMITS TO LOG-LOG GRAPH OF $* * * *$ WATER IEVEL CHANGES AGAINST REDUCED TIME $* * * * *$

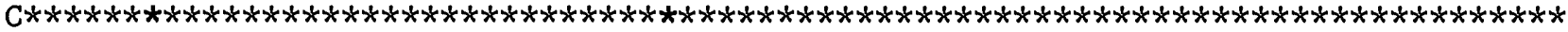

CHARACTER INPUT*10, OUTPUT*10, TITLE $1 * 50$, TITLE $2 * 50$, ANS $* 1$

REAL GXMAX, GXMIN, GYMAX, GYMIN , XAXIS, YAXIS

REAL $\operatorname{POB}(5,100), \operatorname{TOB}(5,100), \operatorname{EPSI}(5)$

INTEGER CHOICE

C GDIU

INITIALIZE VARIABLES FOR GDIU DEVICE CALLS

$\begin{array}{llll}\text { CHARACTER } * 1 & \text { OPT } & / * & \text { DEVICE OPTION CODE } \\ \text { CHARACTER } * 50 & \text { DES } & / * & \text { DEVICE DESCRIPTION } \\ \text { CHARACTER } * 32 & \text { PALET } & / * & \text { DEVICE PALET }\end{array}$

LOGICAL FLAGS $(3) / *$ DEVICE OPTION FLAGS

C GDIU

$/ *$ 1-PLOT FILE REQUIRED

C GDIU

C GDIU

* 2-DEVICE IS NOT A GRAPHIC TERMINAL

* 3-DEVICE HAS GRAPHIC INPUT

$\begin{array}{lllll}\text { REAL } & \text { SIZE }(2) & / * & \text { OPTIONAL MAX WIDTH AND HEIGHT OF PLOT } \\ \text { CHARACTER } * 128 & \text { PLTFIL } & / * & \text { NAME OF PLOT FILE, IF NEEDED } \\ \text { INTEGER } & \text { LUPLOT } & / * & \text { LOGICAL UNIT TO OPEN PLOT FILE ON } \\ \text { INTEGER } & \text { NDEV } & / * & \text { DEVICE NUMBERS } \\ \text { CHARACTER } * 8 & \text { COLOR } & / * & \text { PLOT COLOR }\end{array}$

COMMON /PT/ POB, TOB

COMMON /EPS/ EPSI

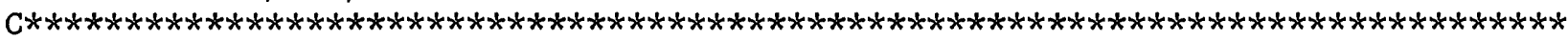

C** EACH OUTPUTFILE WILL BE SEPARATE FOR AN OBSERVATION WELL

C** WITH THE TEST DATA

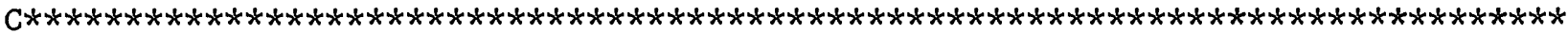

$\mathrm{C}$

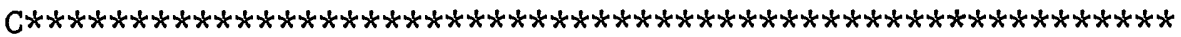


C TERMINAL PROMPTS TO USER FOR OUTPUT CONTROL

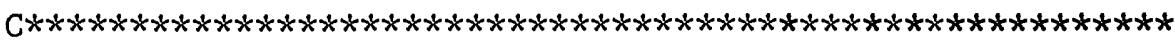

$C * *$ OUTPUT FILE NAMES FOR EACH OBSERVATION WELL PLOT MUST BE UNIQUE

$\mathrm{C}$

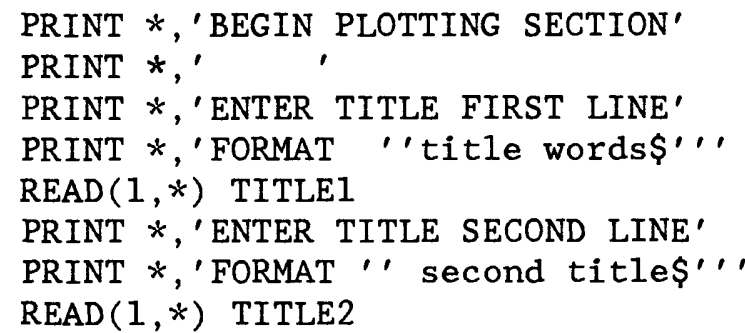

WRITE $(1, *)$ ' THE NEXT FOUR INPUTS: XMAX, XMIN, YMAX, YMIN, REFER'

WRITE $(1, *)$ ' TO THE LOG CYCLES THAT ARE CHOSEN FOR PLOTTING '

WRITE $(1, *)$ ' DATA AND CALCULATED DRAWDOWNS AT THE OBSERVATION'

WRITE $(1, *)$ ' WELLS AS TYPE CURVES, USING LOG-LOG PLOTS.'

WRITE $(1, *)$ ' USE 5 LOG CYCLES FOR X-AXIS, 3 FOR Y AXIS.'

$\operatorname{WRITE}(1, *)$ ' I.E. $\operatorname{MAX} X=0$., MIN $X=-5 ., \operatorname{MAX} Y=1 ., \operatorname{MIN} Y=-2$ ' $^{\prime}$

PRINT *,'MAX-X VALUE $=^{\prime}$

$\operatorname{READ}(1, *)$ GXMAX

PRINT *, 'MIN -X VALUE $=$ '

$\operatorname{READ}(1, *) \operatorname{GXMIN}$

PRINT * ' MAX Y VALUE $=$ '

$\operatorname{READ}(1, *)$ GYMAX

PRINT *, 'MIN Y VALUE $=$ '

$\operatorname{READ}(1, *)$ GYMIN

PRINT *,'NAME THE INPUT FILE'

$\operatorname{READ}^{\prime}(\mathrm{A})^{\prime}$, , INPUT

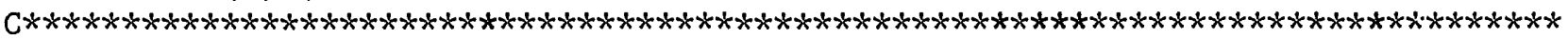

C OPEN OBSERVATION-WELL DATA FILE

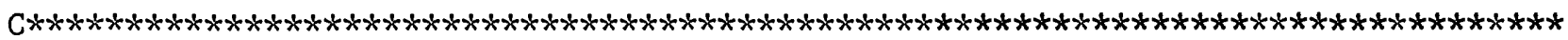

OPEN $(61$, FILE=INPUT, STATUS=' OLD' $)$

PRINT *,'TYPE OF DRAWDOWN DATA? (1=DRAWDOWN, 2=WATER LEVEL)'

$\operatorname{READ}(1, *)$ CHOICE2

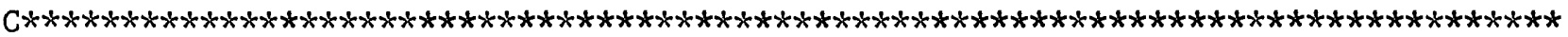

C SET CONTROL COUNTER FOR EPSILON SUBROUTINE, SO THAT THE EPSILON

C STATISTIC IS CALCULATED ONLY ONCE.

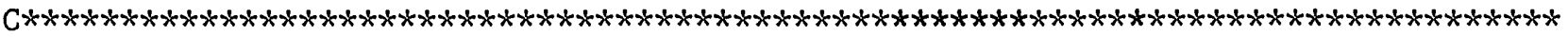

$\mathrm{NEP}=0$

$7 \quad \mathrm{NEP}=\mathrm{NEP}+1$

$8 \quad \mathrm{NDEV}=0$

LUPLT $=13$

C*** SUBROUTINE TO QUERY USER FOR DEVICE

CALI G_QRDV (NDEV)

C

C** SUBROUTINE RETURNS ATTRIBUTES FOR SELECTED DEVICE

CALI G DVDF (OPT, DES, PALET, FLAGS, SIZE, -NDEV, IRTN)

IF (IRTN .NE. NDEV) GO TO 8

$\mathrm{C}$

C SET FLAG SPECIFYING THAT A ZETA PLOT HAS BEEN PRODUCED

IF(FLAGS (1)) THEN

NOZETA $=1$

PRINT *,'TYPE IN THE NAME OF THE OUTPUT FILE'

READ ' (A)', OUTPUT 


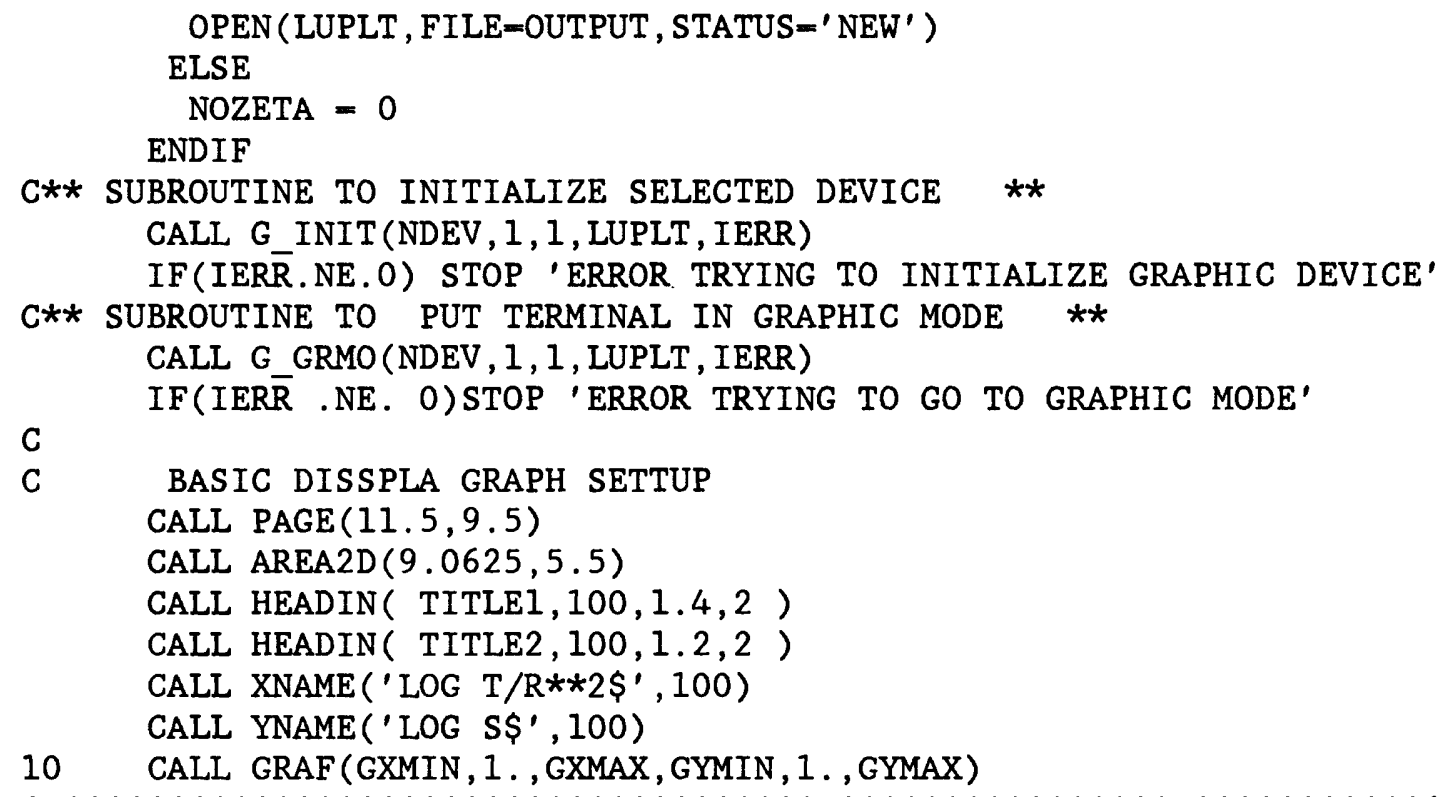




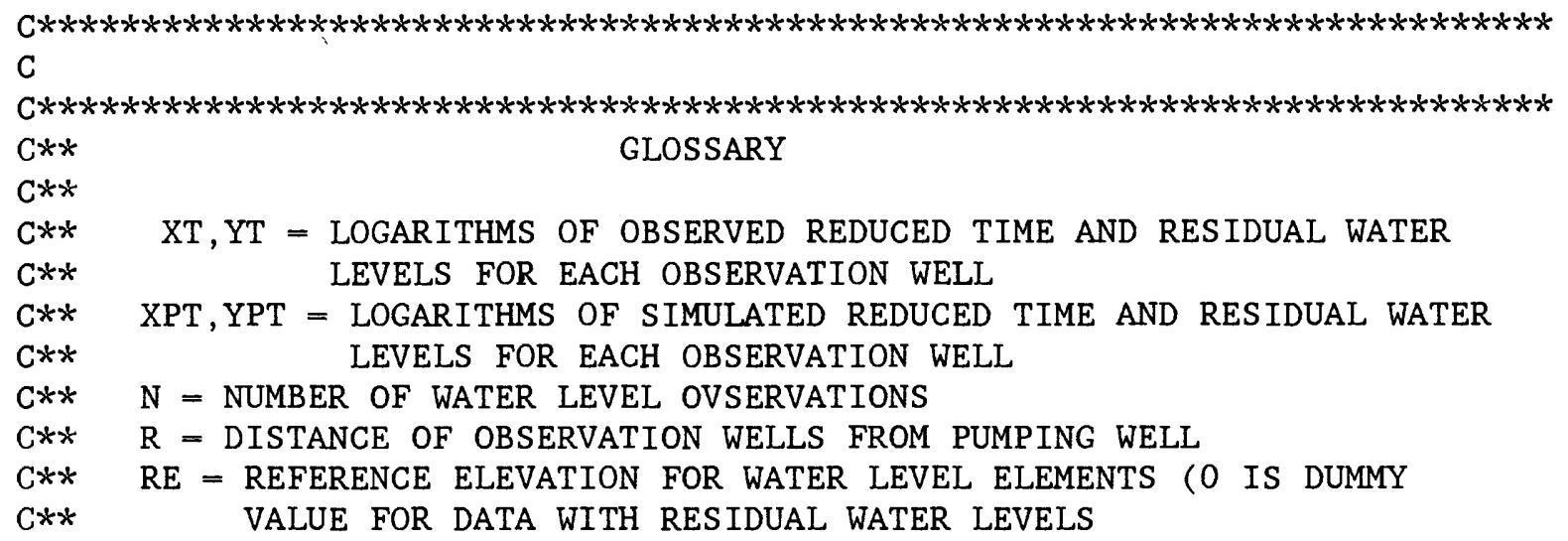




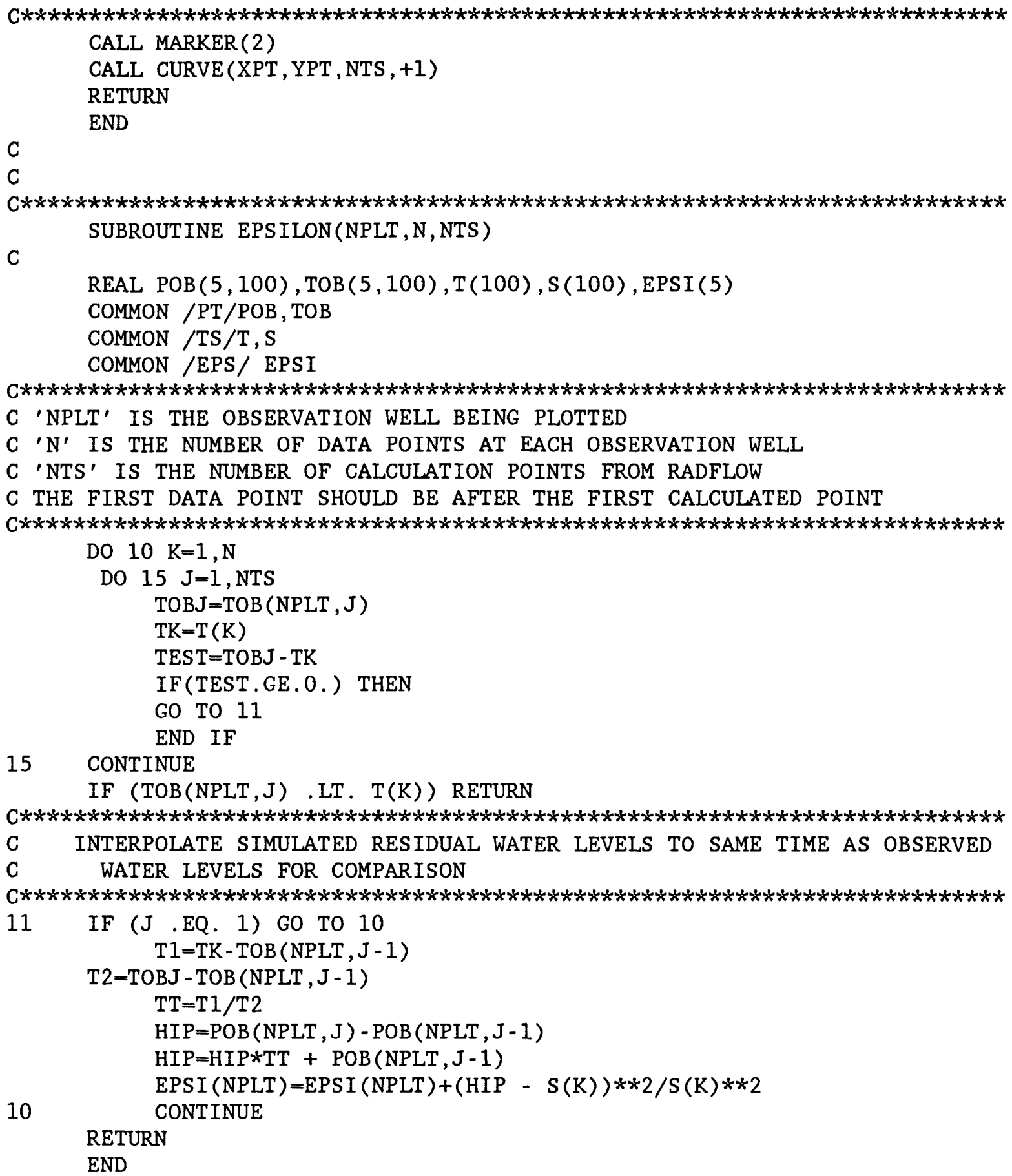

